PNNL-19659

Prepared for the U.S. Department of Energy under Contract DE-AC05-76RL01830

\title{
Assessment of the Idaho National Laboratory Hot Fuel Examination Facility Stack Monitoring Site for Compliance with ANSI/HPS \\ N13.1-1999
}

\section{JA Glissmeyer \\ JE Flaherty}

August 2010

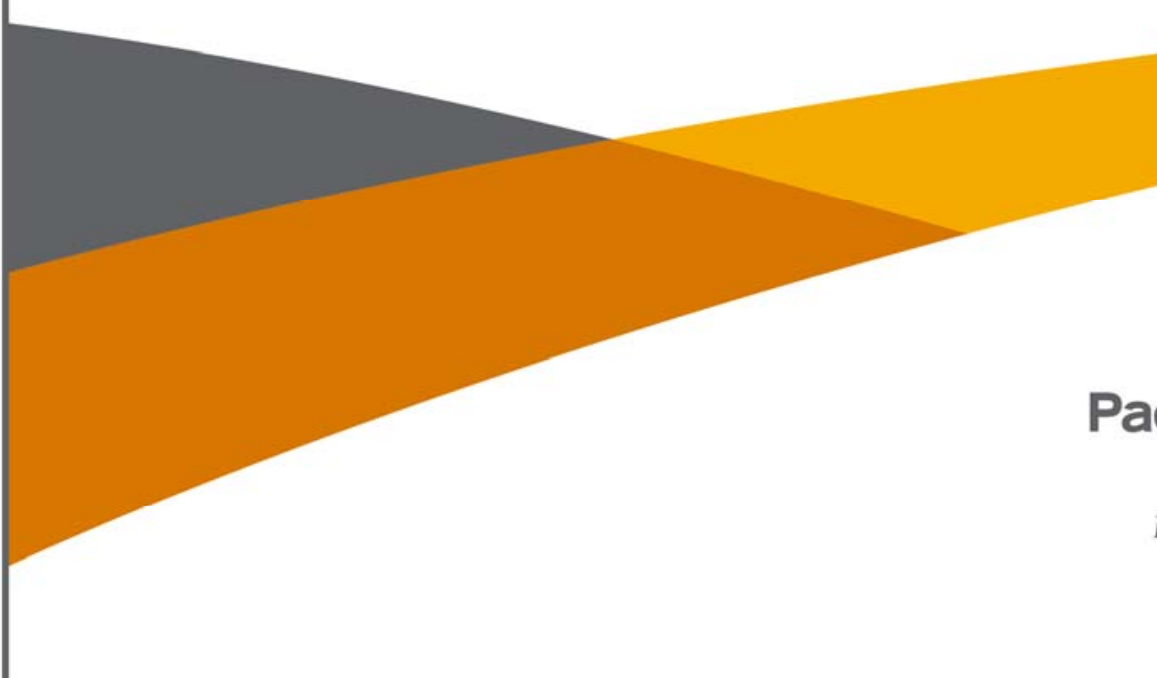




\title{
DISCLAIMER
}

This report was prepared as an account of work sponsored by an agency of the United States Government. Neither the United States Government nor any agency thereof, nor Battelle Memorial Institute, nor any of their employees, makes any warranty, express or implied, or assumes any legal liability or responsibility for the accuracy, completeness, or usefulness of any information, apparatus, product, or process disclosed, or represents that its use would not infringe privately owned rights. Reference herein to any specific commercial product, process, or service by trade name, trademark, manufacturer, or otherwise does not necessarily constitute or imply its endorsement, recommendation, or favoring by the United States Government or any agency thereof, or Battelle Memorial Institute. The views and opinions of authors expressed herein do not necessarily state or reflect those of the United States Government or any agency thereof.

\author{
PACIFIC NORTHWEST NATIONAL LABORATORY \\ operated by \\ BATTELLE \\ for the \\ UNITED STATES DEPARTMENT OF ENERGY \\ under Contract DE-ACO5-76RL01830
}

Printed in the United States of America
Available to DOE and DOE contractors from the Office of Scientific and Technical Information,
P.O. Box 62, Oak Ridge, TN 37831-0062;
ph: (865) 576-8401
fax: (865) 5765728
email: reports@adonis.osti.gov

\author{
Available to the public from the National Technical Information Service, \\ U.S. Department of Commerce, 5285 Port Royal Rd., Springfield, VA 22161 \\ ph: (800) 553-6847 \\ fax: (703) 605-6900 \\ email: orders@nits.fedworld.gov \\ online ordering: http://www.ntis.gov/ordering.htm
}


PNNL-19659

RPT-STMON-007

\title{
Assessment of the Idaho National Laboratory Hot Fuel Examination Facility Stack Monitoring Site for Compliance with ANSI/HPS N13.1-1999
}

\author{
J. A. Glissmeyer \\ J. E. Flaherty
}

August 2010

This document was prepared for Battelle Energy Alliance, LLC as part of a Memorandum of Purchase Order (No. 00097184). The testing described in this document was further guided by the Hot Fuel Examination Facility Air Sampling Test Plan (TP-STMON-015).

Pacific Northwest National Laboratory

Richland, Washington 99352 



\section{Completeness of Testing}

This report describes the results of work and testing specified by test plan TP-STMON015. The work and any associated testing followed the quality assurance requirements outlined in the test specification/plan. The descriptions provided in this test report are an accurate account of both the conduct of the work and the data collected. Test plan results are reported. Also reported are any unusual or anomalous occurrences that are different from expected results. The test results and this report have been reviewed and verified.

\section{Approved:}
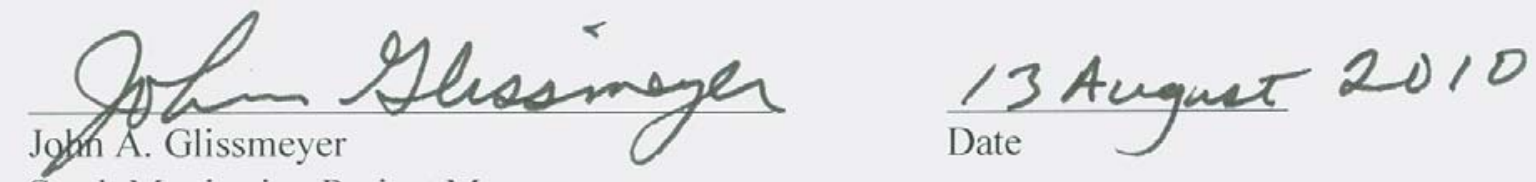

Stack Monitoring Project Manager 


\section{Summary}

This document reports on a series of tests to determine whether the location of the air sampling probe in the Hot Fuel Examination Facility (HFEF) heating, ventilation and air conditioning (HVAC) exhaust duct meets the applicable regulatory criteria regarding the placement of an air sampling probe. Federal regulations ${ }^{(a)}$ require that a sampling probe be located in the exhaust stack according to the criteria of the American National Standards Institute/Health Physical Society (ANSI/HPS) N13.1-1999, Sampling and Monitoring Releases of Airborne Radioactive Substances from the Stacks and Ducts of Nuclear Facilities. These criteria address the capability of the sampling probe to extract a sample that is representative of the effluent stream.

The in-place testing conducted for this project was part of a Memorandum of Purchase Order (MPO; No. 00097184) established between Battelle Energy Alliance, LLC and Pacific Northwest National Laboratory (PNNL). The statement of work (SOW-8469) within this MPO provides information regarding the scope, requirements, safety, and submittals. The testing described in this document was further guided by the Hot Fuel Examination Facility Air Sampling Test Plan (TP-STMON-015).

The tests conducted by PNNL during July 2010 on the HFEF system are described in this report. The sampling probe location is approximately 20 feet from the base of the stack. The stack base is in the second floor of the HFEF, and has a building ventilation stream (limited potential radioactive effluent) as well as a process stream (potential radioactive effluent). The tests conducted on the duct indicate that the process stream is insufficiently mixed with the building ventilation stream. As a result, the air sampling probe location does not meet the criteria of the N13.1-1999 standard.

The series of tests consists of various measurements taken over a grid of points in the duct cross section at the proposed sampling-probe location. The results of the test series on the HFEF exhaust duct as it relates to the criteria from ANSI/HPS N13.1-1999 are summarized below.

1. Uniform Air Velocity: The gas momentum should be uniform across the stack cross section where the sample is extracted. The uniformity is expressed as the variability of the measurements about the mean, expressed as the coefficient of variance (COV). It is calculated as the standard deviation divided by the mean and expressed as a percentage - the lower the COV value, the more uniform the velocity. The acceptance criterion is that the COV of the air velocity must be $\leq 20 \%$ across the cross section of the duct. The results of the measurements at the proposed air sampling probe location ranged from 7.6 to $8.7 \%$, which is well within the acceptance criterion.

2. Angular Flow: The purpose of this test is to determine whether the air velocity vector is aligned with the sampling nozzle. The average flow angle relative to the nozzle axis should not be more than $20^{\circ}$. The average measured values for the two tests were 1.9 and 2.6 degrees, so this criterion was met.

3. Uniform Concentration of Tracer Gases: A uniform contaminant concentration in the sampling plane enables the extraction of samples that represent the true concentration of the stack exhaust. This was

(a) Title 40 of the Code of Federal Regulations (CFR), Part 61, National Emissions Standards for Hazardous Air Pollutants (NESHAP), Subpart H, National Emission Standard For Emissions of Radionuclides other than Radon from Department of Energy Facilities. 
first tested using a tracer gas injected into the process exhaust air duct downstream of the fans and inside the building. The two acceptance criteria are that 1) the COV of the measured tracer-gas concentration is $\leq 20 \%$ across duct cross section and 2) at none of the measurement points does the concentration vary from the mean by $>30 \%$. Seven tests of this type were performed with tracer injections at varying positions in the duct cross-section. All of the results failed the acceptance criteria, and indicate that the process stream does not mix with the building ventilation stream sufficiently to position stack monitoring probe for a representative sample. Values observed were between $59.8 \% \mathrm{COV}$ and $83.7 \% \mathrm{COV}$ with maximum deviation values from $312 \%$ to $499 \%$.

4. Uniform Concentration of Tracer Particles: Uniformity in contaminant concentration at the sampling probe was further demonstrated using tracer particles large enough to exhibit inertial effects. Particles of $10-\mu \mathrm{m}$ aerodynamic diameter were used. The acceptance criterion is that the COV of particle concentration is $\leq 20 \%$ across the sampling probe location. The results of this test were similar to the tracer gas uniformity tests; particle concentrations show a strong gradient across the width of the duct. The results from the two tests conducted were $122.5 \%$ and $150.7 \%$ COV.

Based on these tests, the location of the current air sampling probe does not meet the requirements of the ANSI/HPS N13.1-1999 standard. 


\section{Acronyms}

$\mathrm{AD}$

ANSI

ASME

BEA

CFR

$\mathrm{COV}$

DOE

EPA

FA

FIO

GT

HDI

HEPA

HFEF

HPS

HVAC

INL

MFC

M\&TE

MPO

NESHAP

NPT

OPC

PT

PNNL

QA

QAM

QAP

QARD

RH

$\mathrm{SF}_{6}$ aerodynamic diameter

American National Standards Institute

American Society of Mechanical Engineers

Battelle Energy Alliance, LLC

Code of Federal Regulations

coefficient of variance

U.S. Department of Energy

U.S. Environmental Protection Agency

Flow angle test

for information only

Gas tracer test

"How Do I...?"

High Efficiency Particulate Air, refers to a type of air filters

Hot Fuel Examination Facility

Health Physics Society

heating, ventilation, and air conditioning

Idaho National Laboratory

Materials and Fuels Complex

materials and testing equipment

Memorandum of Purchase Order

National Emissions Standards for Hazardous Air Pollutants

National pipe threads

optical particle counter

Particle tracer test

Pacific Northwest National Laboratory

quality assurance

Quality Assurance Manual

Quality Assurance Plan

Quality Assurance Requirements and Descriptions

remote-handled

sulfur hexafluoride 
SOW

TI

VT statement of work

test instruction

velocity uniformity test 


\section{Acknowledgments}

This work was conducted under a Memorandum of Purchase Order issued by Battelle Energy Alliance, LLC (BEA) to provide funding to Pacific Northwest National Laboratory (PNNL). PNNL is operated for the U.S. Department of Energy by Battelle under Contract DE-AC05-76RL01830.

Preparation and execution of this study involved a number of staff from both PNNL and BEA and its contractors. We would like to particularly acknowledge the support of our quality engineer, Kirsten Meier, and administrative support from Andrea Boehler, Mona Champion, and Chrissy Charron. We appreciate the efforts of summer interns Brian Smith and Quintin Quigley, who traveled with us to help with this study. We would also like to acknowledge the technical reviews conducted by Ernest Antonio, Carmen Arimescu, and Xiao-Ying Yu. Meredith Willingham provided editorial support for this report. The team of support staff at BEA was also integral to the successful completion of the work conducted at the Materials and Fuel Complex (MFC). We especially appreciate the efforts of Jory Inama and Tim Solle for arranging training, radiological worker and radiation protection support, as well as some lastminute crafts support. We encountered a number of challenges during our trip, and we appreciate the willingness of the MFC staff to be flexible in finding solutions along the way. 



\section{Contents}

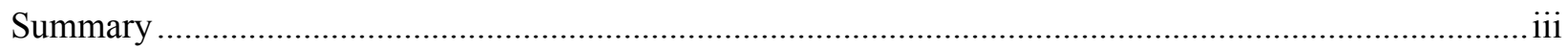

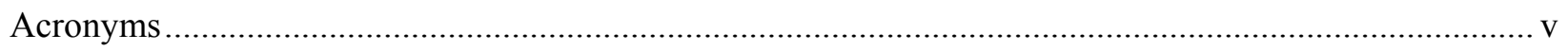

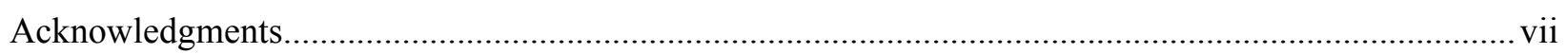

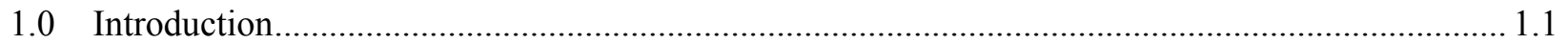

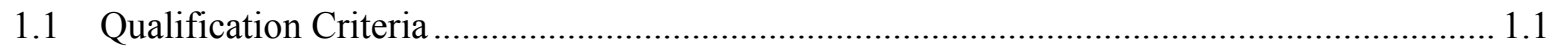

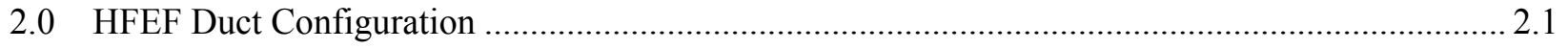

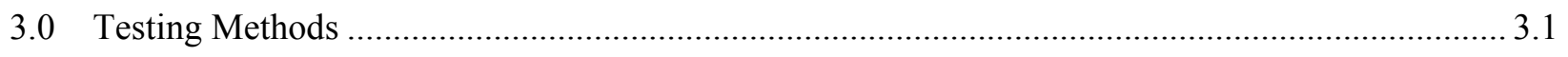

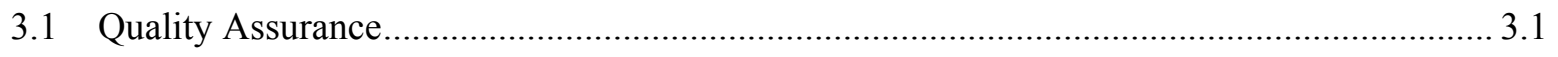

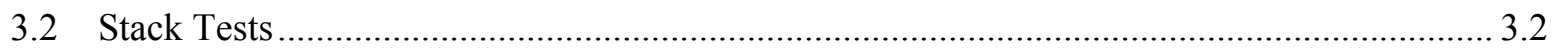

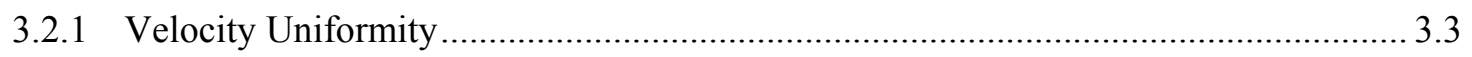

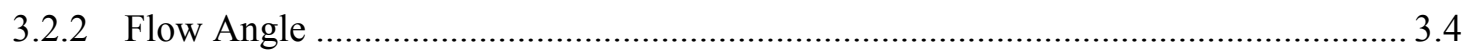

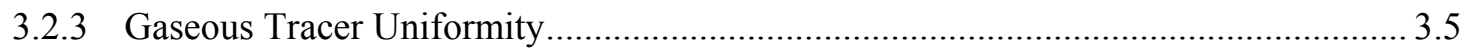

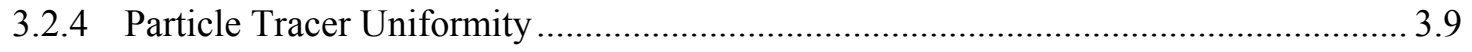

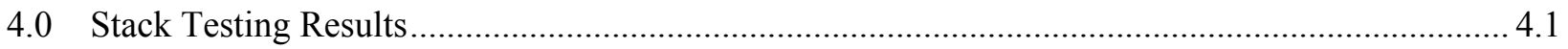

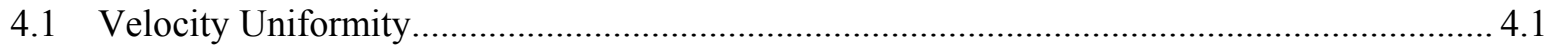

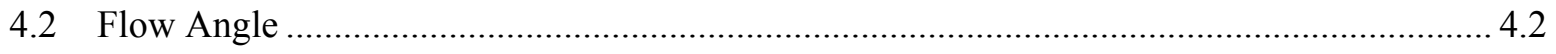

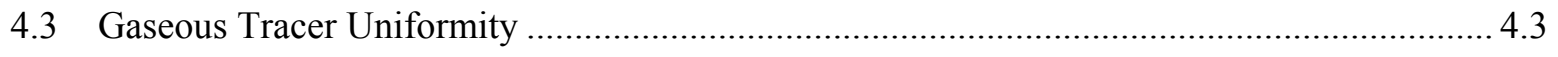

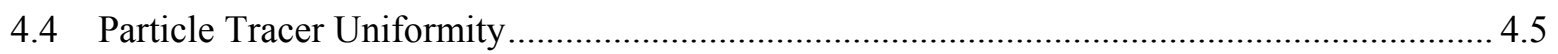

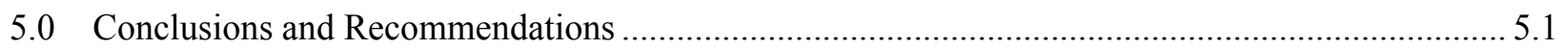

5.1 Potential Stack Monitoring Modifications......................................................................... 5.1

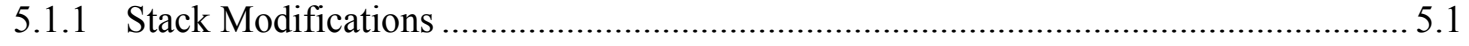

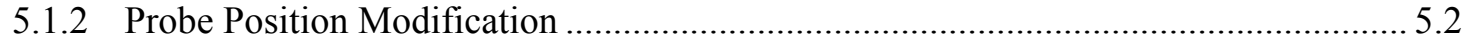

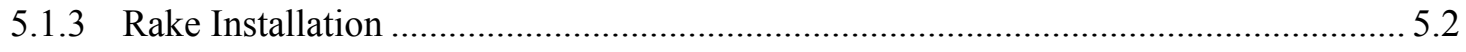

5.1.4 Correction Factor Application .......................................................................... 5.3

5.2 Recommendations to Assist Decision Making ................................................................ 5.3

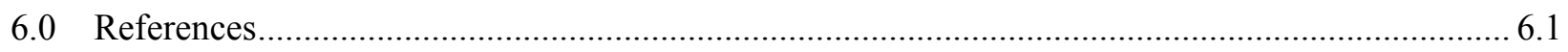

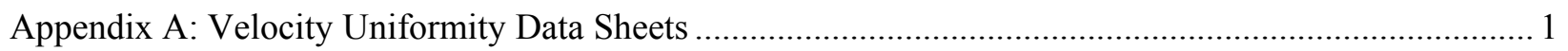

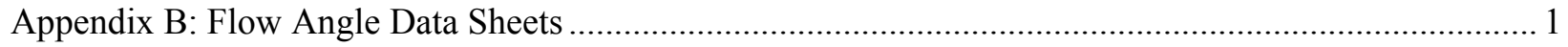

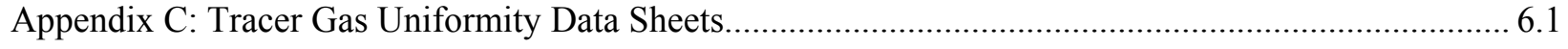

Appendix D: Tracer Particle Uniformity Data Sheets ....................................................................... 6.1 


\section{Figures}

Figure 2.1. Photographs of the building ventilation and process ventilation ducts at the base of the HFEF exhaust stack. .

Figure 2.2. Photograph of the HFEF Building Exhaust Stack .......................................................... 2.3

Figure 2.3. Plan and Side View drawings of the as-built HFEF HVAC system in Room 209 ............... 2.1

Figure 3.1. Cross-Section of the Duct at the Testing Location ............................................................ 3.3

Figure 3.2. Equipment Used for the Velocity Uniformity Test ......................................................... 3.4

Figure 3.3. Equipment Used for the Flow Angle Test ................................................................. 3.5

Figure 3.4. Cross-Section of the Duct Showing the Locations of the Five Primary Gaseous Tracer

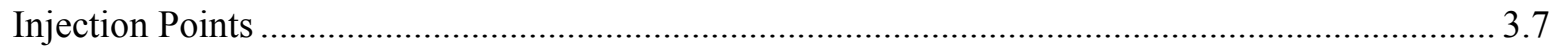

Figure 3.5. Equipment Used for the Gaseous Tracer Sampling.......................................................... 3.7

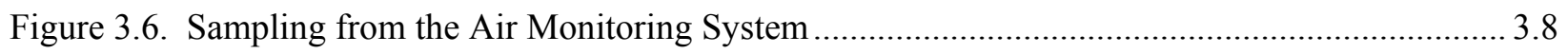

Figure 3.7. Equipment Used for the Particle Injection (and gas injection) ............................................. 3.9

Figure 3.8. Equipment Used for the Particle Sampling ................................................................... 3.10

Figure 4.1. Mean Velocity Measurements at each of the 16 Sampling Locations for VT-2 and VT-3 .... 4.2

Figure 4.2. Mean Flow Angle Measurements at each of the 16 Sampling Locations ............................ 4.3

Figure 4.3. $\mathrm{SF}_{6}$ Concentrations at the 16 Sampling Locations for GT-2 and GT-3 ............................ 4.4

Figure 4.4. $\mathrm{SF}_{6}$ Concentrations at the 16 Sampling Locations for GT-7 ........................................... 4.5

Figure 4.5. Particle Concentrations at the 16 Sampling Locations ..................................................... 4.6

\section{Tables}

Table 4.1. Summary of Velocity Uniformity Tests................................................................................ 4.1

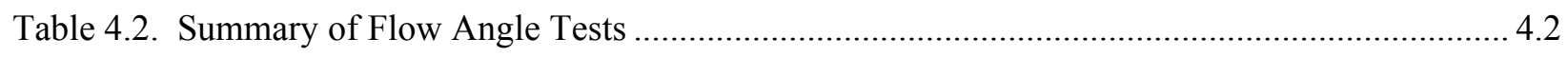

Table 4.3. Summary of Gas Tracer Uniformity Tests............................................................................. 4.4

Table 4.4. Summary of Particle Tracer Uniformity Tests................................................................... 4.6 


\subsection{Introduction}

The Materials and Fuels Complex (MFC) of the Idaho National Laboratory (INL) is a facility that conducts research and development of nuclear fuels. One of the largest facilities at INL for this type of research is the Hot Fuel Examination Facility (HFEF). The HFEF began operations in 1975 with two hot cells for examining irradiated reactor fuels and structural materials. The potential dose associated with the hot cell activities will exceed the 0.1 millirem per year threshold limit given in Title 40 of the Code of Federal Regulations (CFR), Part 61, National Emissions Standards for Hazardous Air Pollutants (NESHAP), Subpart H, National Emission Standard For Emissions of Radionuclides other than Radon from Department of Energy Facilities. As a result, emissions monitoring must be conducted to conform to the applicable federal regulations.

The series of in-place tests performed by the Stack Sampling Project staff at Pacific Northwest National Laboratory (PNNL) assessed whether the particular sampling location in the HFEF heating, ventilation, and air conditioning (HVAC) exhaust duct would meet the applicable regulatory criteria regarding the placement of an air sampling probe. The NESHAP requires that a sampling probe be located in the exhaust stack according to the criteria of the American National Standards Institute/Health Physical Society (ANSI/HPS) N13.1-1999, Sampling and Monitoring Releases of Airborne Radioactive Substances from the Stacks and Ducts of Nuclear Facilities.

The in-place testing conducted for this project was part of the Memorandum Purchase Order (MPO; No. 00097184) established between Battelle Energy Alliance, LLC and PNNL. The statement of work (SOW-8469) within this MPO provides information regarding the scope, requirements, safety, and submittals. The testing described in this document was further guided by the Hot Fuel Examination Facility Air Sampling Test Plan (TP-STMON-015).

\subsection{Qualification Criteria}

The qualification criteria for a stack air monitoring probe location are taken from ANSI/HPS N13.11999 and are paraphrased as follows:

1. Uniform Air Velocity: It is important that the gas velocity across the stack cross-section where the sample is extracted be fairly uniform. Consequently, the velocity is measured at several points in the stack at the position of the sampling nozzle. The uniformity is expressed as the variability of the measurements about the mean. This is expressed using the coefficient of variation $(\mathrm{COV})^{(\mathrm{a})}$, which is the standard deviation divided by the mean and expressed as a percentage. The lower the COV value, the more uniform the velocity. The acceptance criterion is that the COV of the air velocity must be $\leq 20 \%$ across the sampling plane.

2. Angular Flow: Sampling nozzles are typically aligned with the axis of the stack. If the air travels up the stack in cyclonic fashion, the air velocity vector approaching a sampling nozzle could be sufficiently misaligned with the nozzle to impair the extraction of particles. Consequently, the flow angle is measured in the duct near the location of the sampling probe. The average air-velocity angle must not deviate from the axis of the duct by more than $20^{\circ}$.

(a) Coefficient of variation is considered "dated" terminology. The modern terminology is percent relative standard deviation. However, because the standard uses the older terminology, it is also used here. 
3. Uniform Concentration of Tracer Gases: A uniform contaminant concentration in the sampling plane enables the extraction of samples that represent the true concentration within the duct. The uniformity of the concentration is first tested using a tracer gas to represent gaseous effluents. The fan is a good mixer, so injecting the tracer downstream of the fan provides worst-case results. The acceptance criteria are that 1 ) the COV of the measured tracer gas concentration is $\leq 20 \%$ across the sampling location and 2) at no point in the sampling location does the concentration vary from the mean by $>30 \%$.

4. Uniform Concentration of Tracer Particles: The second set of tests addressing contaminant concentration uniformity at the sampling position uses tracer particles large enough to exhibit inertial effects. Tracer particles of 10- $\mu \mathrm{m}$ aerodynamic diameter (AD) are used by default unless it is known that larger contaminant particles will be present in the airstream. The acceptance criterion is that the $\mathrm{COV}$ of particle concentration is $\leq 20 \%$ across the sampling location.

Tests to determine if Criteria 1 through 4 are met were conducted on the HFEF exhaust duct, near the position of the air monitoring probe. The tests conducted by PNNL during July 2010, as well as the results of these tests, are described in subsequent sections of this report. 


\subsection{HFEF Duct Configuration}

The fans for the HFEF exhaust system are housed on the second floor of the HFEF building in Room 209. The HFEF exhaust system is comprised of two main components. The bulk of the flow through the exhaust stack comes from the general building ventilation system, servicing hallways and office spaces. The building ventilation system is powered by two large fans. Three banks of 11 High Efficiency Particulate Air (HEPA) filters are installed upstream of the two building exhaust fans. The HEPA filters have been installed in parallel so that maintenance activities on the filters have a very minor effect on the flow through the system. The reported building ventilation flow was on the order of $35,000 \mathrm{cfm}$.

A smaller portion of the flow comes from the ventilation of the air space serving the building's hot cells through the building exhaust stack - reported to be on the order of 5,000 cfm,. This is referred to as the process stream, and it has three smaller fans available, with two fans typically in operation to power the exhaust. The process stream has the potential to be radioactively contaminated, and is filtered by five HEPA filters to collect any radioactive particulates prior to discharge through the HFEF stack.

The building ventilation and process streams feed into the base of the stack at 90 degrees from each other. The stack maintains essentially the same cross-sectional shape and size from the base to the discharge. The discharge point is approximately $60 \mathrm{ft}$ above the third floor mezzanine roof of the building. Figure 2.1 is a photograph depicting the configuration of the two building streams at the base of the stack. Figure 2.1 (a) was taken looking toward the west. Figure 2.1 (b) was taken from approximately the location of the large orange arrow seen in Figure 2.1 (a). It is looking vertically at the location where the process duct meets the stack. The air from the process and ventilation streams enters the stack base separately, with the process air entering at the side.

The stack exterior is shown in Figure 2.2. The stack testing location was near the upper scaffold platform, while the air monitoring location was a few feet downstream in this section of duct. The distance from the stack base to the stack testing location is approximately 21.5 feet. The current installation of the air monitoring probe at the HFEF exhaust stack is intended to comply with the N13.11999 standard. A rake-style probe was initially used on the HFEF stack, and was located about 10 feet from the stack discharge point. The abandoned probe is visible in Figure 2.2 (a).

Figure 2.3 is a drawing with the plan and side view of the HVAC system in Room 209. The two fans on the left side of the drawing (EF-4a and EF-4b) serves the process flow, while the two fans near the center of the drawing (EF-5a and EF-5b) serves the building ventilation flow. Note that the process side currently has three fans, and other features in the drawing may also be out-of-date. ${ }^{a}$

\footnotetext{
${ }^{a}$ This schematic was extracted from drawing number M-6, Rev E, which was created in 1982 for Argonne National Laboratory. This is the earliest drawing found for this system. This figure is included to illustrate the general layout of the HVAC system.
} 


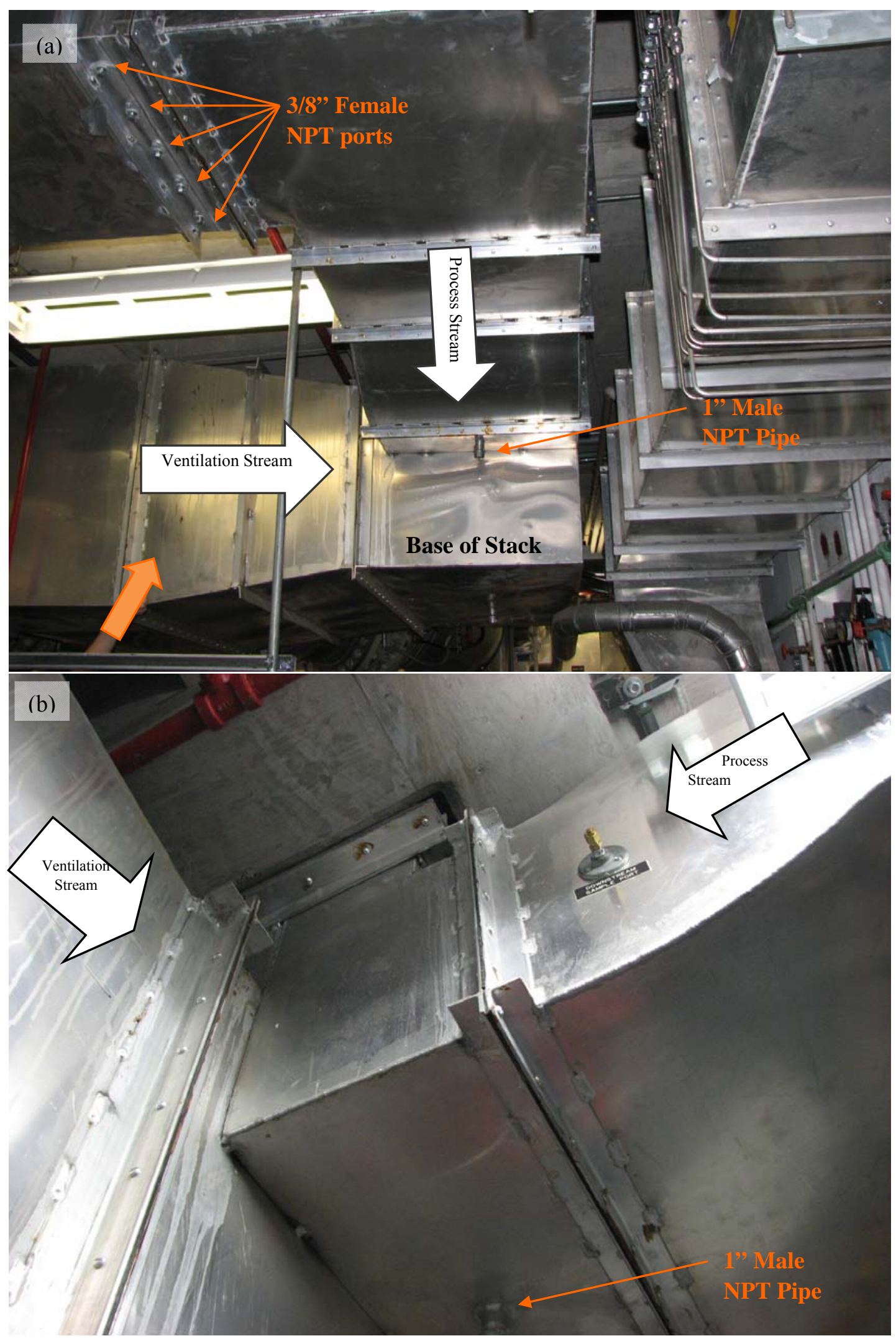

Figure 2.1. Building ventilation and process ventilation ducts at the base of the HFEF exhaust stack. 


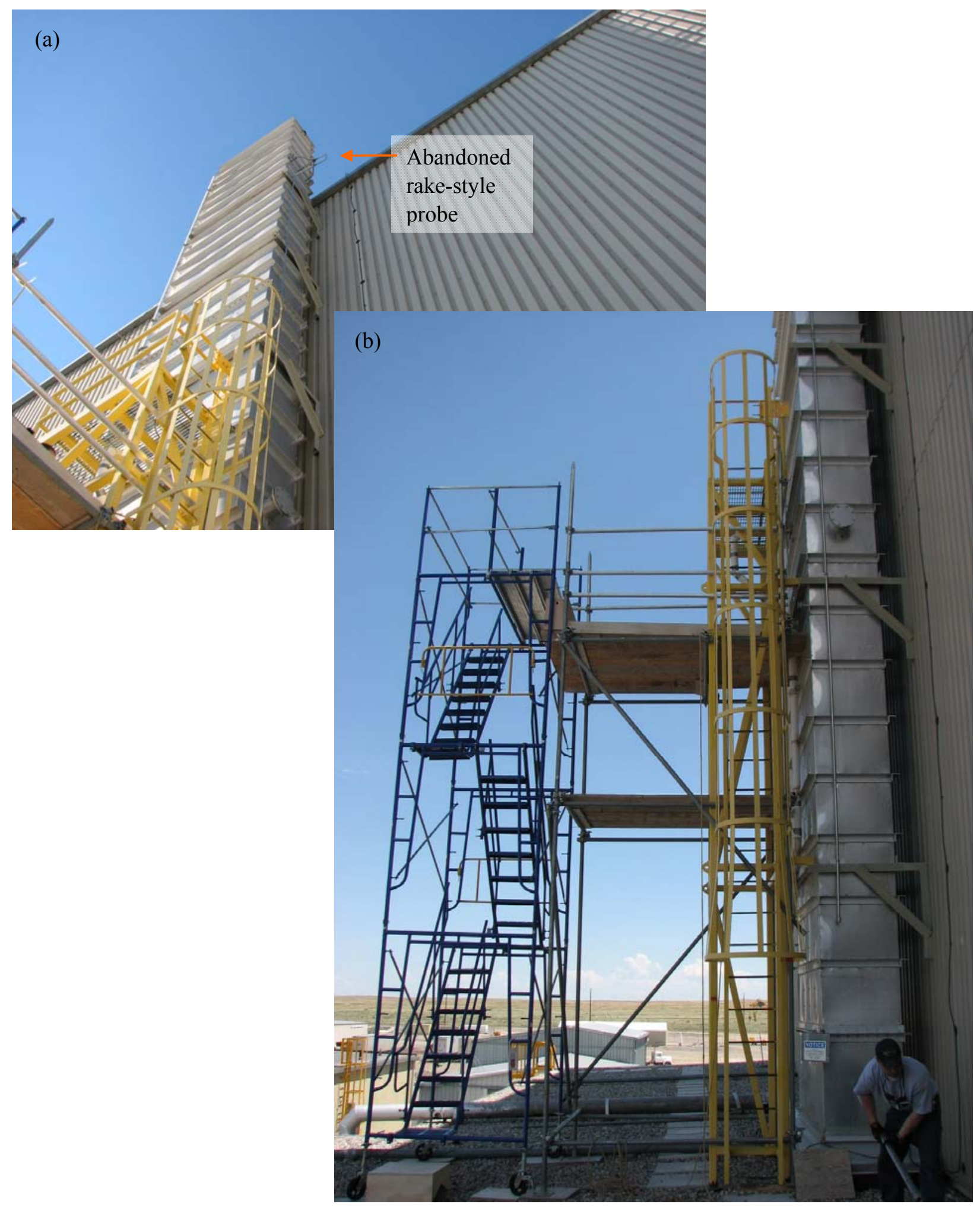

Figure 2.2. HFEF Building Exhaust Stack

(a) Stack discharge above the scaffolding, and (b) Side view of the stack with permanent (yellow) scaffold and scaffold constructed for testing activities described in this report. 


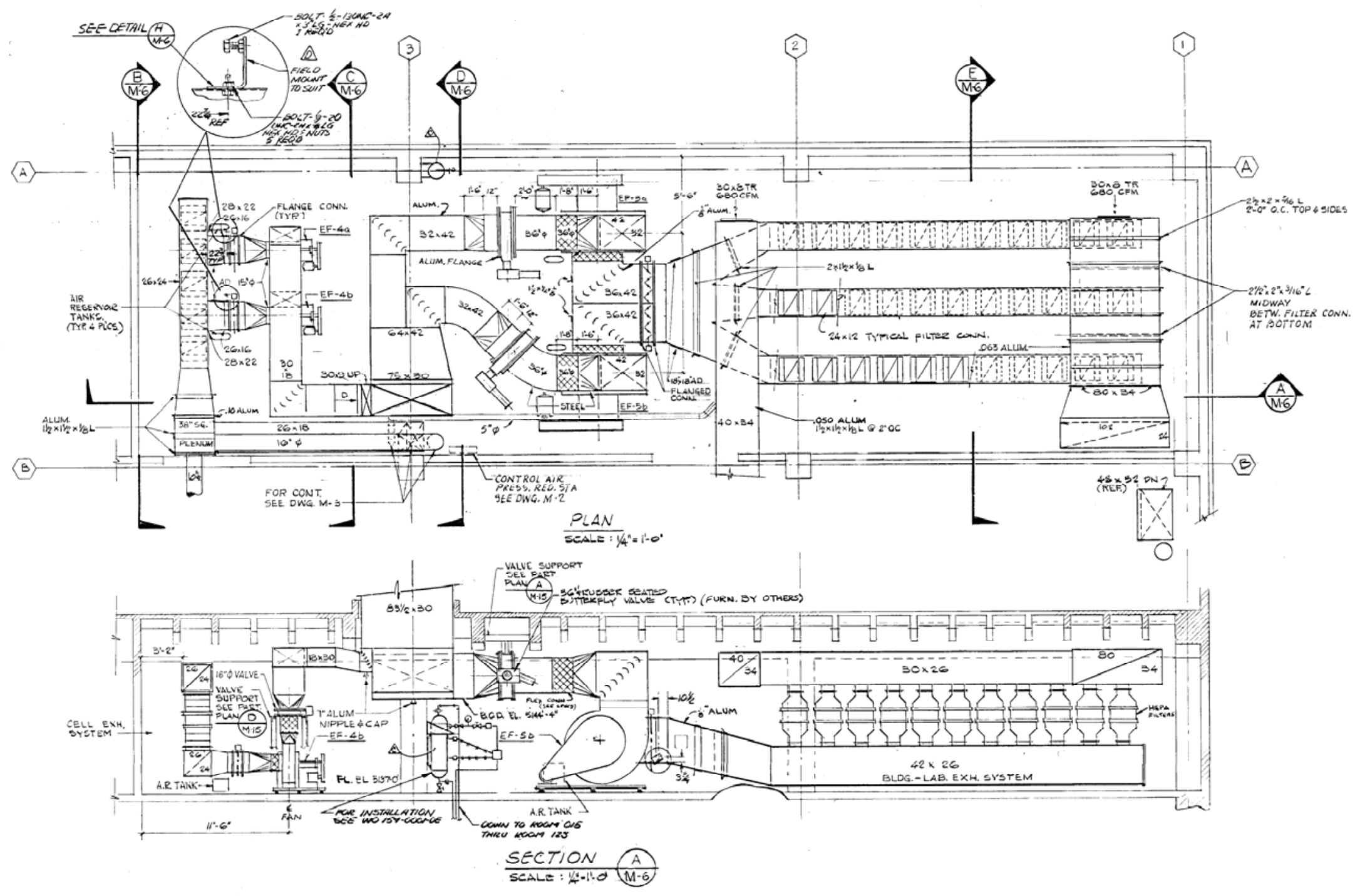

Figure 2.3. Plan and Side View drawings of the as-built HFEF HVAC system in Room 209 This drawing is extracted from Argonne National Laboratory DWG M-6, Rev E (1982). 


\subsection{Testing Methods}

The stack testing methods were based on the requirements of ANSI/HPS N13.1-1999. A test plan, TP-STMON-015, Air Sampling Probe Location Tests of Hot Fuel Examination Facility Air Exhaust System, was prepared by PNNL and approved by BEA. This plan referenced the use of PNNL procedures which define how the test should be conducted in general. A test instruction (TI) was prepared for each test type as follows:

- TI-STMON-017, Velocity Uniformity Test at the Hot Fuels Examination Facility Stack

- TI-STMON-018, Flow Angle Test at the Hot Fuels Examination Facility Stack

- TI-STMON-019, Gas Tracer Mixing Tests at the Hot Fuels Examination Facility Stack

- TI-STMON-020, Tests of Particle Tracer Mixing in HFEF Stack.

These TIs contain specific instructions pertaining to the tests that are not addressed in the more generalized procedures. Such information includes the following:

- Layout of measurement points

- Location of tracer injection points

- List of equipment and instrumentation

- Safety requirements

- List of test runs

- Test description and measurement data sheets with hand entries

- Table of preliminary results.

Because the final data sheets and a description of the test methods are included in this report, the TIs are not included here. A summary of the stack testing methods used for each of the four test types are presented in this section.

\subsection{Quality Assurance}

The Pacific Northwest National Laboratory Quality Assurance (QA) Program is based upon the requirements defined in the U.S. Department of Energy Order 414.1C, Quality Assurance, and 10 CFR 830, Energy/Nuclear Safety Management, and Subpart A-Quality Assurance Requirements (a.k.a., the Quality Rule). PNNL has chosen to implement the following consensus standards in a graded approach:

- ASME NQA-1-2000, Quality Assurance Requirements for Nuclear Facility Applications, Part 1, Requirements for Quality Assurance Programs for Nuclear Facilities.

- ASME NQA-1-2000, Part II, Subpart 2.7, Quality Assurance Requirements for Computer Software for Nuclear Facility Applications.

- ASME NQA-1-2000, Part IV, Subpart 4.2, Graded Approach Application of Quality Assurance Requirements for Research and Development. 
The procedures necessary to implement the requirements are documented through PNNL's "How Do I...?" (HDI). ${ }^{\text {(a) }}$

The Stack Monitoring Project (STMON) implements an NQA-1-2000 Quality Assurance Program, graded on the approach presented in NQA-1-2000, Part IV, Subpart 4.2. The STMON Quality Assurance Manual (QA-STMON-002) describes the technology life cycle stages under the STMON Quality Assurance Plan (QA-STMON-0001). The technology life cycle includes the progression of technology development, commercialization, and retirement in process phases of basic and applied R\&D, engineering and production and operation until process completion. The life cycle is characterized by flexible and informal quality assurance activities in basic research, which becomes more structured and formalized through the applied R\&D stages.

- BASIC RESEARCH- Basic research consists of research tasks that are conducted to acquire and disseminate new scientific knowledge. During basic research, maximum flexibility is desired in order to allow the researcher the necessary latitude to conduct the research.

- APPLIED RESEARCH- Applied research consists of research tasks that acquire data and documentation necessary to assure satisfactory reproducibility of results. The emphasis during this stage of a research task is on achieving adequate documentation and controls necessary to be able to reproduce results.

- DEVELOPMENTAL WORK- Development work consists of research tasks moving toward technology commercialization. These tasks still require a degree of flexibility, and there is still a degree of uncertainty that exists in many cases. The role of quality on development work is to make sure that adequate controls to support movement into commercialization exist.

- RESEARCH AND DEVELOPMENT SUPPORT ACTIVITIES- Support activities are those which are conventional and secondary in nature to the advancement of knowledge or development of technology, but allow the primary purpose of the work to be accomplished in a credible manner. An example of a support activity is controlling and maintaining documents and records. The level of quality for these activities is the same as for developmental work.

The work described in this report has been completed under the QA Technology level of Development Work. STMON addresses internal verification and validation activities by conducting an Independent Technical Review of the final data report in accordance with STMON's procedure QASTMON-601, Document Preparation and Change. This review verifies that the reported results are traceable, that inferences and conclusions are soundly based, and the reported work satisfies the Test Plan objectives.

\subsection{Stack Tests}

The tests described in the following sub-sections were conducted under typical operating conditions for the HVAC system. Of the three fans that are installed on the process ventilation portion of this system, typically fans number EF 4-A and EF 4-B (which are the two downstream fans) are in operation, with EF 4-C in standby mode. The building ventilation portion of the system has two fans, EF 5-A and

(a) System for managing the delivery of laboratory-level policies, requirements, and procedures. 
EF 5-B, which are normally in operation. The total flow through the HFEF exhaust stack was approximately $34,000 \mathrm{scfm}$ during the stack testing activities described in this report.

Measurements were made at specific locations within the duct for each of the four tests described in the following sub-sections. The number and distance between measurement points was based on the U.S. Environmental Protection Agency (EPA) procedure 40 CFR 60, Appendix A, Method 1, for rectangular ducts. The nominally $83 \times 30$ inch exhaust duct was divided into 16 equal-area sections and stack testing measurements were made at the center points of these areas. The measurements were made through four ports installed across the width of the exhaust duct as shown in Figure 3.1. The ports were numbered 1 through 4 from west to east; in Figure 3.1, the far right port is Port 1. Circular markers in Figure 3.1 indicate the position of each measurement point. The measurement point closest to the port was Point 1 , while the point farthest from the port was Point 4. Each of the tests described in the following subsections were conducted at each of these 16 measurement points.

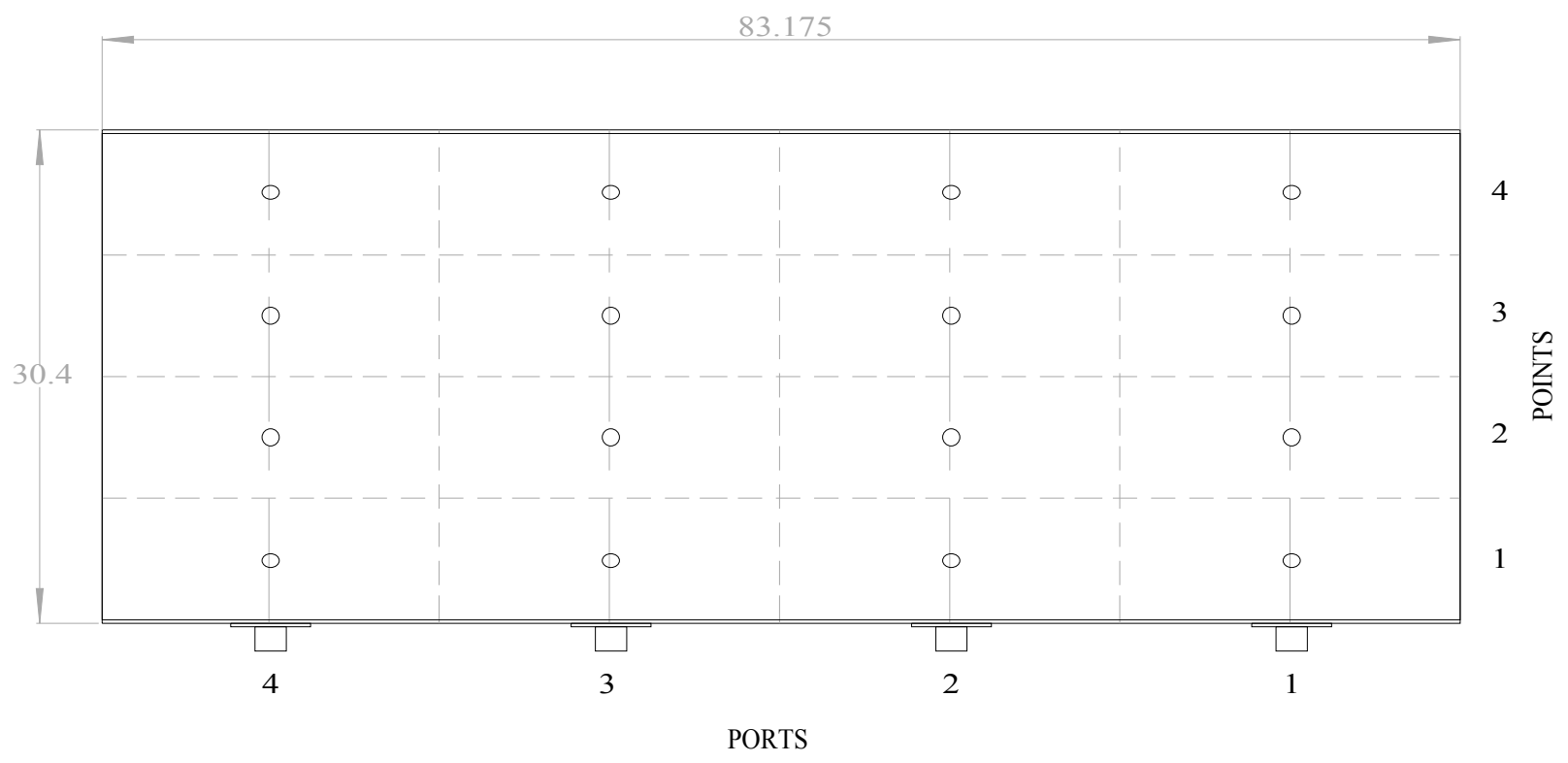

Figure 3.1. Cross-Section of the Duct at the Testing Location.

\subsubsection{Velocity Uniformity}

The uniformity of air velocity at the stack monitoring location indicates that the momentum in the stack is well-mixed. The method used to conduct the velocity uniformity tests was based on 40 CFR 60, Appendix A, Method 1. The criterion for acceptance from the velocity uniformity test is that the COV should be less than $20 \%$.

The air velocity was measured three times at each of the 16 grid points across the cross-section of the duct. The average of the three measurements was used to determine the mean and standard deviation of the velocity across the cross-sectional plane. The coefficient of variance (also known as the percent relative standard deviation) was calculated as 100 times the standard deviation divided by the mean. 
Each air velocity measurement was made using a handheld thermal anemometer (TSI, Model 8355, Shoreview, MN). Figure 3.2 shows the equipment inserted into a port for measurement as well as a separate photo showing the entire instrument. To conduct this test, workers adhered to the procedure EMS-JAG-04 and the test instruction TI-STMON-017.

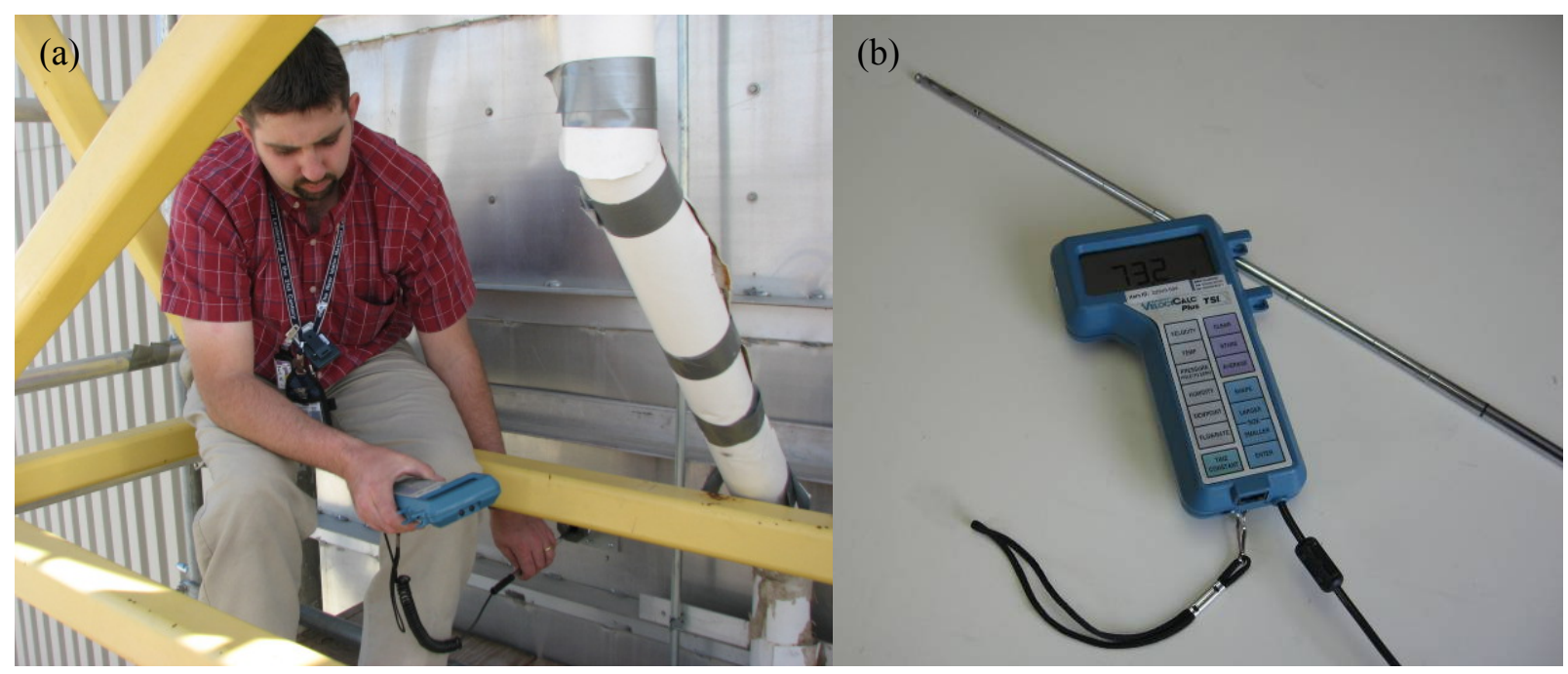

Figure 3.2. Equipment Used for the Velocity Uniformity Test. (a) Radiological Worker II inserting the probe in Port 3. (b) Thermal anemometer (similar to the one used in stack tests).

\subsubsection{Flow Angle}

The air velocity vector approaching the sample nozzle should be aligned with the axis of the nozzle within an acceptable deviation angle so that the sample extraction performance is not degraded. The test method is based on 40 CFR 60, Appendix A, Method 1, Section 11.4. The term "flow angle" refers to the angle between the velocity vector of the flow in the duct and the axis of the sampling nozzle. For the stack testing activities, the flow angle was measured at a grid of 16 points in a cross section of the duct near the location of the air monitoring probe. The criterion for acceptance from the flow-angle test is that the average angle must be $<20^{\circ}$.

The flow angle measurements were made using an S-type Pitot tube (Dwyer Instruments, 160S-48 A14V, Michigan City, IN) attached by flexible tubing to a slant-tube manometer (Dwyer Instruments, 400-5) and an angle-indicating device as shown in Figure 3.3. For this test, the S-type Pitot tube was rotated so that the planes of the two openings at the tip of the tube were parallel to the flow in the duct. The Pitot tube is considered perpendicular to the flow in this position. The circular protractor-level was affixed to the Pitot tube and was used to measure the angle of the probe. When the pressures on both tubes of the S-type Pitot tube were equal (as indicated by the manometer), the Pitot tube was perpendicular to the velocity vector. The procedure EMS-JAG-05 and the test instruction TI-STMON018 were used to conduct this test. 

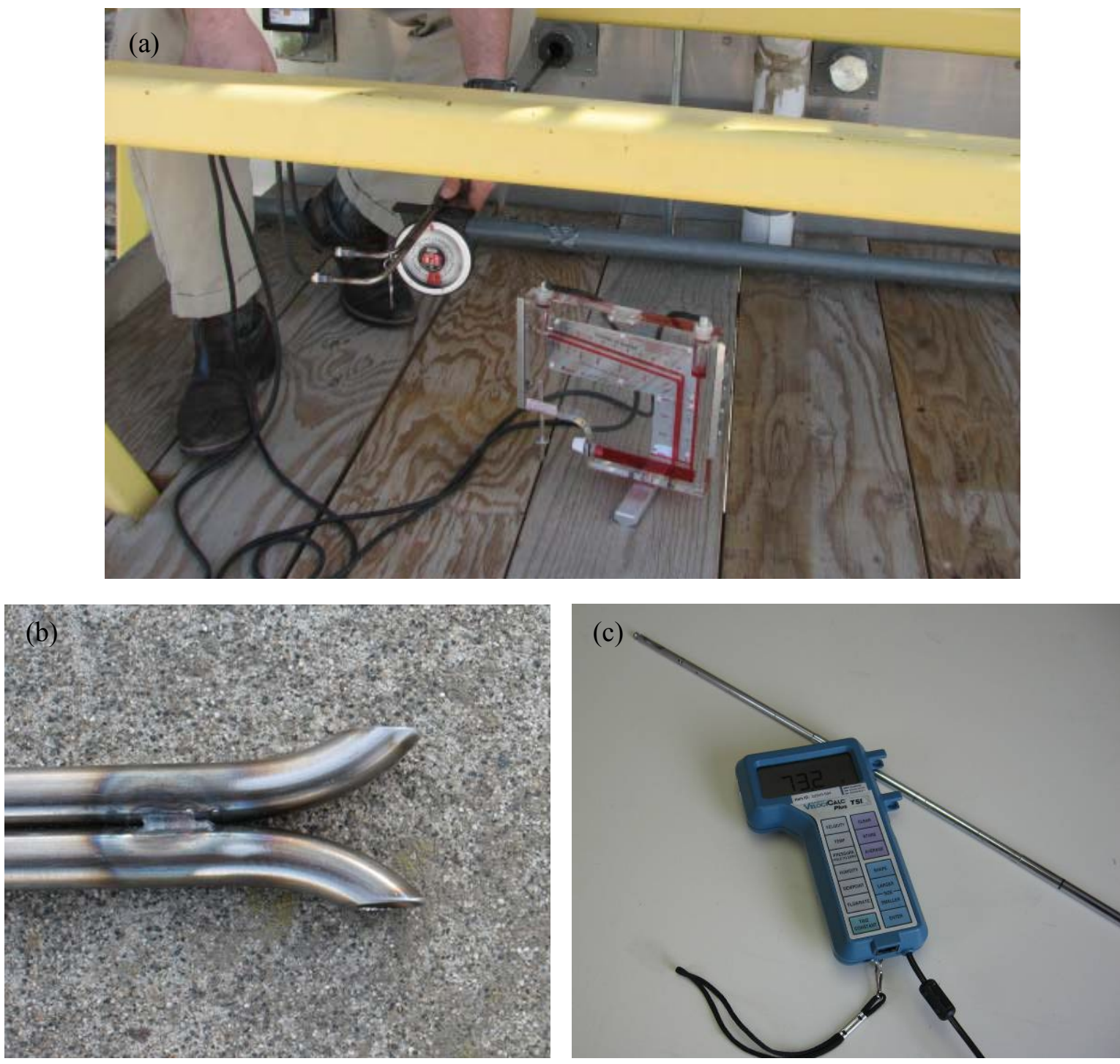

Figure 3.3. Equipment Used for the Flow Angle Test.

(a) S-type Pitot tube installed in Port 3 at the HFEF exhaust duct. The Pitot tube is connected to a slant-tube manometer, and has a protractor level attached to it to indicate the flow angle. (b) The tip of the S-type Pitot tube. (c) The thermal anemometer.

\subsubsection{Gaseous Tracer Uniformity}

The gaseous contaminant concentration mixing near the monitoring location was demonstrated using the tracer gas sulfur hexafluoride $\left(\mathrm{SF}_{6}\right)$. A compressed gas cylinder and flow controller was used to deliver a constant stream of $\mathrm{SF}_{6}$ into the duct. The gaseous tracer was injected into the duct air through the row of $53 / 8$-inch NPT ports shown in Figure 2.1. These ports are downstream of the fans and upstream of the vertical bend in the duct at the bottom of the stack. Five different injection points were used at this location. The five injection points were at the centerline and the four corners of the duct. The 
corner injections were within $20 \%$ of the hydraulic diameter of the duct. Figure 3.4 is a schematic showing the duct cross section with the five injection locations.

In addition to the five primary $\mathrm{SF}_{6}$ injection locations, two injections were conducted at a secondary injection point near the junction with the base of the stack. These two injections were conducted at a 1inch pipe nipple, which was used for the aerosol injection. See Figure 2.1 for the location of the 1-inch pipe nipple relative to the primary $\mathrm{SF}_{6}$ injections.

For each test run, the tracer concentration was measured three times at each of the 16 grid points across the sampling location. A photoacoustic gas analyzer (Brüel \& Kjær, Model 1302, Ballerup, Denmark) was used to measure tracer gas concentrations. The concentration variation is the important result for this test, so systematic calibration bias is not important in the test results. However, the analyzer response was checked using calibration standards before and after conducting the test series to verify an adequate instrument response. The response was considered acceptable if the concentration from the instrument was within $10 \%$ of the calibration standard.

A simple probe was used to extract the sample and deliver it to the gas analyzer. A small pump drew air from within the stack through the probe. The gas analyzer then sampled the air from the sample line for analysis. Figure 3.5 shows the equipment set-up for this test. The gas analyzer collected air samples from a tee in the main sample line. The procedure EMS-JAG-01 and the test instruction TI-STMON-019 were used to conduct this test.

In addition to gaseous concentration measurements made at the sampling ports, the concentration was also measured through the air monitoring probe during the last test. In that instance, the photoacoustic gas analyzer was connected to the grab sample canister (also known as the "bomb") which is connected to the air monitoring stream. Figure 3.6 shows the equipment set-up during this test. In this test, the exhaust stream from the small pump was discharged into the process stack through one of the $3 / 8$-inch NPT ports. 


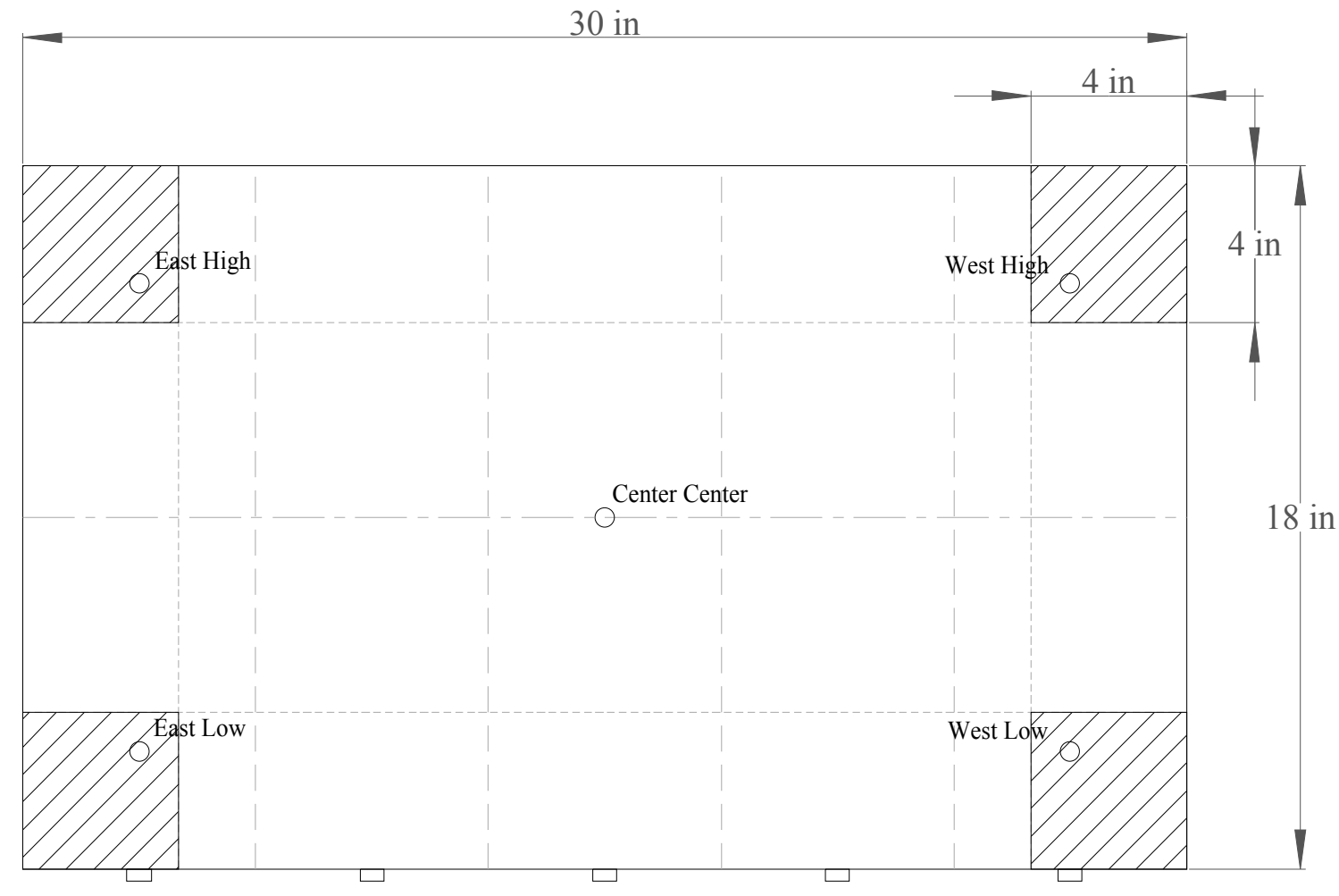

Figure 3.4. Cross-Section of the Duct Showing the Locations of the Five Primary Gaseous Tracer Injection Points.

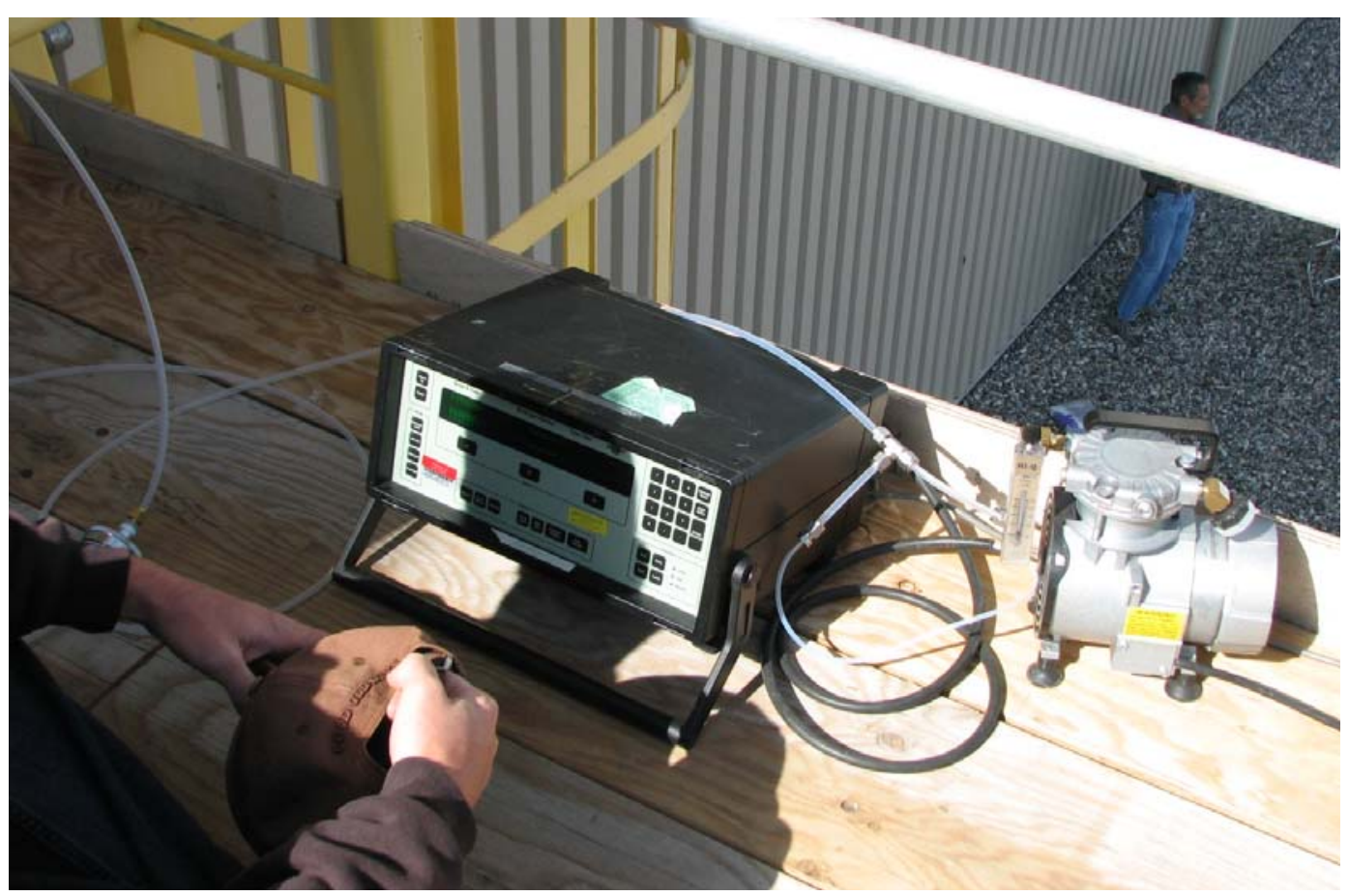

Figure 3.5. Equipment Used for the Gaseous Tracer Sampling. The photoacoustic analyzer (center) and a small air pump. 


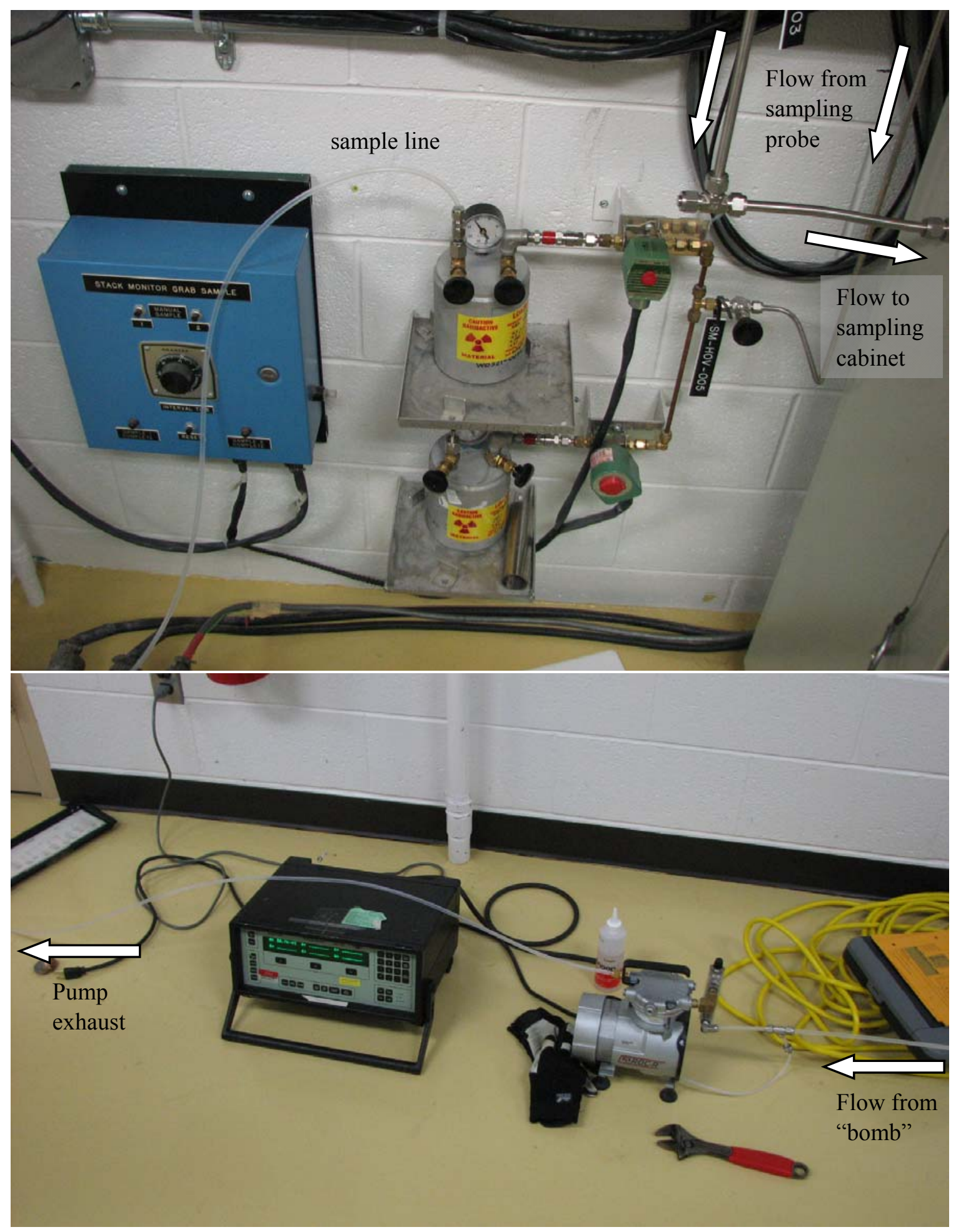

Figure 3.6. Sampling from the Air Monitoring System.

The top panel shows the sample line connected to the downstream end of the grab sample canister, also known as the "bomb." The bottom panel shows the sample pump and analyzer. 


\subsubsection{Particle Tracer Uniformity}

The uniformity of the particulate contaminant concentration was demonstrated using polydisperse pump oil particles as a particle tracer. Vacuum pump oil was drawn into a compressed-air-driven spray nozzle housed in a plastic chamber. These aerosol particles were injected into the duct air at an injection point downstream of the fans and slightly upstream of the vertical bend in the duct as shown in Figure 2.1. Figure 3.7 is a photograph that shows the equipment set-up for the aerosol injection. The plastic chamber is also referred-to as the aerosol generator. The aerosol was injected near the centerline of the duct at the 1 -inch pipe nipple using a $3 / 4$-inch injection probe. This test was repeated to gain some sense of the reproducibility of the results.

The concentration of the particles is measured at the sampling grid points with a calibrated optical particle counter (OPC, Met-One Model A2408, Grants Pass, OR). A simple probe was used to extract the sample and deliver it to the OPC. Figure 3.7 shows the sampling set-up, with the simple probe connected to the optical particle counter. The OPC sorts the particles into six size channels. As mentioned in Section 1.1, the particles of interest have an AD of $10 \mu \mathrm{m}$. Therefore, only data in the 9- to $11-\mu \mathrm{m}$ channel of the OPC were used. The particle concentration was measured three times at each of the 16 grid points across the cross-section of the duct. The criterion for acceptance from the particle uniformity test is that the COV should be less than 20\%. The procedure EMS-JAG-02 and the test instruction TI-STMON-020 were used to conduct this test.

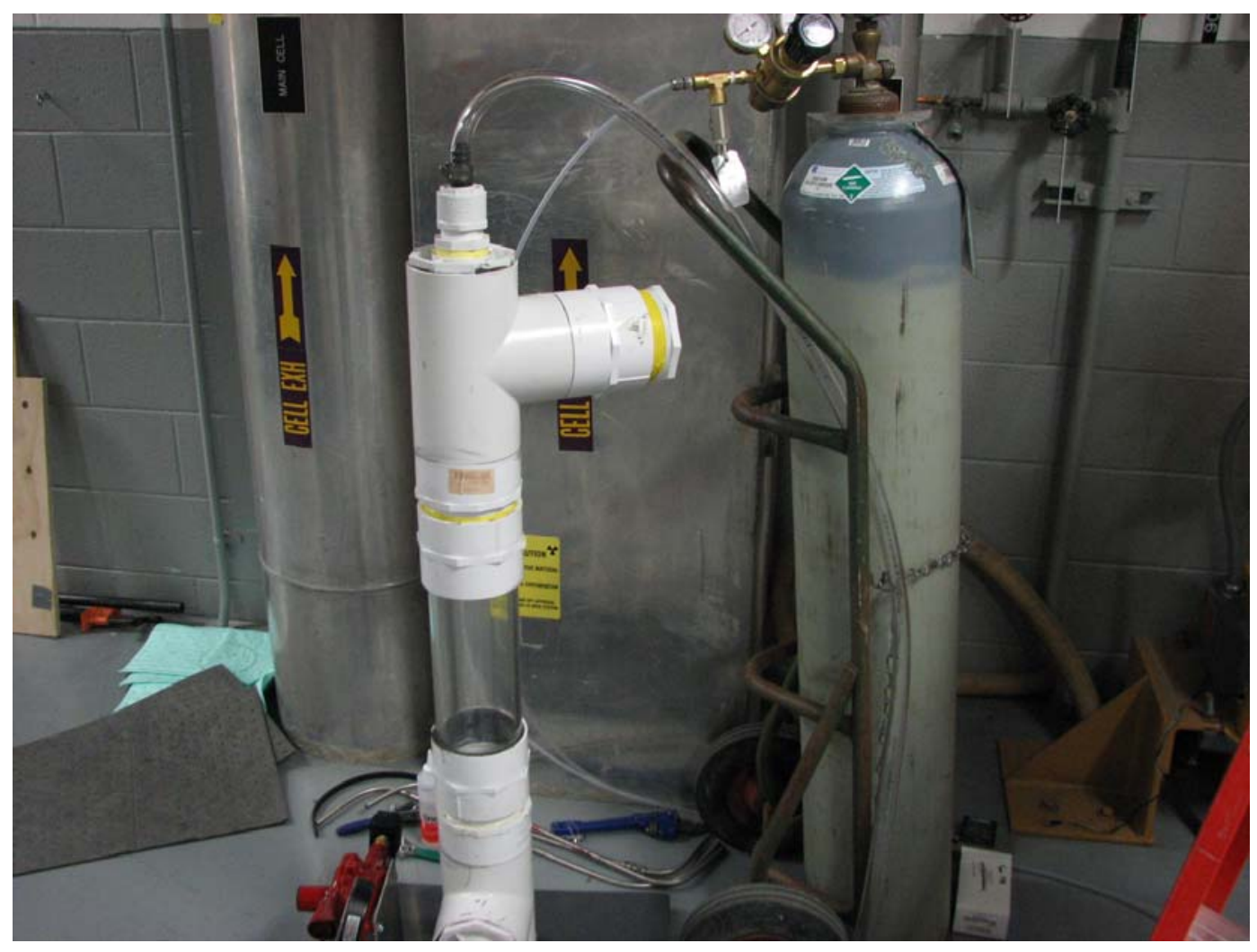

Figure 3.7. Equipment Used for the Particle Injection (and gas injection)

The white PVC chamber is the aerosol generator, while the grey cylinder on the right contains $\mathrm{SF}_{6}$ for gas uniformity tests. 


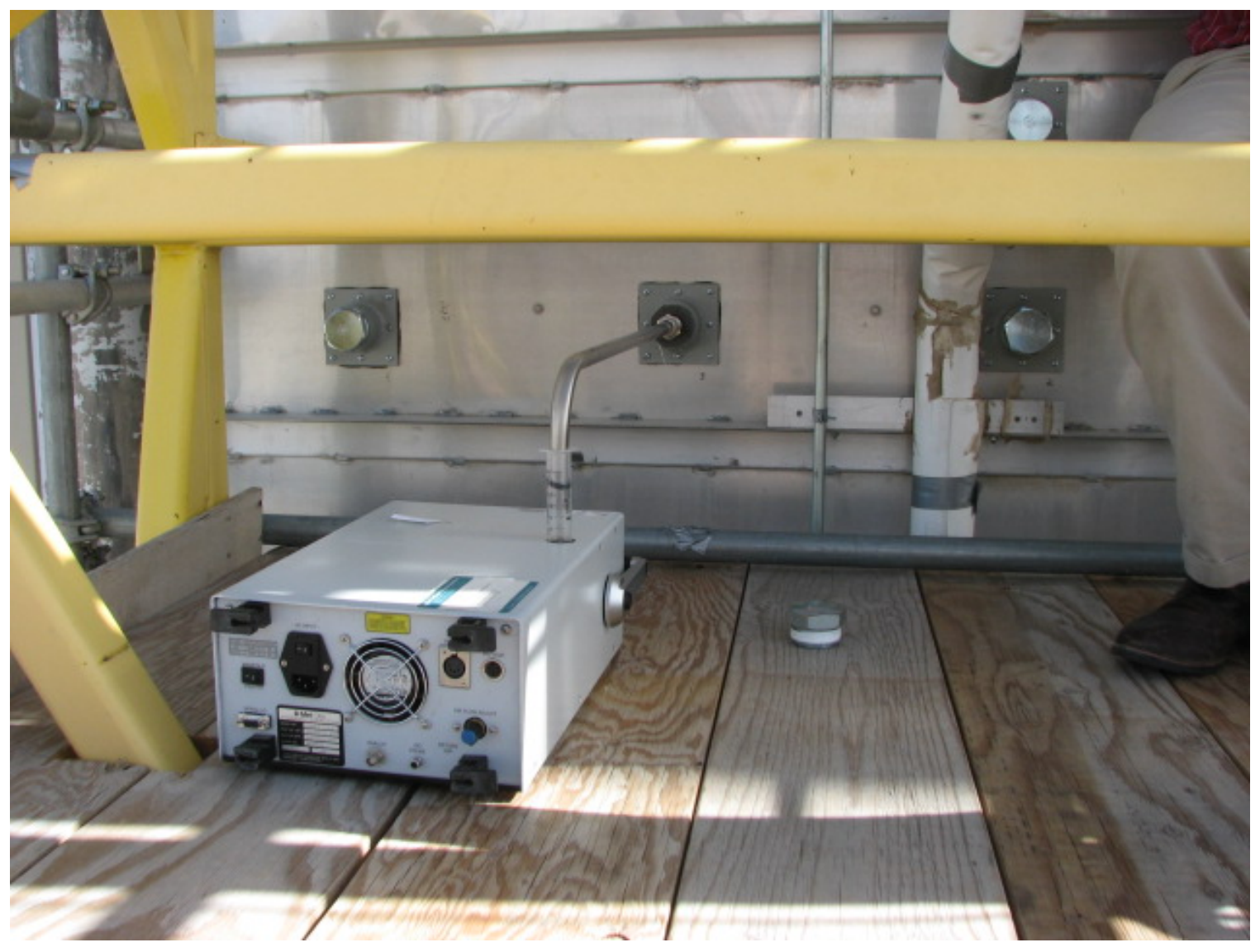

Figure 3.8. Equipment Used for the Particle Sampling

The optical particle counter is installed at Port 3. 


\subsection{Stack Testing Results}

This section summarizes the results of the stack testing activities. Independent reviews were performed to verify the data transcription and calculations. The final data sheets have been included in Appendices A through D.

The stack was field-measured to verify the dimensions. The depth ranged from $30.5-30.3125$-inches and the average was 30.1875-inches. The stack width was about 83.2-inches.

\subsection{Velocity Uniformity}

Table 4.1 lists the results for the velocity uniformity tests performed on the HFEF duct. Initially, only two tests were planned; the second test was intended simply as a check of the reproducibility of the results. However, during the first velocity test (VT), Run VT-1, a quarterly fan maintenance procedure was conducted, which caused the airflow to fluctuate. The testing was placed on hold until the maintenance was complete, about 30 minutes later. Given the potential for varying fan conditions before and after the fan maintenance procedure, two additional tests were conducted. In all cases, the results were well within the criterion of COV values less than $20 \%$. VT-1 had a slightly larger \%COV (8.7 $\% \mathrm{COV}$ ) compared to the other two tests ( 7.6 and $7.7 \% \mathrm{COV})$, which may be attributable to the fan maintenance activity conducted during the VT-1 test. The mean velocity at each of the 16 sampling locations for the last two velocity test is included in Figure 4.1 as an example. The completed data sheets from these three tests are available in Appendix A.

Table 4.1. Summary of Velocity Uniformity Tests

\begin{tabular}{cccc}
\hline Fan Operating Configuration & Run No & scfm & $\% \mathrm{COV}^{(\mathrm{a})}$ \\
\hline 2 process and 2 ventilation & VT -1 & 33,248 & $8.7 \%$ \\
2 process and 2 ventilation & VT -2 & 33,227 & $7.6 \%$ \\
2 process and 2 ventilation & VT -3 & 33,586 & $7.7 \%$ \\
\hline
\end{tabular}

(a) COV must be $\leq 20 \%$ 

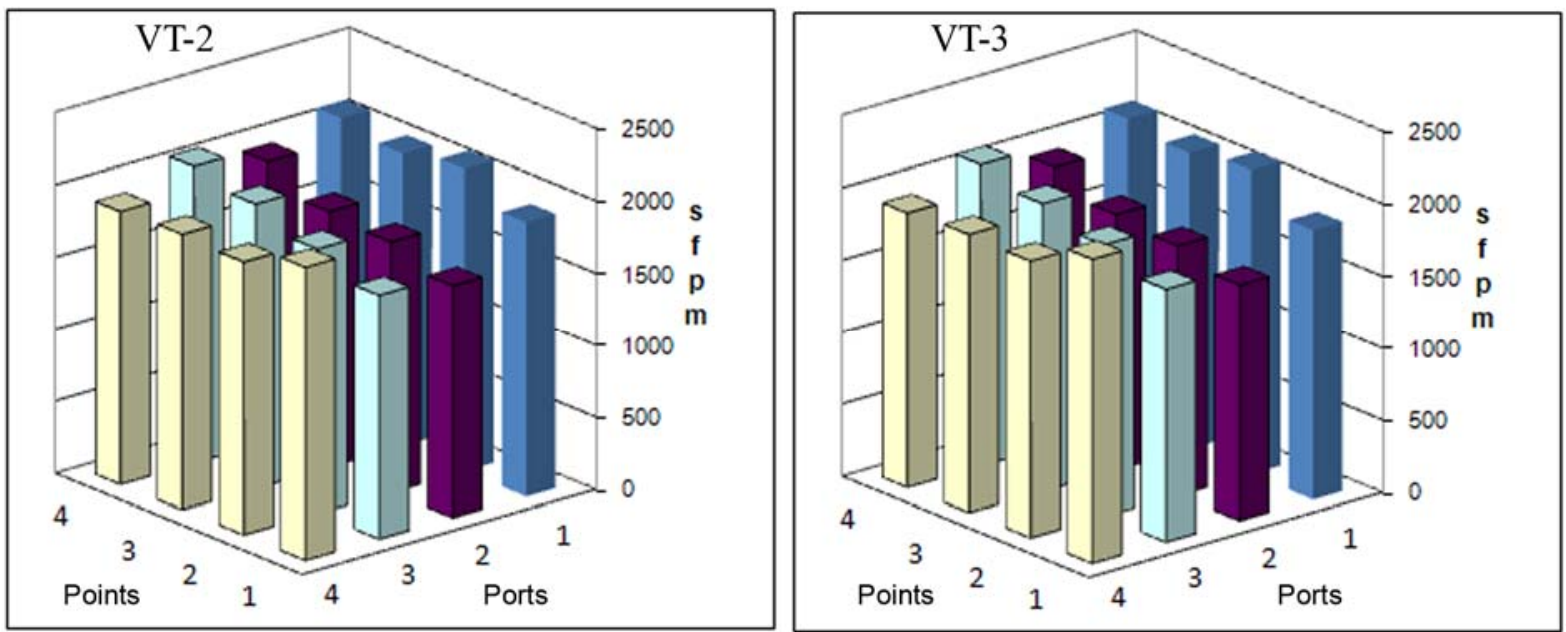

Figure 4.1. Mean Velocity Measurements at each of the 16 Sampling Locations for VT-2 and VT-3.

\subsection{Flow Angle}

Table 4.2 lists the results for the flow angle (FA) tests performed on the HFEF exhaust duct. In both cases, the results were well within the criterion of COV values less than $20 \%$. The mean flow angle at each of the 16 sampling locations is included in Figure 4.2. The completed data sheets from these two tests are available in Appendix B.

Table 4.2. Summary of Flow Angle Tests

\begin{tabular}{ccc}
\hline Fan Operating Configuration & Run No & Mean Absolute Flow Angle $^{(\mathrm{a})}$ \\
\hline 2 process and 2 ventilation & FA -1 & $2.6^{\circ}$ \\
2 process and 2 ventilation & FA -2 & $1.9^{\circ}$ \\
\hline
\end{tabular}

(a) Mean absolute flow angle must be $\leq 20^{\circ}$. 

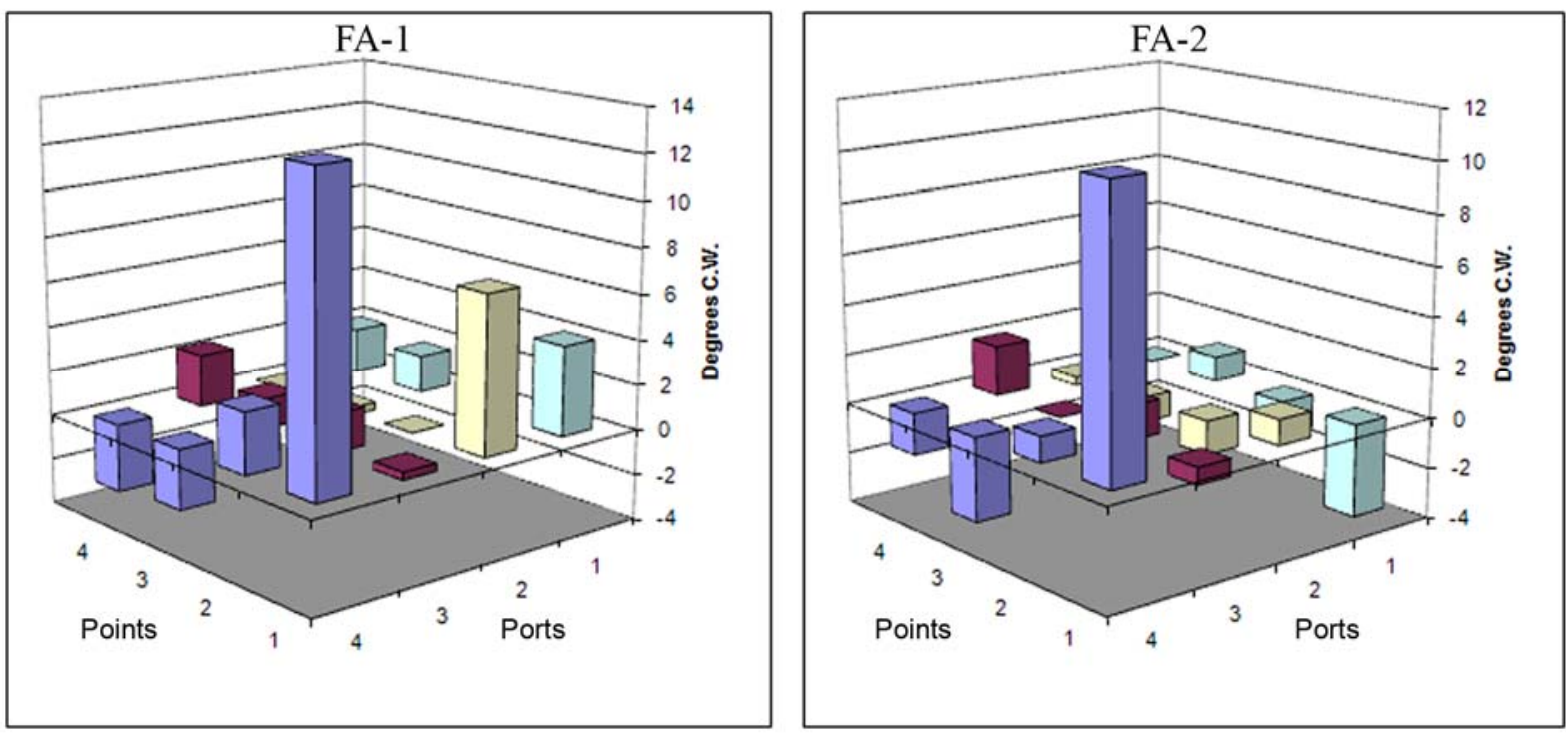

Figure 4.2. Mean Flow Angle Measurements at each of the 16 Sampling Locations

\subsection{Gaseous Tracer Uniformity}

Prior to and after the gas tracer testing, the response of the gas analyzer was checked against calibration standards. The calibration check is typically used to make certain that the instrument response is stable and that the concentration reported by the instrument is in agreement with the calibration standard (within 10\%). The instrument response during these calibration checks indicated a reasonable level of agreement with the calibration standard concentrations; measurements were between $102 \%$ and $105 \%$ of the reported concentrations of the standards.

Table 4.3 lists the results for the gaseous tracer (GT) uniformity tests performed on the HFEF duct. In all cases, the results show that there is very poor mixing of the process stream within the exhaust stack. For each of the injection positions, the results were much larger than the acceptance criteria; i.e., COV values less than $20 \%$ and a maximum deviation from the mean of less than $30 \%$. The lowest $\%$ COV test $(59.8 \% \mathrm{COV})$ resulted from the West High injection location, whereas the highest \%COV test $(83.7$ $\% \mathrm{COV}$ ) was from the East Low injection location, which is the opposite corner. These two injection locations also had the smallest and largest maximum deviation values. The West High injection had a 498.9\% deviation from the mean, whereas the East Low injection had a $311.7 \%$ deviation from the mean. The mean $\mathrm{SF}_{6}$ concentration at each of the 16 sampling locations for the cases with the lowest and highest $\mathrm{COV}$ values is included in Figure 4.3 as an example. The completed data sheets from these eight tests are available in Appendix C.

The aerosol injection probe, which was $3 / 4$-inch outside diameter OD, was too large to fit into the $3 / 8$ inch ports where the five primary $\mathrm{SF}_{6}$ injections were made. The aerosol injection was made at the 1-inch pipe nipple instead. The $\mathrm{SF}_{6}$ was also injected at the pipe nipple to develop a more direct comparison between the gaseous and aerosol mixing from a common injection point. The result of the SF6 injection at the 1-inch pipe nipple was similar to the results from the five primary injection locations. Although the $90^{\circ}$ bend in the duct between the two injection locations would presumably contribute to the mixing of 
the tracer within the process duct, the final distribution of concentrations at the sampling ports was essentially un-affected by the change in injection position.

The concentration through the air monitoring probe was measured at the end of Run GT-7. Although the air monitoring probe is between Test Ports 2 and 3 (and it is laterally closer to Port 2), the concentrations measured through the probe were more similar to the values measured at Port 3 .

Table 4.3. Summary of Gas Tracer Uniformity Tests

\begin{tabular}{|c|c|c|c|c|}
\hline Fan Operating Configuration & Injection Position & Run No & $\%$ Max Deviation ${ }^{(a)}$ & $\% \mathrm{COV}^{(\mathrm{b})}$ \\
\hline 2 process and 2 ventilation & East High & $\mathrm{GT}-1$ & $319.2 \%$ & $81.2 \%$ \\
\hline 2 process and 2 ventilation & East Low & $\mathrm{GT}-2$ & $311.7 \%$ & $83.7 \%$ \\
\hline 2 process and 2 ventilation & West High & $\mathrm{GT}-3$ & $498.9 \%$ & $59.8 \%$ \\
\hline 2 process and 2 ventilation & West Low & $\mathrm{GT}-4$ & $451.8 \%$ & $65.4 \%$ \\
\hline 2 process and 2 ventilation & Center Center & $\mathrm{GT}-5$ & $401.2 \%$ & $71.4 \%$ \\
\hline 2 process and 2 ventilation & Pipe Nipple Center & $\mathrm{GT}-6$ & $323.1 \%$ & $81.2 \%$ \\
\hline 2 process and 2 ventilation & Pipe Nipple Center & $\mathrm{GT}-7$ & $322.0 \%$ & $79.7 \%$ \\
\hline
\end{tabular}
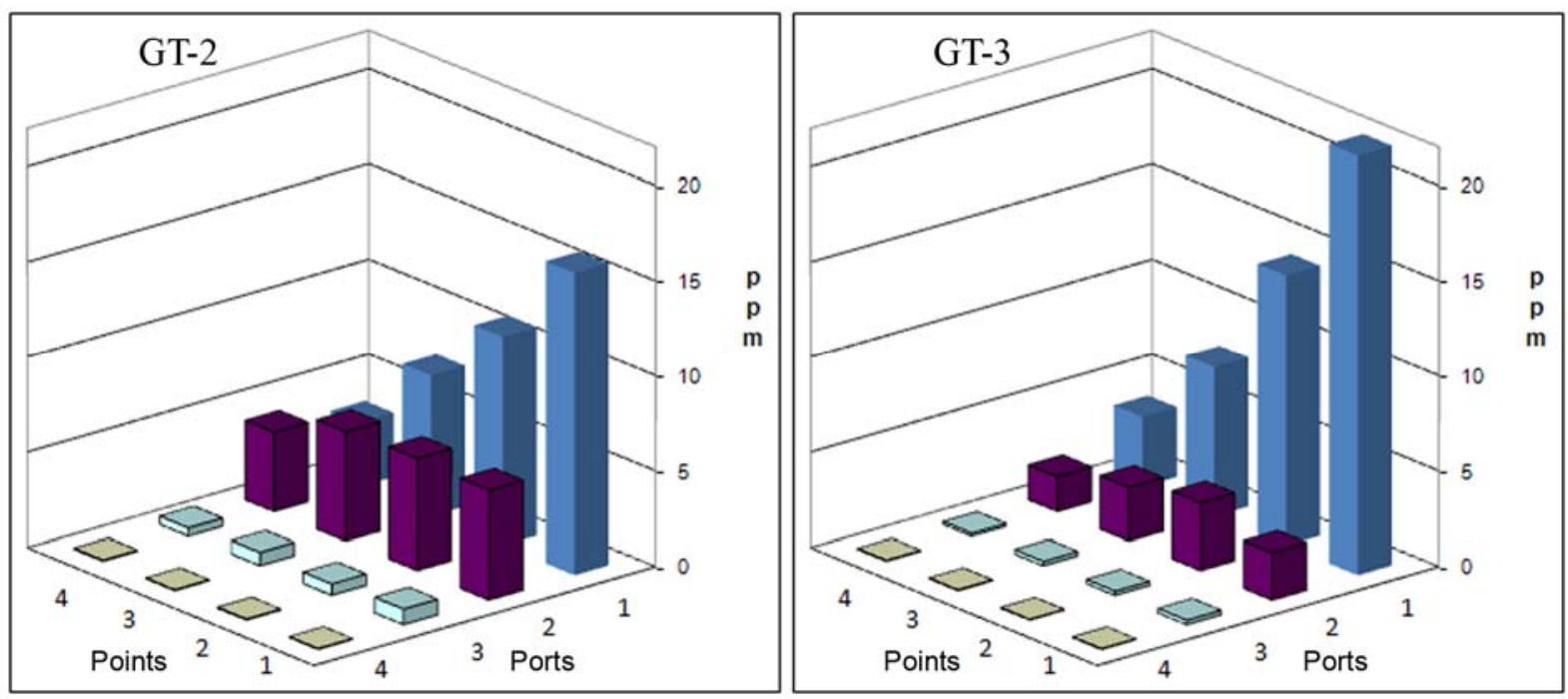

Figure 4.3. $\mathrm{SF}_{6}$ Concentrations at the 16 Sampling Locations for GT-2 and GT-3. 
Figure 4.4 is a diagram of the tracer gas concentrations at each measurement point during Run GT-7. The small diamond symbol shows the approximate location of air sampling probe. There is no ready explanation for the non-linear concentration gradient from Port 2 to Port 3; however, we postulate that is caused by the lack of a source of large scale turbulence to cause effective mixing, since the small scale turbulence is inadequate to promote mixing.

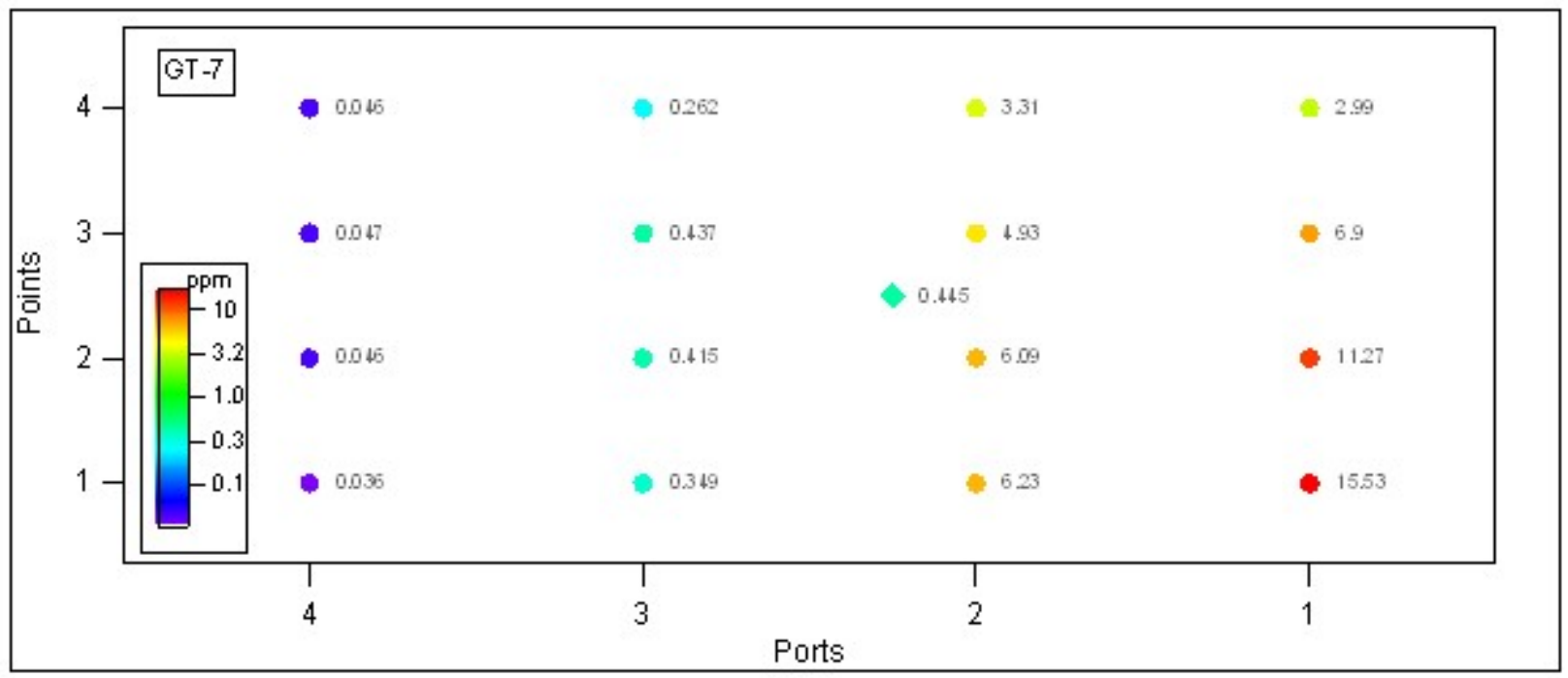

Figure 4.4. $\mathrm{SF}_{6}$ Concentrations at the 16 Sampling Locations for GT-7.

\subsection{Particle Tracer Uniformity}

Table 4.4 lists the results for the particle tracer (PT) uniformity tests performed on the HFEF exhaust duct. The results of these two tests were similar to the results of the gaseous tracer test. The tests did not fall within the criterion of COV values less than $20 \%$. The two tests had $\% \mathrm{COV}$ values of 122.5 and $150.7 \% \mathrm{COV}$. These results are slightly worse than the gaseous tracer results, indicating that the inertial effects of the particles may be contributing to the reduced mixing. The maximum deviation from the mean is also listed in Table 4.4 for information only. There is no acceptance criterion for this measure. The mean 9- to 11- $\mu$ m particle concentration at each of the 16 sampling locations during Run PT-2 is included in Figure 4.5 as an example. The completed data sheets from these two tests are available in Appendix D.

For the particle uniformity tests, a rigid sampling probe is connected to the optical particle counter using o-rings to create an air-tight connection to a modified syringe, which fits the OPC inlet. The space constraints between the permanent (yellow) scaffolding and the deck of the scaffolding installed for these tests prevented the measurement at Port 4, Point 1. This point was skipped for both of the particle tracer tests. 
Table 4.4. Summary of Particle Tracer Uniformity Tests

\begin{tabular}{ccccc}
\hline Fan Operating Configuration & Injection Position & Run No & $\%$ Max Deviation & $\% \mathrm{COV}^{(\mathrm{a})}$ \\
\hline 2 process and 2 ventilation & Pipe Nipple Center & PT -1 & $339.1 \%$ & $122.5 \%$ \\
2 process and 2 ventilation & Pipe Nipple Center & PT -2 & $496.4 \%$ & $150.7 \%$ \\
\hline
\end{tabular}

(a) COV must be $\leq 20 \%$.
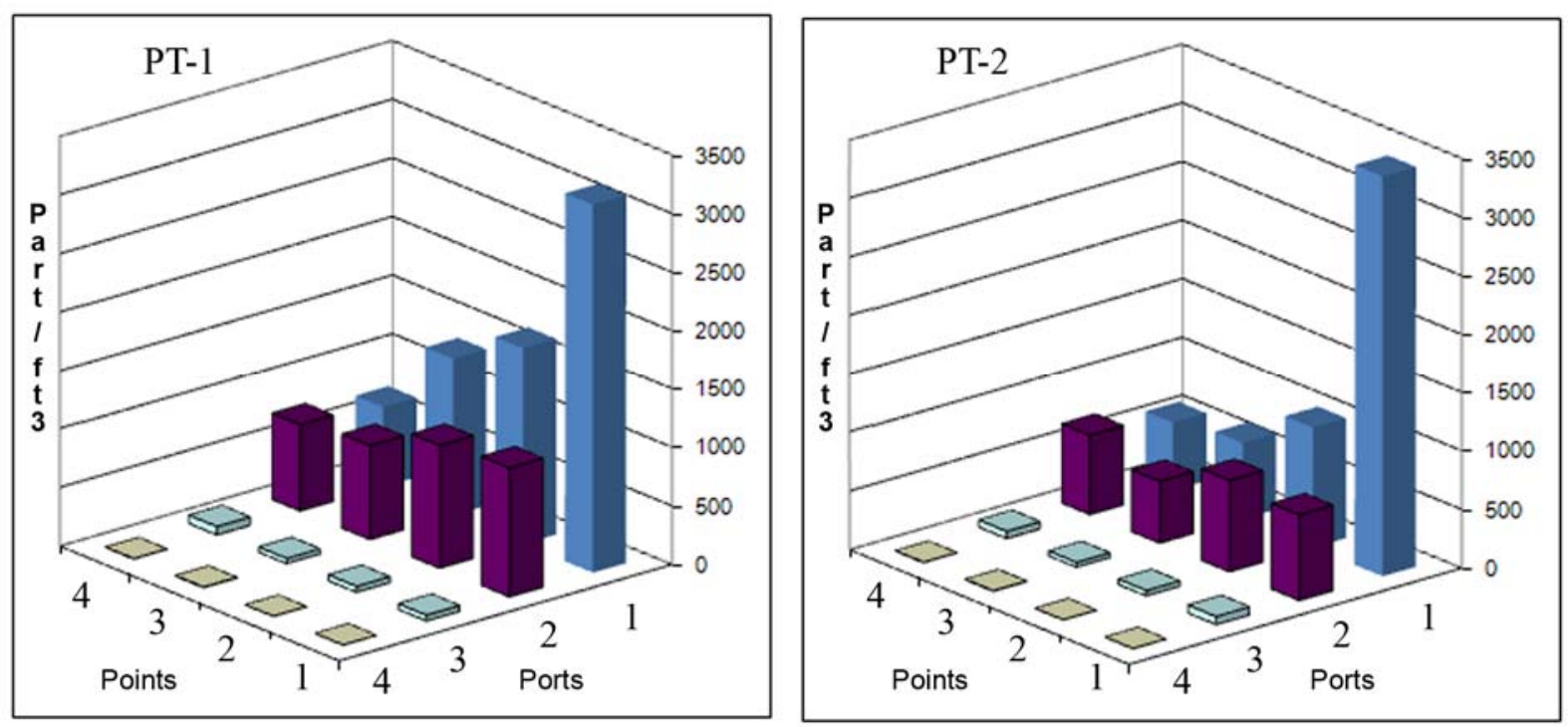

Figure 4.5. Particle Concentrations at the 16 Sampling Locations. 


\subsection{Conclusions and Recommendations}

A series of tests were conducted at the stack air monitoring location on the Hot Fuel Examination Facility at the Materials and Fuels Complex of the Idaho National Laboratory during July 2010. Tests of velocity uniformity and flow angle indicate that the location of the shrouded probe used for the air monitoring on this stack is compliant with the criteria outlined in ANSI/HPS N13.1-1999. Velocity uniformity measurements indicate an $8 \% \mathrm{COV}$ in velocity, and an average of less than $3^{\circ}$ flow angle deviation. However, the tests of gaseous and particulate tracer uniformity indicate that there is very poor mixing of the process stream with the building ventilation stream. There is a sharp gradient in gaseous and particulate concentrations across the width of the exhaust stack. The gaseous tracer uniformity measurements indicate from 60 to $84 \% \mathrm{COV}$ in gas concentrations and up to $150 \% \mathrm{COV}$ in particulate concentrations.

The main factor contributing to the poor mixing is the large difference between the building ventilation flow and the process flow. The process flow is approximately a factor of 8 smaller than the building ventilation flow, and as a result, does not have the momentum necessary to mix into the building ventilation flow as the two streams enter separately at the bottom of the stack. The process stream is confined to one side of the stack and there is no large scale turbulence to mix it with the ventilation stream.

During one of the gaseous tracer tests, in addition to the gaseous tracer concentrations at the testing port locations, concentrations were measured through the shrouded probe by sampling air in the air monitoring system. By doing this, we could make a direct comparison between the average concentration measured across the cross-section of the exhaust duct and the single point concentration at the air monitoring probe. It was observed that the gas tracer concentration measured through the air monitoring probe was approximately one-tenth of the average concentration.

The current location of the air monitoring probe does not meet the requirements of the ANSI/HPS N13.1-1999 standard. Moving the probe downstream in the exhaust duct is not likely to result in a compliant location. Therefore, modifications to the probe location or the stack must be made to ensure that an appropriate sample is collected for monitoring the stack emissions. Several possible modifications are discussed below for consideration.

\subsection{Potential Stack Monitoring Modifications}

A number of possible solutions exist to resolve either the non-compliant stack conditions or sampling position. Several of these solutions are described in the following subsections, starting with the most preferred approach for full compliance with the ANSI/HPS N13.1-1999 standard.

\subsubsection{Stack Modifications}

There are several stack modifications that may improve the mixing of the process stream relative to the exhaust stack.

- Install a mixing box where the two streams come together. 
- Install an Air Blender ${ }^{\circledR}$ (Blender Products Inc., Denver, CO) near the base of the stack.

- Alter the connection of the process flow with the building ventilation flow upstream of the exhaust stack. Although space constraints in Room 209 may be a concern, the process flow could be re-routed so that it mixes well with the building ventilation stream. Perhaps inserting the process stream into the stack base via a long diffuser pipe would distribute that stream across the width of the stack.

- Construct a separate exhaust stack to service the process stream exclusively. This would eliminate the need to mix the process stream uniformly with the building ventilation stream.

Stack modifications would require that stack tests be conducted to ensure that the sampling location is compliant with ANSI/HPS N13.1-1999. This could be achieved by conducting the four types of test on the actual stack. Alternatively, a scale model of the stack could be constructed for conducting the four types of tests, and confirmatory tests of the velocity and flow angle would be conducted on the actual stack. Also, if a pre-tested stack design is used, then only the confirmatory tests are needed. Computational modeling may assist in screening different designs. This latter option may be advantageous if several stack modification designs are considered, and the results of different designs are desired. There is likely to be a pressure drop cost associated with any of these modifications.

\subsubsection{Probe Position Modification}

Moving the probe downstream in the exhaust stack may not result in a compliant sampling location. Consideration should be given to scale model testing before taking that approach. Alternatively, it may be advantageous to move the probe to the west (closer to the port 1 location). Emission measurements may be over-reported, depending on the location. However, with moving the probe laterally, the resulting system would still be out of technical compliance with the contaminant mixing criteria of the ANSI/HPS N13.1-1999 standard, so awaiver from EPA Region X may need to be requested for the mixing criteria.

\subsubsection{Rake Installation}

Because a large concentration gradient is observed across the width of the exhaust duct, it may be reasonable to use a multi-nozzle probe (also known as a "rake") in the duct instead of the single shrouded probe. Prior to installation of the shrouded probe in 2005 the HFEF used a multipoint isokinetic rake. This rake is still located in the HFEF stack and potentially could be used again. It is important to note that the shrouded probe installation was not conducted as part of a modification to the facility.

Testing similar to what was done during gas tracer test GT-7 may indicate the potential success of that approach. Additional testing or modeling would be required to see if a rake and the associated sample delivery piping would comply with ANSI/HPS N13.1-1999 requirements for sample delivery. If successful, this approach would still technically be not complaint with the ANSI standard, which is based on sampling from a well-mixed stream, so a waiver from EPA Region X may need to be requested for the mixing criteria. 


\subsubsection{Correction Factor Application}

A sampling bias was discovered during the last gas tracer test, which indicated that the tracer concentration measured in the sampling system was about $1 / 10^{\text {th }}$ that of the stack concentration. This sample bias may be used as a correction factor for all past and future air sampling data, which would forgo any of the other remedies mentioned above. However, this approach has some disadvantages which are enumerated below.

- The sample bias and the gas tracer uniformity results indicate a very sharp gradient in gas concentration.

- The indicated bias is the result of only a single data point. Additional testing may be considered to build confidence in the consistency of the sampling bias.

- The indicated bias may have no relationship to the bias for particles.

- The sharp gradient implied by the gas concentration measured through the sampling system may indicate in-leakage or another problem associated with the sampling system.

\subsection{Recommendations to Assist Decision Making}

There are some investigations that would assist in making decisions about the course of action. These would include:

1. Obtain as built drawings of the sample lines for the current air sampling system and for the abandoned rake near the top of the stack.

2. Partially repeat the gas tracer uniformity test with simultaneous sampling from the position aligned with the current sampling probe and from the tee where the gas sample bomb extracts its sample. This may help to clarify the concentration gradient between Test Ports 2 and 3 and to provide a baseline tracer concentration to compare against the concentration observed at the tee.

3. Inspect the condition of the current sampling probe and sample transport lines for correct assembly and leak-tightness.

4. Perform the qualification tests at a higher accessible elevation on the stack to explore whether that presents a more suitable sampling location.

5. Perform a test similar to \#2 above for the abandoned probe near the top of the stack.

6. Estimate particle line loss in the current sample transport system and hypothetical systems connected to probes at other locations in the stack.

These investigations should help to clarify which remediation measures, not involving reconfiguring the HVAC ductwork, that are most likely to result in a representative sample. 


\subsection{References}

10 CFR 830, Subpart A. 2008. "Quality Assurance Requirements.” Code of Federal Regulations, U.S. Department of Energy.

40 CFR 60, Appendix A, Method 1, 2008. "Sample and Velocity Traverses for Stationary Sources." Code of Federal Regulations, U.S. Environmental Protection Agency.

40 CFR 61, Subpart H, 2002. "National Emission Standard for Emissions of Radionuclides other than Radon from Department of Energy Facilities." Code of Federal Regulations, U.S. Environmental Protection Agency.

American National Standards Institute (ANSI). 1999. Sampling and Monitoring Releases of Airborne Radioactive Substances from the Stacks and Ducts of Nuclear Facilities. ANSI/HPS N13.1-1999, Health Physics Society, McLean, Virginia.

American Society of Mechanical Engineers (ASME). 2000. NQA-1-2000, Quality Assurance Requirements for Nuclear Facility Applications. New York.

DOE Order 414.1C. “Quality Assurance.” U.S. Department of Energy, Washington, D.C. 


\section{Appendix A}

\section{Velocity Uniformity Data Sheets}




\section{Appendix A: Velocity Uniformity Data Sheets}

\begin{tabular}{|c|c|c|c|c|c|c|}
\hline & & ELOCITY & AVERSE D & ATA FORM & & \\
\hline Site & INL HFEF & & & Run No. & VT-1 & \\
\hline Date & $7 / 13 / 10$ & & Fan & Configuration & 2 process and & ventilation \\
\hline Testers & JAG/JEF & & & Setting & N.A. & \\
\hline Duct Width & 83.175 & & & Stack Temp & 77.5 & $\operatorname{deg} F$ \\
\hline Duct Depth & 30.2 & & & tart/End Time & $1355 / 1528$ & \\
\hline Stack X-Area & 17.4 & $\mathrm{ft} 2$ & & Velocity units & $\mathrm{sft} / \mathrm{min}$ & \\
\hline Distance to disturbance & 21.5 & & & & & \\
\hline & & Trial ----> & 1 & 2 & 3 & Mean \\
\hline Port & Point & Depth, in. & & Velc & city & \\
\hline 1 & 1 & 3.77 & 2190 & 2090 & 2120 & 2133.3 \\
\hline 1 & 2 & 11.32 & 2300 & 2180 & 2210 & 2230.0 \\
\hline 1 & 3 & 18.87 & 2070 & 2000 & 2040 & 2036.7 \\
\hline 1 & 4 & 26.41 & 2100 & 2090 & 2100 & 2096.7 \\
\hline 2 & 1 & 3.77 & 1650 & 1630 & 1710 & 1663.3 \\
\hline 2 & 2 & 11.32 & 1720 & 1710 & 1730 & 1720.0 \\
\hline 2 & 3 & 18.87 & 1770 & 1710 & 1730| & 1736.7 \\
\hline 2 & 4 & 26.41 & 1890 & 1840 & 1920 & 1883.3 \\
\hline 3 & 1 & 3.77 & 1670 & 1820 & 1760 & 1750.0 \\
\hline 3 & 2 & 11.32 & 1780 & 1790 & 1850 & 1806.7 \\
\hline 3 & 3 & 18.87 & 1900 & 1940 & 1880 & 1906.7 \\
\hline 3 & 4 & 26.41 & 1980 & 2040 & 2010 & 2010.0 \\
\hline 4 & 1 & 3.77 & 2010 & 2000 & 2040 & 2016.7 \\
\hline 4 & 2 & 11.32 & 1810 & 1880 & 1930 & 1873.3 \\
\hline 4 & 3 & 18.87 & 1870 & 1880 & 1900 & 1883.3 \\
\hline 4 & 4 & 26.41 & 1600 & 1830 & 1820 & 1750.0 \\
\hline & Averages - & -------> & 1894.4 & 1901.9 & 1921.9 & 1906.0 \\
\hline & & $\underline{\text { sfpm }}$ & & v. from mean & & \\
\hline & Mean & 1906.0 & & & Flow scfm & 33248 \\
\hline & Min Point & 1663.3 & & $-12.7 \%$ & Vel. Std. Dev. & 166.5 \\
\hline & Max Point & 2230.0 & & $17.0 \%$ & Vel. cov as $\%$ & 8.7 \\
\hline
\end{tabular}

Stack temp

Equipment temp Ambient temp

Stack static

Ambient pressure

Total Stack pressure

Ambient humidity

\begin{tabular}{|c|c|}
\hline Start & \multirow{2}{*}{$\begin{array}{c}\text { Finish } \\
77\end{array}$} \\
\hline 78 & \\
\hline N.A. & N.A. \\
\hline 73 & 76 \\
\hline N.A. & N.A. \\
\hline 841 & 840 \\
\hline 841 & 840 \\
\hline $23 \%$ & $22 \%$ \\
\hline
\end{tabular}

Notes:

Each measurement is an average of 5.

About 1430, generator test conducted on builidng, and stack velocity dropped to about $900 \mathrm{fpm}$ momentarily.

Testing halted at Port 2, Point 4, trial 2.

At about 1500, restart.

From the stripchart, stack flow was $65 \%$ of $51900 \mathrm{cfm}$.

(That is about $33735 \mathrm{scfm}$ )

Had dropped to $46 \%$ during generator test (23874 scfm).

\begin{tabular}{|ll|}
\hline & \\
\hline $\begin{array}{l}\text { Entries made by: } \\
\text { Signature/date }\end{array}$ & $\begin{array}{l}\text { John Glissmeyer 7/13/2010 } \\
\text { signature on original }\end{array}$ \\
\hline
\end{tabular}

Instuments Used:

Cal Due

Fisher Scientific SN $90936818 \quad$ 09/29/10

TSI VelociCalc SN $305039 \quad 6 / 23 / 2011$

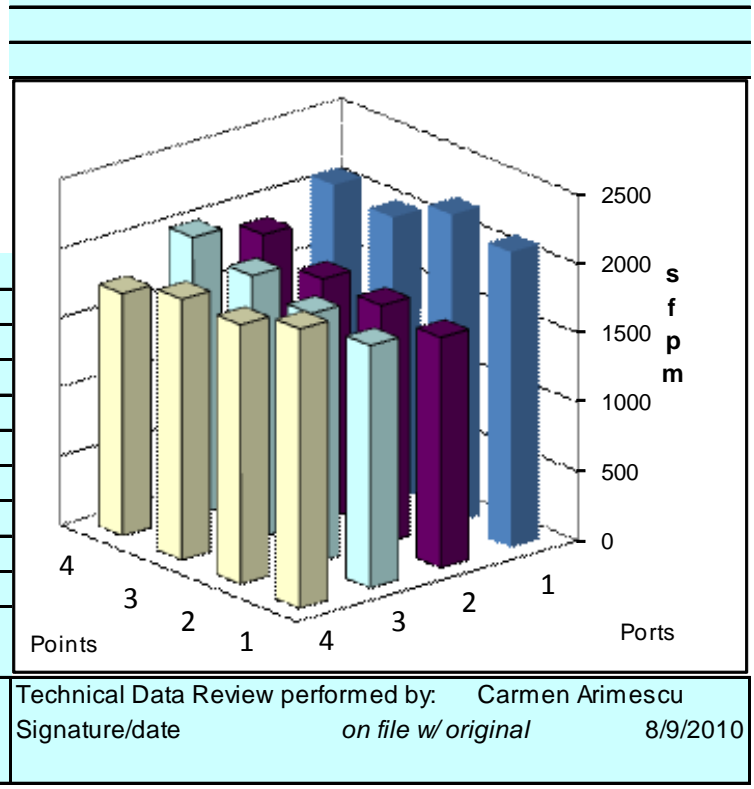

A. 1 


\section{VELOCITY TRAVERSE DATA FORM}

\begin{tabular}{|c|c|c|c|c|c|c|}
\hline Site & INL HFFF & & & Run No. & VT-2 & \\
\hline Date & $7 / 20 / 10$ & & Fan & Configuration & 2 process and & 2 ventilation \\
\hline Testers & JAG/JEF & & & Setting & N.A. & \\
\hline Duct Width & 83.175 & in. & & Stack Temp & 79.0 & $\operatorname{deg} F$ \\
\hline Duct Depth & 30.2 & & & tart/End Time & $0915 / 1000$ & \\
\hline Stack X-Area & 17.4 & $\mathrm{ft} 2$ & & Velocity units & $\mathrm{sft} / \mathrm{min}$ & \\
\hline Distance to disturbance & 21.5 & & & & & \\
\hline & & Trial ----> & 1 & 2 & 3 & Mean \\
\hline Port & Point & Depth, in. & & Velc & ocity & \\
\hline 1 & 1 & 3.77 & 1900 & 1930 & 1880 & 1903.3 \\
\hline 1 & 2 & 11.32 & 2110 & 2080 & 2100 & 2096.7 \\
\hline 1 & 3 & 18.87 & 2040 & 2030 & 2010 & 2026.7 \\
\hline 1 & 4 & 26.41 & 2110 & 2100 & 2080 & 2096.7 \\
\hline 2 & 1 & 3.77 & 1630 & 1590 & 1610 & 1610.0 \\
\hline 2 & 2 & 11.32 & 1750 & 1730 & 1740 & 1740.0 \\
\hline 2 & 3 & 18.87 & 1760 & 1780 & 1790 & 1776.7 \\
\hline 2 & 4 & 26.41 & 1900 & 2000 & 1930 & 1943.3 \\
\hline 3 & 1 & 3.77 & 1640 & 1690 & 1740 & 1690.0 \\
\hline 3 & 2 & 11.32 & 1810 & 1820 & 1880 & 1836.7 \\
\hline 3 & 3 & 18.87 & 1940 & 2020 & 1960 & 1973.3 \\
\hline 3 & 4 & 26.41 & 2000 & 2100 & 2070 & 2056.7 \\
\hline 4 & 1 & 3.77 & 2010 & 2020 & 2060 & 2030.0 \\
\hline 4 & 2 & 11.32 & 1890 & 1900 & 1890 & 1893.3 \\
\hline 4 & 3 & 18.87 & 1900 & 1900 & 1930 & 1910.0 \\
\hline 4 & 4 & 26.41 & 1910 & 1890 & 1880 & 1893.3 \\
\hline & Averages - & $\overline{---->}$ & 1893.8 & 1911.3 & 1909.4 & 1904.8 \\
\hline & & sfpm & & v. from mean & & \\
\hline & Mean & 1904.8 & & & Flow scfm & 33227 \\
\hline & Min Point & 1610.0 & & $-15.5 \%$ & Vel. Std. Dev. & 144.9 \\
\hline & Max Point & 2096.7 & & $10.1 \%$ & Vel. CoV as \%[ & 7.6 \\
\hline
\end{tabular}

Stack temp

Equipment temp

Ambient temp

Stack static

Ambient pressure

Total Stack pressure

Ambient humidity

\begin{tabular}{|c|c|l}
\multicolumn{1}{c|}{ Start } & \multicolumn{1}{c}{ Finish } & \\
\cline { 1 - 2 } 80 & 78 & F \\
\cline { 1 - 2 } N.A. & N.A. & F \\
\hline 71 & 70 & F \\
\cline { 1 - 2 } N.A. & N.A. & mbars \\
\cline { 1 - 2 } 847 & 848 & mbars \\
\hline 847 & 848 & mbars \\
\cline { 1 - 2 } $23 \%$ & $29 \%$ & RH \\
\hline
\end{tabular}

Notes:

Stack flow in control room is $67 \%$

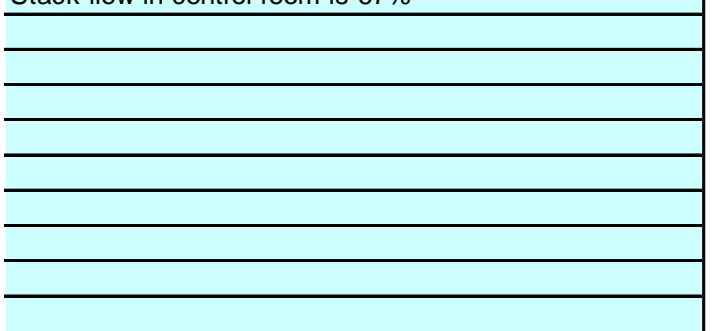

Entries made by:

Signature/date
John Glissmeyer 7/13/2010

signature on original
Instuments Used:

Cal Due

Fisher Scientific SN 90936818

TSI VelociCalc SN 305039

09/29/10

\begin{tabular}{ll} 
TSI Velocicalc SN 305039 & 6/23/2011 \\
\hline
\end{tabular}

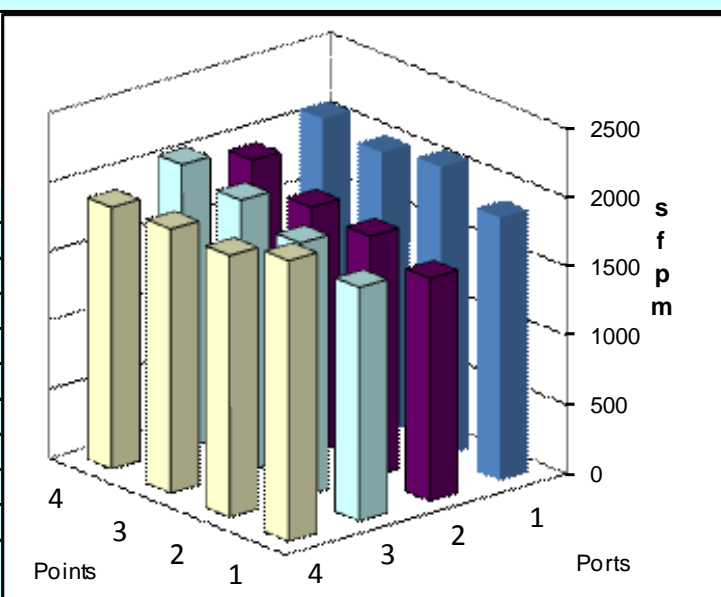

Technical Data Review performed by: Carmen Arimescu

Signature/date

on file w/ original

$8 / 9 / 2010$ 


\section{VELOCITY TRAVERSE DATA FORM}

\begin{tabular}{|c|c|c|c|c|c|c|}
\hline Site & INL HFEF & & & Run No. & VT-3 & \\
\hline Date & $7 / 20 / 10$ & & Fan & Configuration & 2 process and & 2 ventilation \\
\hline Testers & $\overline{Q Q / J E F}$ & & & Setting & N.A. & \\
\hline Duct Width & 83.175 & in. & & Stack Temp & 78.0 & $\overline{\operatorname{deg} F}$ \\
\hline Duct Depth & 30.2 & & & tart/End Time & $1000 / 1041$ & \\
\hline Stack X-Area & 17.4 & $\mathrm{ft} 2$ & & Velocity units & $\mathrm{sft} / \mathrm{min}$ & \\
\hline Distance to disturbance & 21.5 & & & & & \\
\hline & & Trial ----> & 1 & 2 & 3 & Mean \\
\hline Port & Point & Depth, in. & & Velc & ocity & \\
\hline 1 & 1 & 3.77 & 1830 & 1870 & 1910 & 1870.0 \\
\hline 1 & 2 & 11.32 & 2110 & 2120 & 2100 & 2110.0 \\
\hline 1 & 3 & 18.87 & 2080 & 2060 & 2020 & 2053.3 \\
\hline 1 & 4 & 26.41 & 2130 & 2100 & 2110 & 2113.3 \\
\hline 2 & 1 & 3.77 & 1610 & 1660 & 1640 & 1636.7 \\
\hline 2 & 2 & 11.32 & 1730 & 1730 & 1740 & 1733.3 \\
\hline 2 & 3 & 18.87 & 1780 & 1790 & 1760 & 1776.7 \\
\hline 2 & 4 & 26.41 & 1980 & 1900 & 1900 & 1926.7 \\
\hline 3 & 1 & 3.77 & 1740 & 1760 & 1760 & 1753.3 \\
\hline 3 & 2 & 11.32 & 1870 & 1900 & 1890 & 1886.7 \\
\hline 3 & 3 & 18.87 & 1980 & 2020 & 1990 & 1996.7 \\
\hline 3 & 4 & 26.41 & 2070 & 2070 & 2130 & 2090.0 \\
\hline 4 & 1 & 3.77 & 2020 & 2140 & 2160 & 2106.7 \\
\hline 4 & 2 & 11.32 & 1920 & 1920 & 1920 & 1920.0 \\
\hline 4 & 3 & 18.87 & 1920 & 1930 & 1940 & 1930.0 \\
\hline 4 & 4 & 26.41 & 1900 & 1910 & 1900 & 1903.3 \\
\hline & Averages - & $\overline{---->}$ & 1916.9 & 1930.0 & 1929.4 & 1925.4 \\
\hline & & sfpm & & v. from mean & & \\
\hline & Mean & $\overline{1925.4}$ & & & Flow scfm & 33586 \\
\hline & Min Point & 1636.7 & & $-15.0 \%$ & Vel. Std. Dev. & 147.8 \\
\hline & Max Point & 2113.3 & & $9.8 \%$ & Vel. CoV as \%[ & 7.7 \\
\hline
\end{tabular}

Stack temp

Equipment temp

Ambient temp

Stack static

Ambient pressure

Total Stack pressure

Ambient humidity

\begin{tabular}{|c|c|l}
\multicolumn{1}{c|}{ Start } & \multicolumn{1}{c}{ Finish } & \\
\cline { 1 - 2 } 78 & 78 & $\mathrm{~F}$ \\
\cline { 1 - 2 } N.A. & N.A. & F \\
\cline { 1 - 2 } 70 & 67 & F \\
\cline { 1 - 2 } N.A. & N.A. & mbars \\
\cline { 1 - 2 } 847 & 848 & mbars \\
\cline { 1 - 2 } 847 & 848 & mbars \\
\cline { 1 - 2 } $23 \%$ & $25 \%$ & RH \\
\hline
\end{tabular}

Notes:

Stack flow in control room is $67 \%$ of 51900

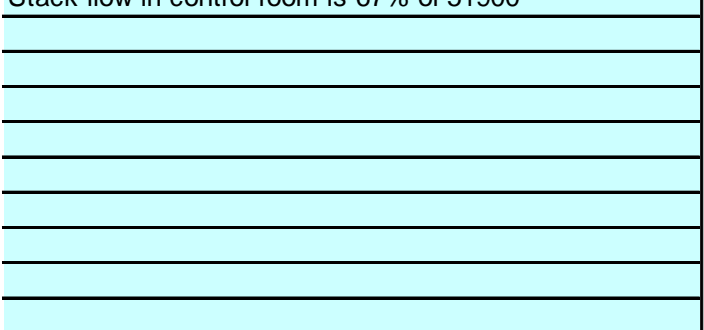

Entries made by:

Signature/date
John Glissmeyer 7/13/2010

signature on original
Instuments Used:

Cal Due

Fisher Scientific SN 90936818

TSI VelociCalc SN 305039

09/29/10
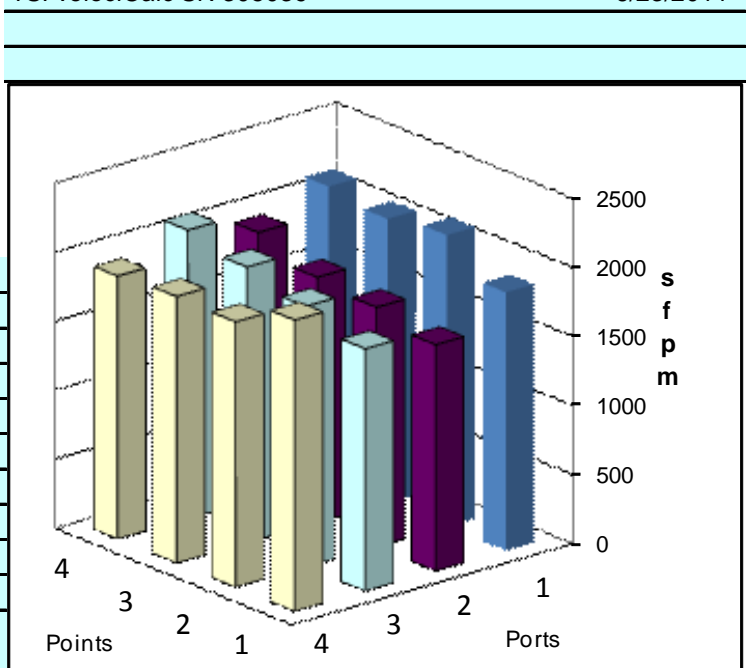

Technical Data Review performed by: Carmen Arimescu

Signature/date

on file w/ original

$8 / 9 / 2010$ 
Appendix B

Flow Angle Data Sheets 


\section{Appendix B: Flow Angle Data Sheets}

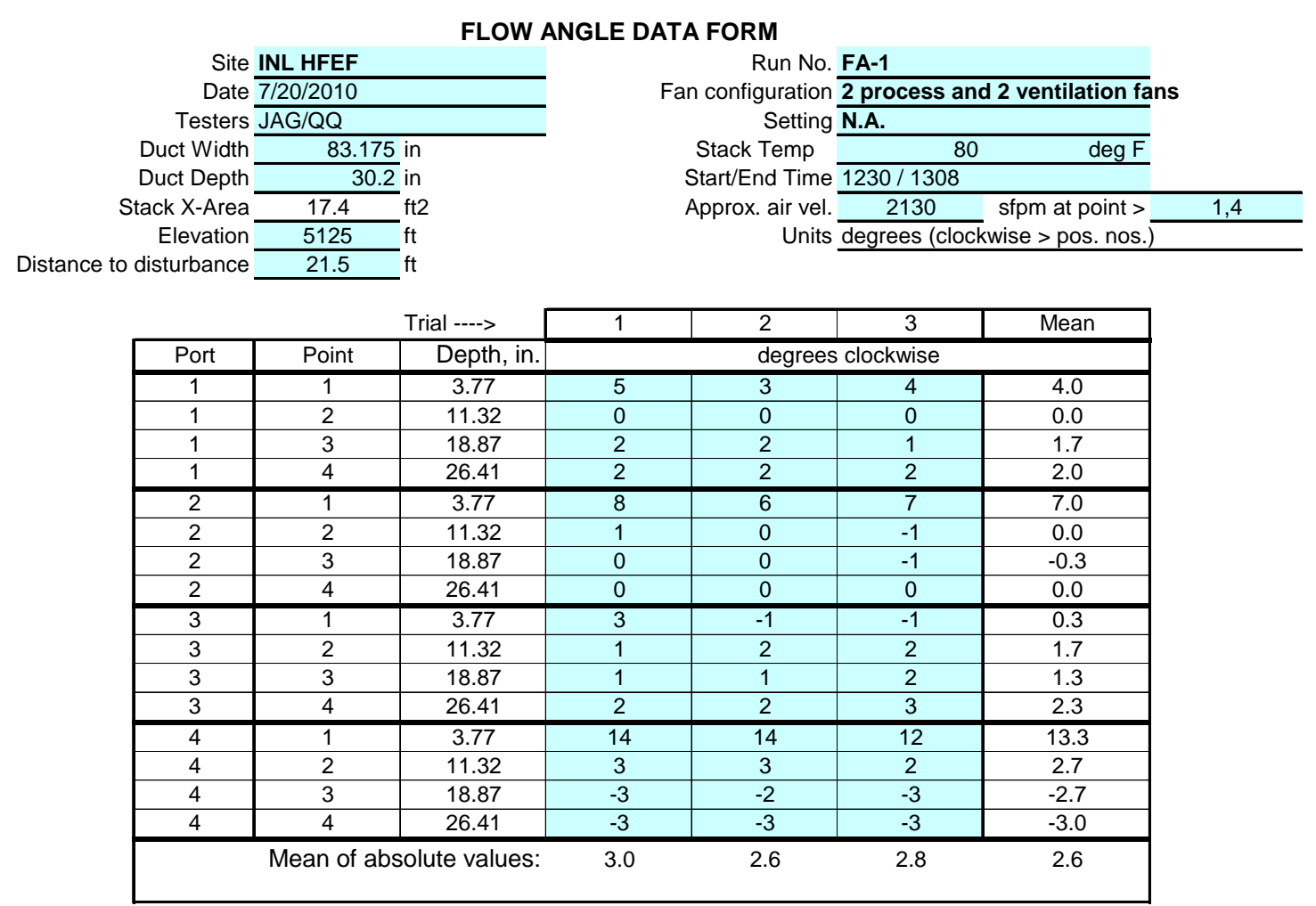

\begin{tabular}{lll} 
Instuments Used: & & Cal. Due \\
\cline { 3 - 3 } S-type pitot $\# 13$ & Dwyer 160S-48A-14V & Cert. of conformance \\
\hline Velocity sensor & TSI VelociCalc SN\# 305039 & $6 / 23 / 2011$ \\
\hline Angle indicator & Empire protractor level & Cat. 3 \\
\hline Manometer & Dwyer 400-5, S36N & Cat. 3 \\
\hline
\end{tabular}

Note:

To assure similar hose connections

between the manometer and pitot tube, rotating

the pitot tube assembly clockwise drives the

meniscus to the right (to higher pos. numbers).

Notes:

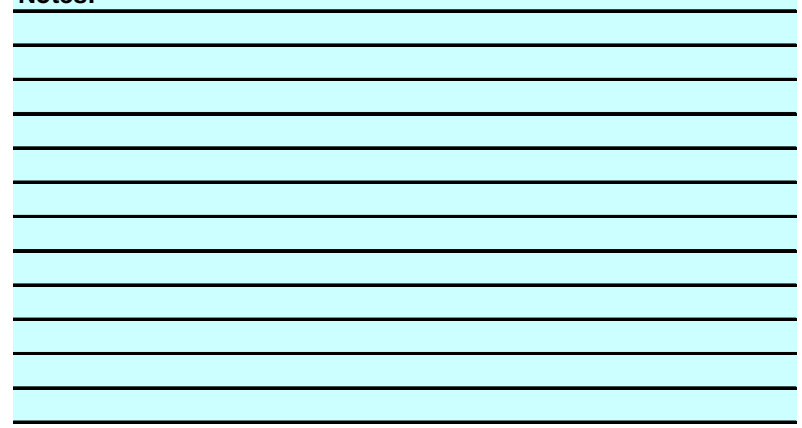

Entries made by:

Signature/date
John Glissmeyer 7/20/10

Signature on original

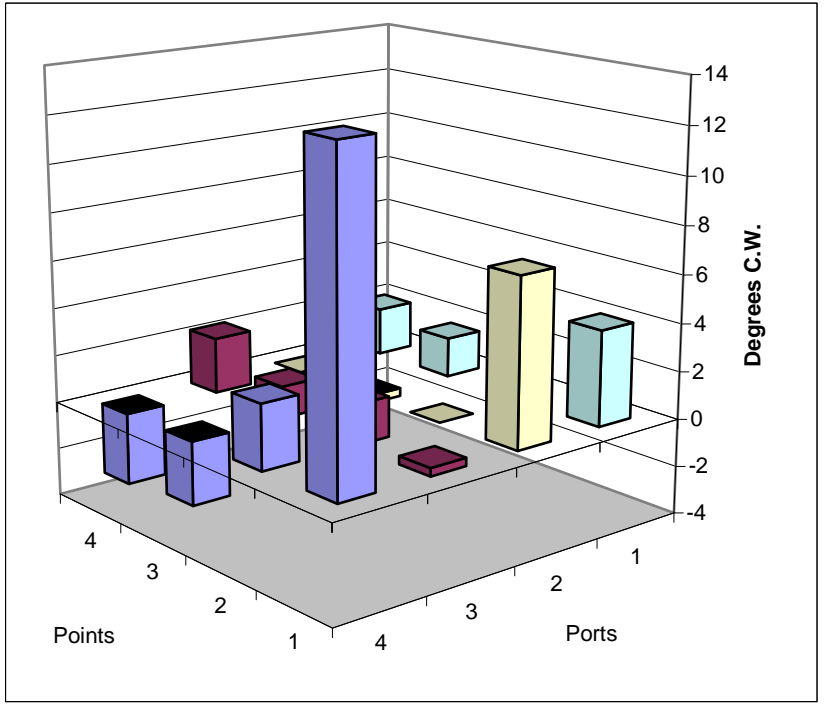

Technical Data Review performed by:

Signature/date

Carmen Arimescu 8/10/10

Signature on original

B. 1 


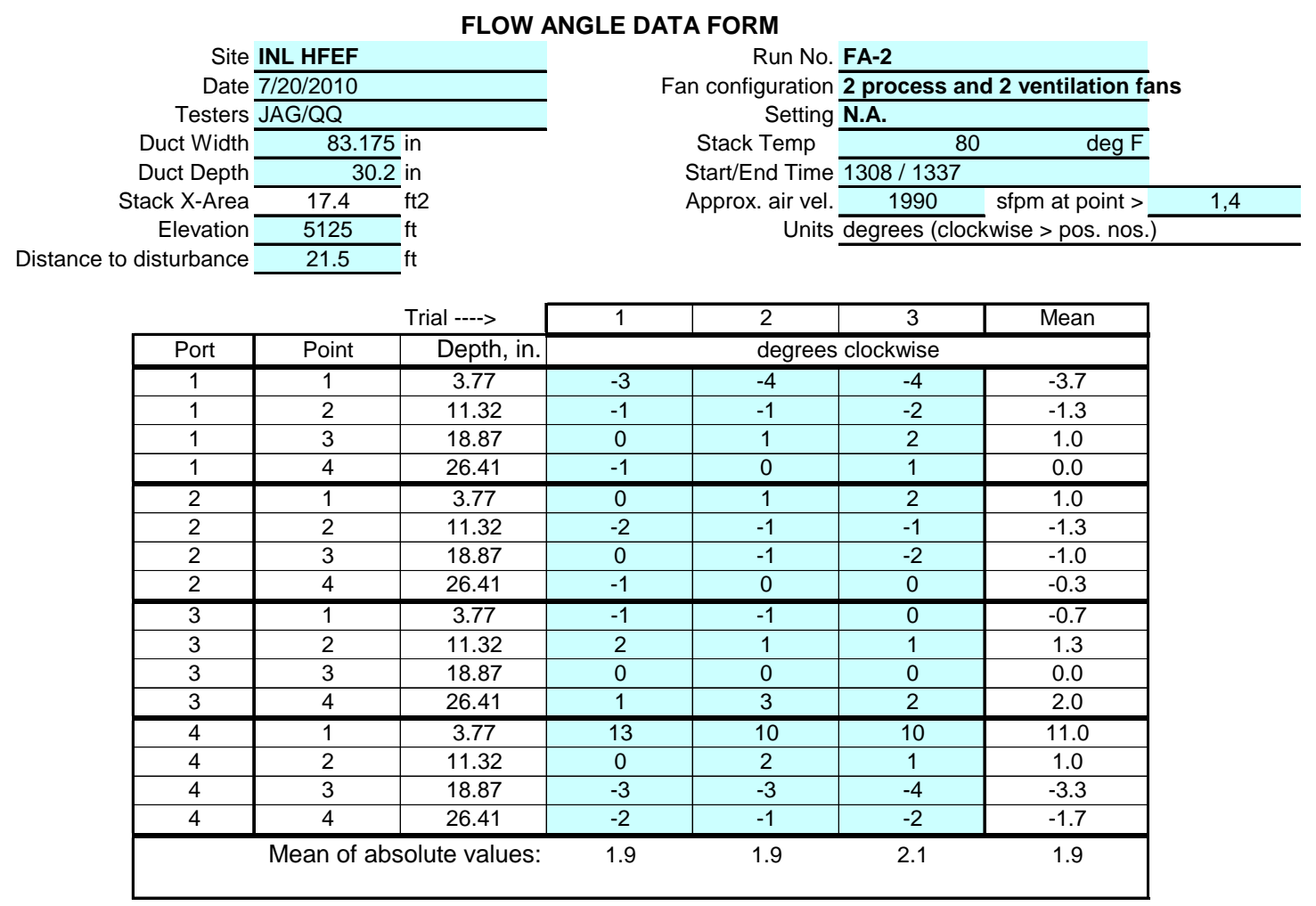

\begin{tabular}{lll} 
Instuments Used: & & Cal. Due \\
\cline { 3 - 3 } S-type pitot \#13 & Dwyer 160S-48A-14V & Cert. of conformance \\
\hline Velocity sensor & TSI VelociCalc SN\# 305039 & $6 / 23 / 2011$ \\
\hline Angle indicator & Empire protractor level & Cat. 3 \\
\hline Manometer & Dwyer 400-5, S36N & Cat. 3 \\
\hline
\end{tabular}

Note:

To assure similar hose connections

between the manometer and pitot tube, rotating

the pitot tube assembly clockwise drives the

meniscus to the right (to higher pos. numbers).

Notes:
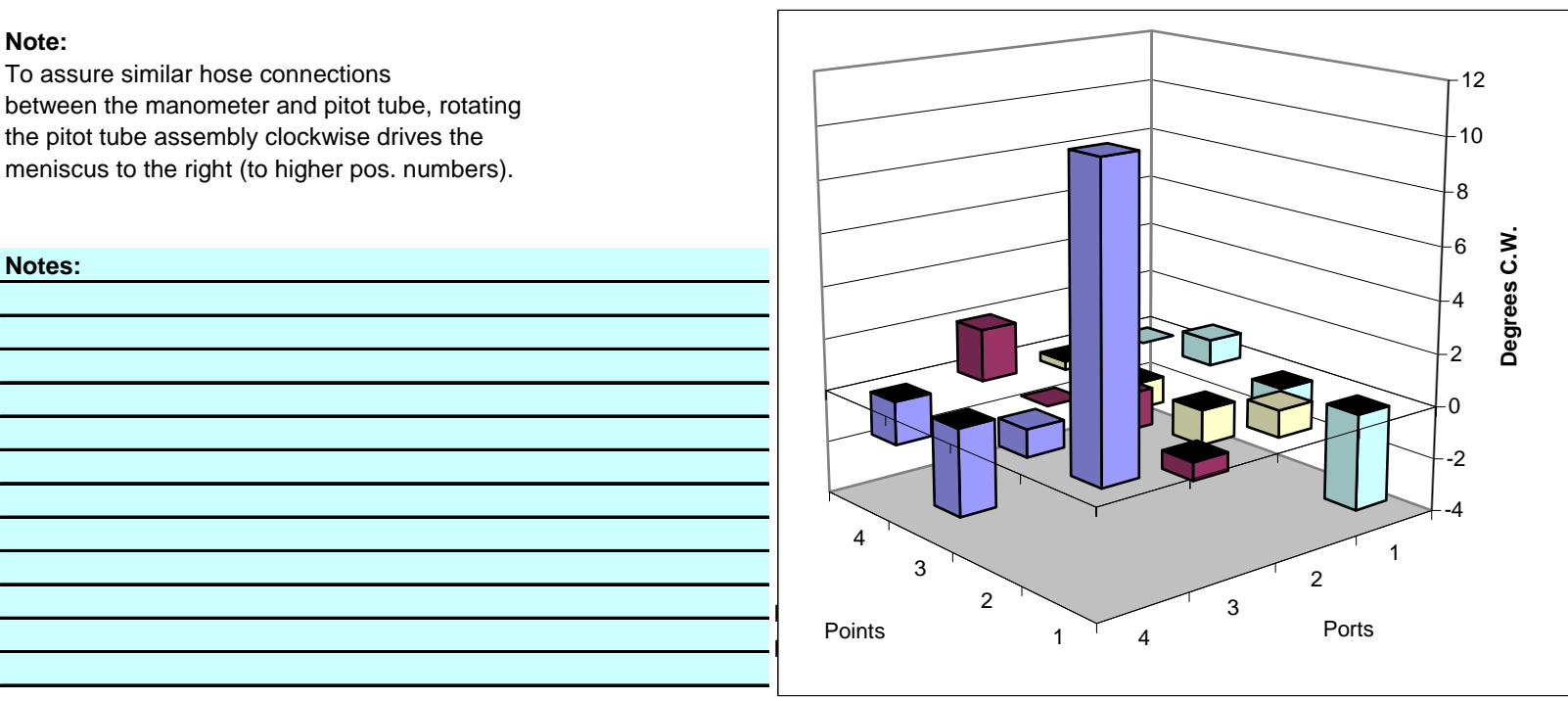

Entries made by:

John Glissmeyer 7/20/10

Technical Data Review performed by:

Signature on original

Carmen Arimescu 8/10/10

Signature on original 
Appendix C

\section{Tracer Gas Uniformity Data Sheets}




\section{Appendix C: Tracer Gas Uniformity Data Sheets}

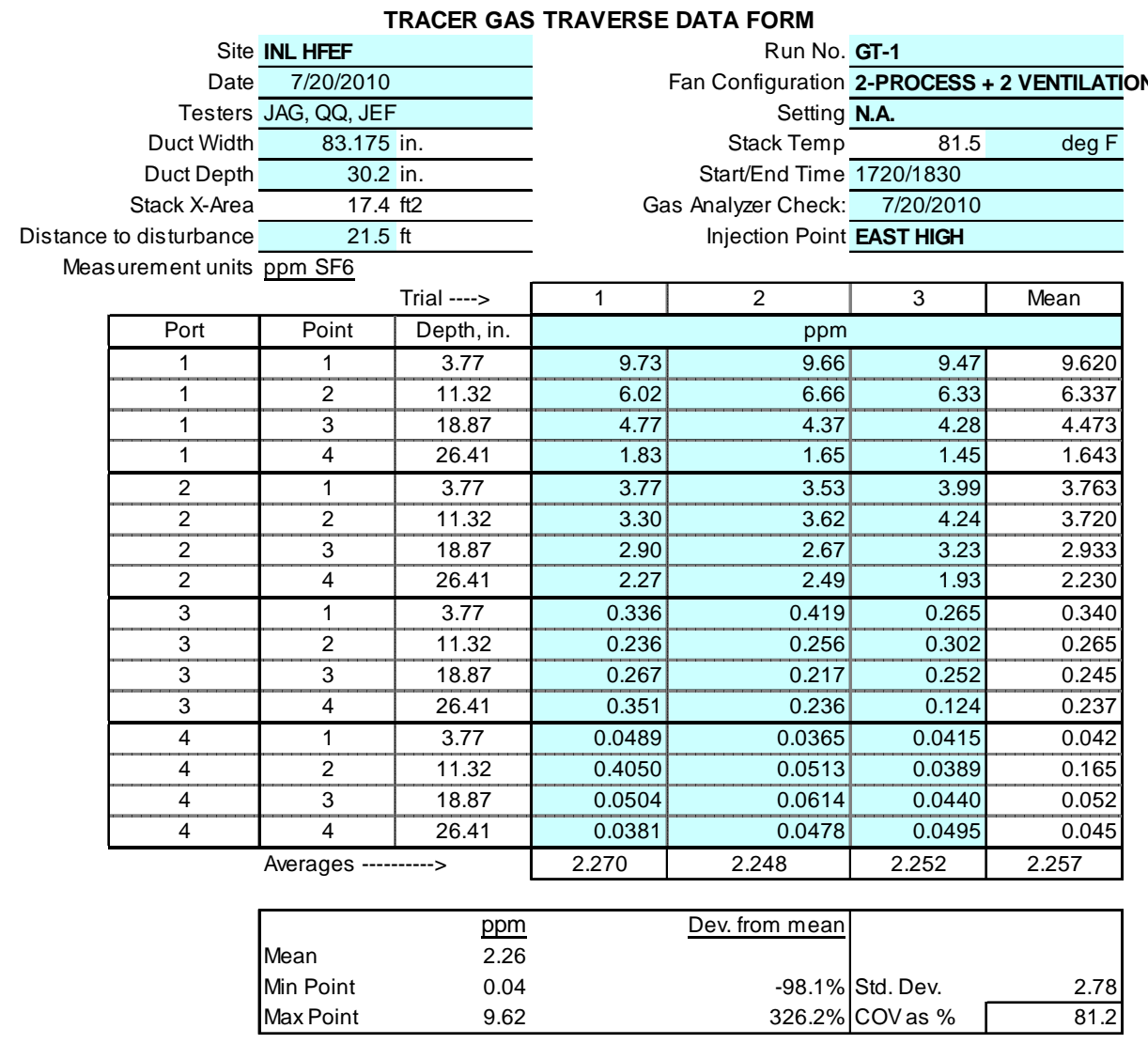

Tracer tank pressure Injection flowmeter

Stack Temp

Center Pt. air vel.

Sampling flowmeter

Ambient pressure

Ambient humidity

Ambient Temp

B\&K vapor correction

Back-Gd gas

No. Bk-Gd samples

\begin{tabular}{|c|c|c|}
\hline Start & Finish & \\
\hline 300 & 300 & psig \\
\hline 2 & 2 & Ipm \\
\hline 81 & 82 & ${ }^{\circ} \mathrm{F}$ \\
\hline 1880 & 2030 & $\mathrm{fpm}$ \\
\hline 5 & 5 & Ipm \\
\hline 845 & 845 & in $\mathrm{Hg}$ \\
\hline 21 & 17 & $\mathrm{RH}$ \\
\hline 83 & 98 & ${ }^{\circ} \mathrm{F}$ \\
\hline NO & $\mathrm{NO}$ & $\mathrm{Y} / \mathrm{N}$ \\
\hline $89,55,56,50$ & $52,65,63,60$ & $\mathrm{ppb}$ \\
\hline & 4 & \\
\hline
\end{tabular}

Notes:

For point 4, the distance can be short about 1/4-inch.

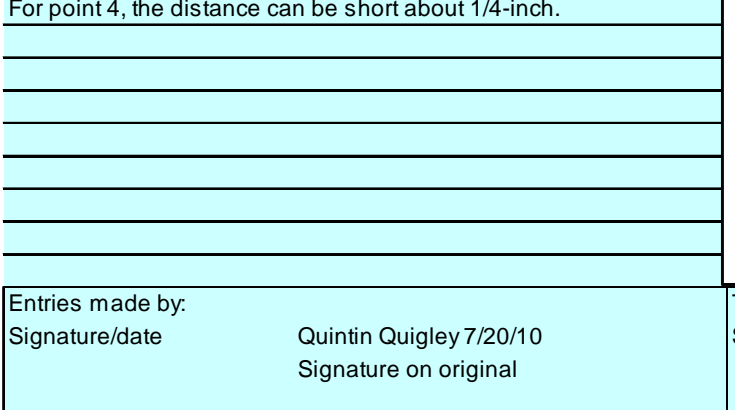

Instruments Used:

B\&K 1302 Gas Analyzer SN 1804888

Cal Due

TSI VelociCalc SN 305039

Omega FMA-2606A flowmeter SN 27708

Fisher Weather Station SN $90936818 \quad 5 / 27 / 2011$

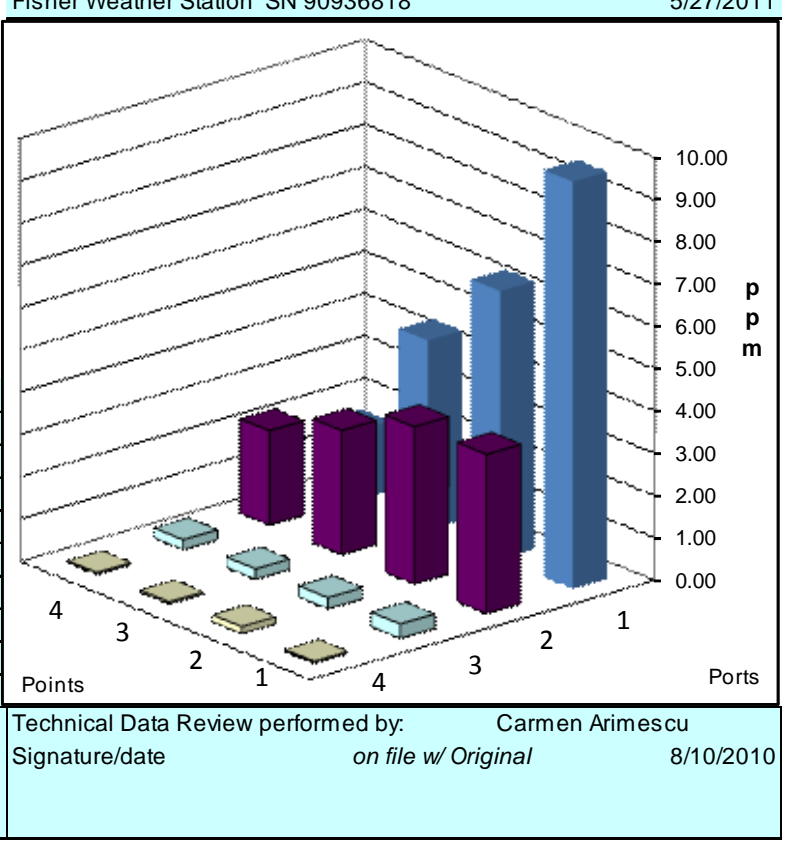

C. 1 


\begin{tabular}{|c|c|c|c|c|c|c|}
\hline \multicolumn{7}{|c|}{ TRACER GAS TRAVERSE DATA FORM } \\
\hline \multicolumn{3}{|c|}{ Site INL HFF } & \multicolumn{4}{|c|}{ Run No. GT-2 } \\
\hline Date & $7 / 21 / 20$ & & \multicolumn{4}{|c|}{ Fan Configuration 2-PROCESS + 2 VENTILATIC } \\
\hline \multicolumn{3}{|c|}{ Testers JAG, QQ, JEF } & \multicolumn{4}{|c|}{ Setting N.A. } \\
\hline Duct Width & \multirow{2}{*}{\multicolumn{2}{|c|}{$\frac{83.175 \text { in. }}{30.2 \text { in. }}$}} & & Stack Temp & 79 & $\operatorname{deg} \mathrm{F}$ \\
\hline Duct Depth & & & \multicolumn{4}{|c|}{ Start/End Time $\overline{0835 / 0935}$} \\
\hline Stack X-Area & \multicolumn{2}{|c|}{$17.4 \mathrm{ft} 2$} & \multirow{2}{*}{\multicolumn{2}{|c|}{$\begin{array}{r}\text { Gas Analyzer Check: } \\
\text { Injection Point }\end{array}$}} & $7 / 20 / 2010$ & \\
\hline \multirow{3}{*}{$\begin{array}{r}\text { Distance to disturbance } \\
\text { Measurement units }\end{array}$} & \multicolumn{2}{|c|}{$21.5 \mathrm{ft}$} & & & \multicolumn{2}{|l|}{ EAST LOW } \\
\hline & ppm SF6 & & & & & \\
\hline & \multicolumn{2}{|r|}{ Trial ----> } & 1 & 2 & 3 & Mean \\
\hline Port & Point & Depth, in. & \multicolumn{4}{|c|}{$\mathrm{ppm}$} \\
\hline 1 & 1 & 3.77 & 16.80 & 13.50 & 17.30 & 15.867 \\
\hline 1 & 2 & 11.32 & 12.90 & 10.00 & 10.00 & 10.967 \\
\hline 1 & 3 & 18.87 & 7.79 & 6.52 & 7.81 & 7.373 \\
\hline 1 & 4 & 26.41 & 3.23 & 2.56 & 4.32 & 3.370 \\
\hline 2 & 1 & 3.77 & 5.39 & 4.79 & 6.96 & 5.713 \\
\hline 2 & 2 & 11.32 & 5.43 & 6.14 & 5.95 & 5.840 \\
\hline 2 & 3 & 18.87 & 5.58 & 5.42 & 6.13 & 5.710 \\
\hline 2 & 4 & 26.41 & 3.20 & 5.09 & 4.15 & 4.147 \\
\hline 3 & 1 & 3.77 & 1.100 & 0.678 & 0.650 & 0.809 \\
\hline 3 & 2 & 11.32 & 0.542 & 0.593 & 0.621 & 0.585 \\
\hline 3 & 3 & 18.87 & 0.601 & 0.551 & 0.924 & 0.692 \\
\hline 3 & 4 & 26.41 & 0.227 & 0.413 & 0.627 & 0.422 \\
\hline 4 & 1 & 3.77 & 0.0438 & 0.0300 & 0.0363 & 0.037 \\
\hline 4 & 2 & 11.32 & 0.0551 & 0.0348 & 0.0436 & 0.045 \\
\hline 4 & 3 & 18.87 & 0.0515 & 0.0112 & 0.0511 & 0.038 \\
\hline 4 & 4 & 26.41 & 0.0358 & 0.0472 & 0.0576 & 0.047 \\
\hline & \multicolumn{2}{|c|}{ Averages ---------> } & 3.936 & 3.524 & 4.102 & 3.854 \\
\hline & \multicolumn{4}{|r|}{ Dev. from mean } & \multirow{4}{*}{$\begin{array}{l}\text { Std. Dev. } \\
\text { COV as \% }\end{array}$} & \\
\hline & Mean & 3.85 & & & & \\
\hline & Min Point & 0.04 & & $-99.0 \%$ & & 4.61 \\
\hline & Max Point & 15.87 & & $311.7 \%$ & & 83.7 \\
\hline
\end{tabular}

Tracer tank pressure Injection flowmeter

Stack Temp

Center Pt. air vel.

Sampling flowmeter

Ambient pressure

Ambient humidity

Ambient Temp

B\&K vapor correction

Back-Gd gas

No. Bk-Gd samples

\begin{tabular}{|c|c|c|}
\hline Start & Finish & \\
\hline 300 & 300 & 0 psic \\
\hline 3.75 & 3.75 & $5 \mathrm{Ipm}$ \\
\hline 79 & 79 & $9{ }^{\circ} \mathrm{F}$ \\
\hline 1770 & 1830 & $0 \mathrm{fpm}$ \\
\hline 5 & 5 & $5 \mathrm{Ipm}$ \\
\hline 843 & 843 & 3 in \\
\hline 27 & 24 & $4 \mathrm{RH}$ \\
\hline 64 & 71 & $1{ }^{\circ} \mathrm{F}$ \\
\hline NO & $\mathrm{NO}$ & Y/N \\
\hline $38,26,27,37$ & $51,48,41,56$ & $6 \mathrm{ppb}$ \\
\hline 4 & & 4 \\
\hline
\end{tabular}

Notes:

Point 4 on all ports is about $1 / 4$ inch short of planned point due to probe interference with the permanent scaffold.

Total stack flow displayed in control room was about $64 \%$ of $51,900 \mathrm{cfm}$.



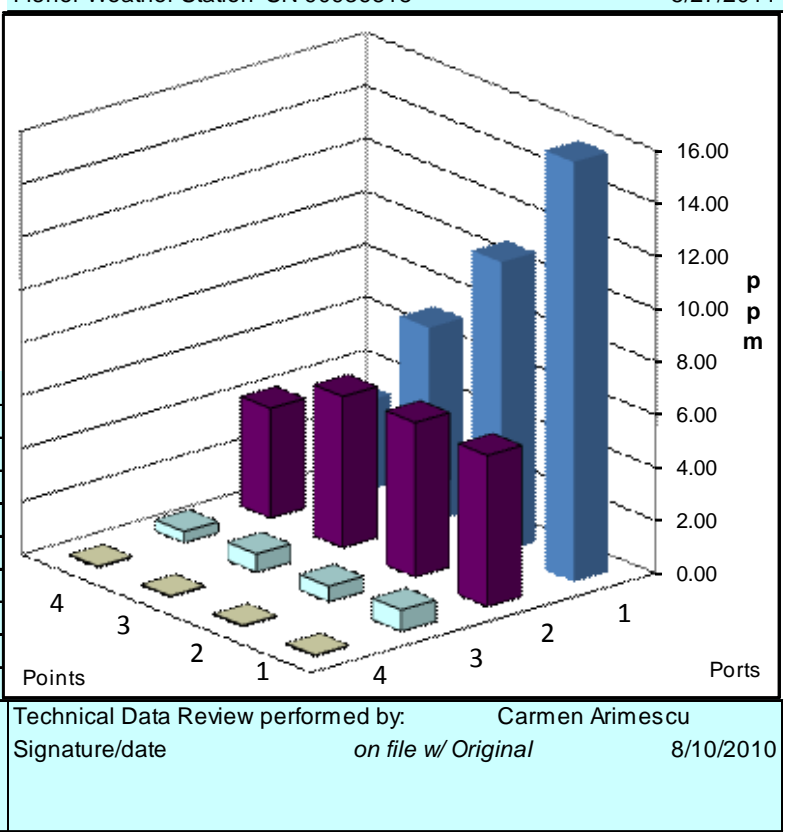




\begin{tabular}{|c|c|c|c|c|c|c|}
\hline \multicolumn{7}{|c|}{ TRACER GAS TRAVERSE DATA FORM } \\
\hline \multicolumn{3}{|c|}{ Site INL HFEF } & \multicolumn{4}{|c|}{ Run No. GT-3 } \\
\hline Date & \multicolumn{2}{|c|}{$7 / 21 / 2010$} & \multicolumn{4}{|c|}{ Fan Configuration 2-PROCESS + 2 VENTILATIC } \\
\hline Testers $\bar{j}$ & \multicolumn{2}{|c|}{ JAG, QQ, JEF } & \multicolumn{2}{|r|}{ Setting } & \multicolumn{2}{|l|}{ N.A. } \\
\hline Duct Width & \multicolumn{2}{|c|}{83.175 in. } & & Stack Temp & 79.5 & $\operatorname{deg} \mathrm{F}$ \\
\hline Duct Depth & \multicolumn{2}{|c|}{$30.2 \mathrm{in.}$} & \multicolumn{4}{|c|}{ Start/End Time $\overline{0950 / 1035}$} \\
\hline Stack X-Area & & \multirow{2}{*}{\multicolumn{3}{|c|}{$\begin{array}{l}\text { Gas Analyzer Check: } \quad 7 / 20 / 2010 \\
\text { Injection Point WEST HIGH }\end{array}$}} & \\
\hline \multirow{2}{*}{$\begin{array}{l}\text { Distance to disturbance } \\
\text { Measurement units }\end{array}$} & \multicolumn{2}{|c|}{$21.5 \mathrm{ft}$} & & & & Injection Point WEST HIGH \\
\hline & ppm SF6 & & \\
\hline \multicolumn{3}{|r|}{ Trial ----> } & 1 & 2 & 3 & Mean \\
\hline Port & Point & Depth, in. & \multicolumn{4}{|c|}{$\mathrm{ppm}$} \\
\hline 1 & 1 & 3.77 & 23.3 & 22.9 & 20.6 & 22.267 \\
\hline 1 & 2 & 11.32 & 13.2 & 14.4 & 15.0 & 14.200 \\
\hline 1 & 3 & 18.87 & 7.67 & 7.58 & 8.22 & 7.823 \\
\hline 1 & 4 & 26.41 & 3.22 & 3.85 & 3.91 & 3.660 \\
\hline 2 & 1 & 3.77 & 2.25 & 2.67 & 2.49 & 2.470 \\
\hline 2 & 2 & 11.32 & 4.22 & 3.12 & 3.21 & 3.517 \\
\hline 2 & 3 & 18.87 & 2.85 & 2.87 & 2.65 & 2.790 \\
\hline 2 & 4 & 26.41 & 1.83 & 2.00 & 1.61 & 1.813 \\
\hline 3 & 1 & 3.77 & 0.190 & 0.232 & 0.267 & 0.230 \\
\hline 3 & 2 & 11.32 & 0.280 & 0.191 & 0.157 & 0.209 \\
\hline 3 & 3 & 18.87 & 0.216 & 0.225 & 0.238 & 0.226 \\
\hline 3 & 4 & 26.41 & 0.158 & 0.152 & 0.118 & 0.143 \\
\hline 4 & 1 & 3.77 & 0.0227 & 0.0448 & 0.0307 & 0.033 \\
\hline 4 & 2 & 11.32 & 0.0315 & 0.0292 & 0.0377 & 0.033 \\
\hline 4 & 3 & 18.87 & 0.0374 & 0.0443 & 0.0365 & 0.039 \\
\hline 4 & 4 & 26.41 & 0.0419 & 0.0392 & 0.0308 & 0.037 \\
\hline & Averages & $->$ & 3.720 & 3.772 & 3.663 & 3.718 \\
\hline & & ppm & & Dev. from mean & & \\
\hline & Mean & 3.72 & & & & \\
\hline & Min Point & 0.03 & & $-99.1 \%$ & Std. Dev. & 6.22 \\
\hline & Max Point & 22.27 & & $498.9 \%$ & COV as \% & 59.8 \\
\hline
\end{tabular}

Tracer tank pressure Injection flowmeter

Stack Temp

Center Pt. air vel.

Sampling flowmeter

Ambient pressure

Ambient humidity

Ambient Temp

B\&K vapor correction

Back-Gd gas

No. Bk-Gd samples

\begin{tabular}{|c|c|c|}
\hline Start & Finish & \\
\hline 300 & 300 & psig \\
\hline 3.75 & 3.75 & Ipm \\
\hline 79 & 80 & ${ }^{\circ} \mathrm{F}$ \\
\hline 1830 & 1850 & fpm \\
\hline 5 & 5 & Ipm \\
\hline 843 & 843 & in $\mathrm{H}$ \\
\hline 24 & 24 & $\mathrm{RH}$ \\
\hline 71 & 71 & ${ }^{\circ} \mathrm{F}$ \\
\hline $\mathrm{NO}$ & $\mathrm{NO}$ & $\mathrm{Y} / \mathrm{N}$ \\
\hline $51,48,41,56$ & $50,51,55,46$ & $\mathrm{ppb}$ \\
\hline 4 & 4 & \\
\hline
\end{tabular}

Notes:

Point 4 on all ports is about $1 / 4$ inch short of planned point due to

probe interference with the permanent scaffold.

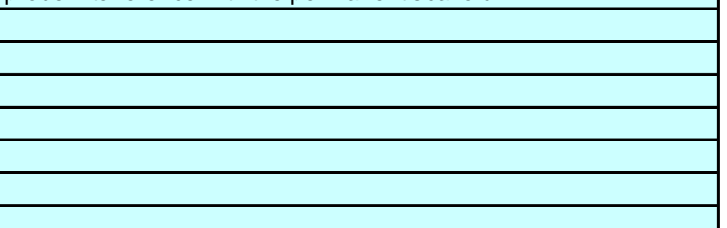

Entries made by:

B\&K 1302 Gas Analyzer SN 1804888

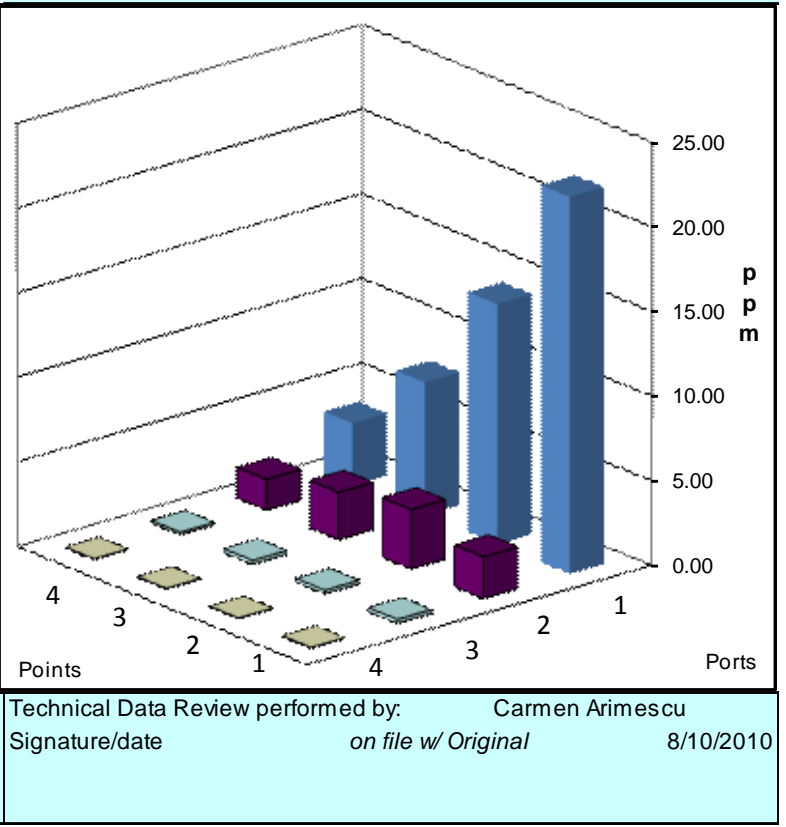




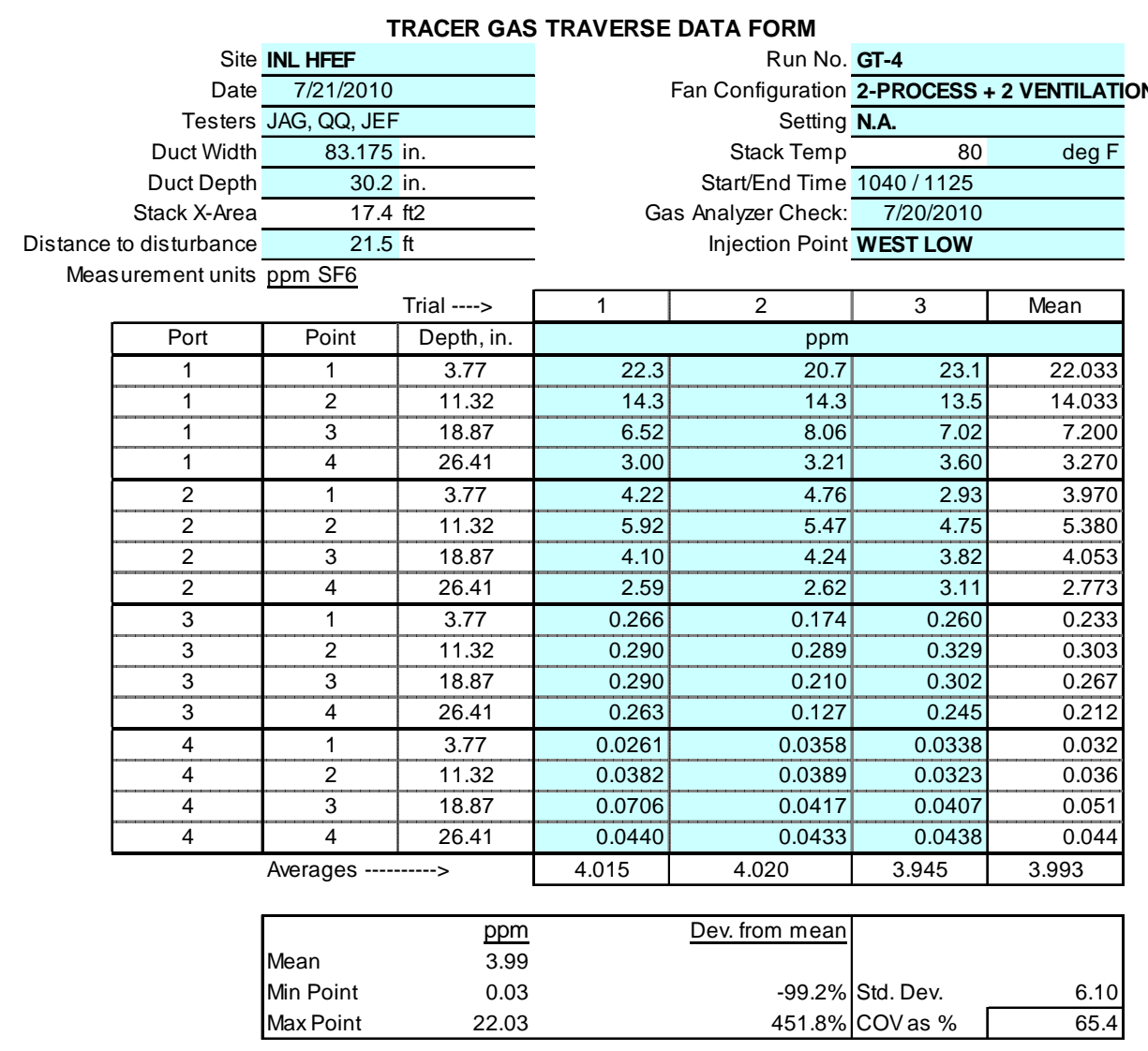

Tracer tank pressure Injection flowmeter Stack Temp Center Pt. air vel. Sampling flowmeter Ambient pressure Ambient humidity Ambient Temp B\&K vapor correction Back-Gd gas

No. Bk-Gd samples

Notes:

Point 4 on all ports is about $1 / 4$ inch short of planned point due to probe interference with the permanent scaffold.

Reference velocity measurements taken at Port 2, point 4

\begin{tabular}{|ll|}
\hline & \\
\hline & \\
\hline & Jutries made by: \\
Signature/date & Julia Flaherty $7 / 21 / 10$ \\
\end{tabular}

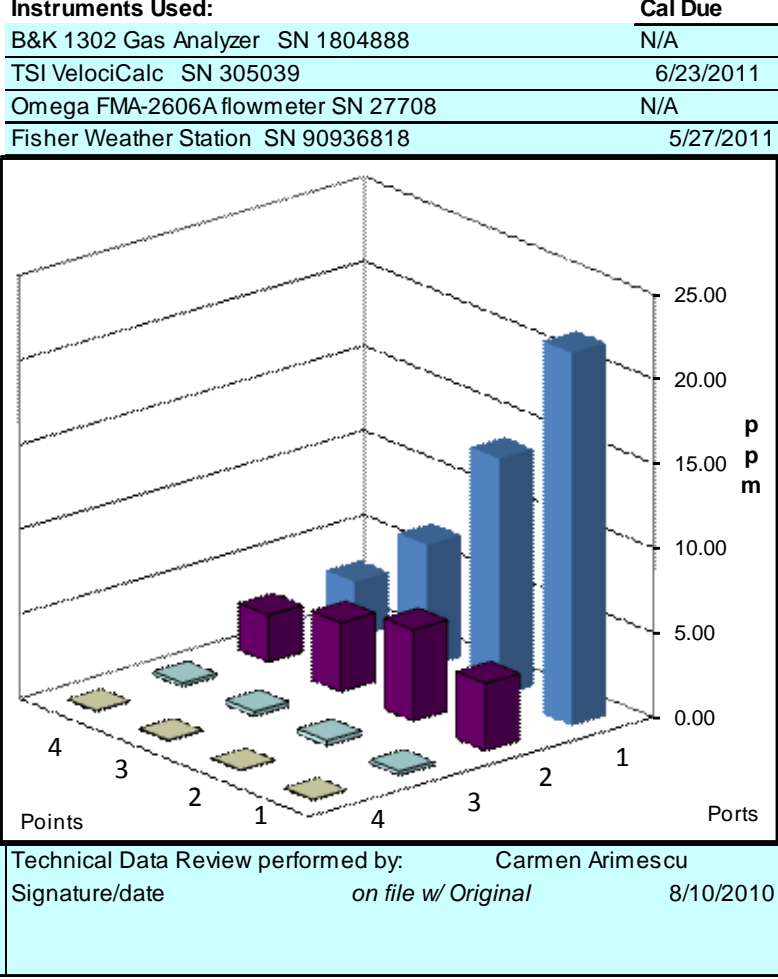




\begin{tabular}{|c|c|c|c|c|c|c|}
\hline \multicolumn{7}{|c|}{ TRACER GAS TRAVERSE DATA FORM } \\
\hline \multicolumn{3}{|c|}{ Site INL HFEF } & \multicolumn{4}{|c|}{ Run No. GT-5 } \\
\hline Date & $7 / 21 / 20$ & & \multicolumn{4}{|c|}{ Fan Configuration 2-PROCESS + 2 VENTILATIC } \\
\hline \multicolumn{3}{|c|}{ Testers $\overline{\mathrm{QQ}, \mathrm{JEF}}$} & \multicolumn{4}{|c|}{ Setting $\overline{\text { N.A. }}$} \\
\hline Duct Width & \multicolumn{2}{|c|}{83.175 in. } & & Stack Temp & 81 & $\operatorname{deg} \mathrm{F}$ \\
\hline Duct Depth & & & \multicolumn{4}{|c|}{ Start/End Time $1431 / 1550$} \\
\hline Stack X-Area & \multicolumn{2}{|c|}{$\begin{array}{l}30.2 \mathrm{~m} \text {. } \\
17.4 \mathrm{ft} 2\end{array}$} & \multicolumn{2}{|c|}{ Gas Analyzer Check: } & \multicolumn{2}{|l|}{$7 / 20 / 2010$} \\
\hline Distance to disturbance & \multicolumn{2}{|c|}{$21.5 \mathrm{ft}$} & \multicolumn{4}{|c|}{ Injection Point CENTER CENTER } \\
\hline Measurement units & ppm SF6 & & & & & \\
\hline \multicolumn{3}{|r|}{ Trial ----> } & 1 & 2 & 3 & Mean \\
\hline Port & Point & Depth, in. & \multicolumn{4}{|c|}{$\mathrm{ppm}$} \\
\hline 1 & 1 & 3.77 & 21.6 & 21.0 & 20.0 & 20.867 \\
\hline 1 & 2 & 11.32 & 14.1 & 13.3 & 13.6 & 13.667 \\
\hline 1 & 3 & 18.87 & 7.08 & 7.34 & 7.99 & 7.470 \\
\hline 1 & 4 & 26.41 & 3.25 & 3.91 & 3.15 & 3.437 \\
\hline 2 & 1 & 3.77 & 5.68 & 4.97 & 5.64 & 5.430 \\
\hline 2 & 2 & 11.32 & 5.29 & 5.52 & 6.03 & 5.613 \\
\hline 2 & 3 & 18.87 & 5.03 & 4.60 & 5.32 & 4.983 \\
\hline 2 & 4 & 26.41 & 3.39 & 3.03 & 3.58 & 3.333 \\
\hline 3 & 1 & 3.77 & 0.334 & 0.419 & 0.396 & 0.383 \\
\hline 3 & 2 & 11.32 & 0.352 & 0.335 & 0.502 & 0.396 \\
\hline 3 & 3 & 18.87 & 0.537 & 0.509 & 0.367 & 0.471 \\
\hline 3 & 4 & 26.41 & 0.314 & 0.242 & 0.336 & 0.297 \\
\hline 4 & 1 & 3.77 & 0.0516 & 0.0532 & 0.0588 & 0.055 \\
\hline 4 & 2 & 11.32 & 0.0614 & 0.0608 & 0.0766 & 0.066 \\
\hline 4 & 3 & 18.87 & 0.0773 & 0.0619 & 0.0670 & 0.069 \\
\hline 4 & 4 & 26.41 & 0.0636 & 0.0605 & 0.0855 & 0.070 \\
\hline & \multicolumn{2}{|c|}{ Averages ---------> } & 4.201 & 4.088 & 4.200 & 4.163 \\
\hline & \multicolumn{4}{|r|}{ Dev. from mean } & \multirow{4}{*}{$\begin{array}{l}\text { Std. Dev. } \\
\text { cov as \% }\end{array}$} & \\
\hline & Mean & 4.16 & & & & \\
\hline & Min Point & 0.05 & & $-98.7 \%$ & & 5.83 \\
\hline & Max Point & 20.87 & & $401.2 \%$ & & 71.4 \\
\hline
\end{tabular}

Tracer tank pressure Injection flowmeter Stack Temp Pt. 2,4 air vel. Sampling flowmeter Ambient pressure Ambient humidity Ambient Temp B\&K vapor correction Back-Gd gas

No. Bk-Gd samples

\begin{tabular}{|c|c|c|}
\hline Start & Finish & \\
\hline 300 & 300 & psig \\
\hline 3.75 & 3.75 & Ipm \\
\hline 81 & 81 & ${ }^{\circ} \mathrm{F}$ \\
\hline 1970 & 1690 & $\mathrm{fpm}$ \\
\hline 5 & 5 & Ipm \\
\hline 843 & 843 & in $\mathrm{Hg}$ \\
\hline 32 & 32 & $\mathrm{RH}$ \\
\hline 81 & 82 & ${ }^{\circ} \mathrm{F}$ \\
\hline NO & $\mathrm{NO}$ & $\mathrm{Y} / \mathrm{N}$ \\
\hline $71,54,59,66$ & $61,72,69,57$ & $\mathrm{ppb}$ \\
\hline 4 & 4 & $n$ \\
\hline
\end{tabular}

Notes:

Point 4 on all ports is about $1 / 4$ inch short of planned point due to probe interference with the permanent scaffold.

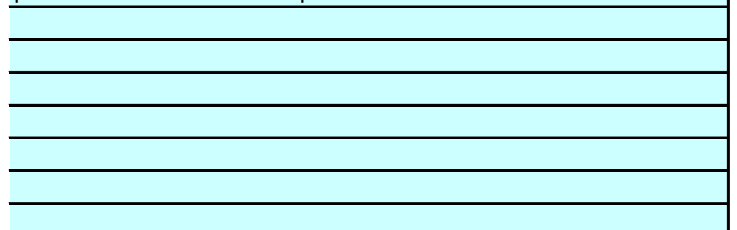

$5 / 27 / 2011$

Signature/date




\begin{tabular}{|c|c|c|c|c|c|c|}
\hline \multicolumn{7}{|c|}{ TRACER GAS TRAVERSE DATA FORM } \\
\hline \multicolumn{3}{|c|}{ Site INL HFEF } & \multicolumn{4}{|c|}{ Run No. GT-6 } \\
\hline Date & $7 / 21 / 20$ & & \multicolumn{4}{|c|}{ Fan Configuration 2-PROCESS + 2 VENTILATIC } \\
\hline \multicolumn{3}{|c|}{ Testers $\underline{\mathrm{QQ}, \mathrm{JEF}}$} & \multicolumn{4}{|c|}{ Setting N.A. } \\
\hline Duct Width & \multicolumn{2}{|c|}{83.175 in. } & \multicolumn{2}{|r|}{ Stack Temp } & 82 & $\operatorname{deg} \mathrm{F}$ \\
\hline Duct Depth & \multicolumn{2}{|c|}{30.2 in. } & \multicolumn{4}{|c|}{ Start/End Time $1550 / 1648$} \\
\hline Stack X-Area & \multicolumn{2}{|c|}{$17.4 \mathrm{ft} 2$} & \multirow{2}{*}{\multicolumn{2}{|c|}{$\begin{array}{r}\text { Gas Analyzer Check: } \\
\text { Injection Point }\end{array}$}} & $7 / 20 / 2010$ & \\
\hline Distance to disturbance & \multicolumn{2}{|c|}{$21.5 \mathrm{ft}$} & & & \multicolumn{2}{|c|}{ t Pipe Nipple Center } \\
\hline \multicolumn{7}{|c|}{ Measurement units ppm SF6 } \\
\hline \multicolumn{3}{|r|}{ Trial ----> } & 1 & 2 & 3 & Mean \\
\hline Port & Point & Depth, in. & \multicolumn{4}{|c|}{$\mathrm{ppm}$} \\
\hline 1 & 1 & 3.77 & \multicolumn{4}{|c|}{18.3} \\
\hline 1 & 2 & 11.32 & 12.6 & 10.7 & 12.0 & 11.767 \\
\hline 1 & 3 & 18.87 & 7.39 & 7.43 & 8.09 & 7.637 \\
\hline 1 & 4 & 26.41 & 3.00 & 2.81 & 3.17 & 2.993 \\
\hline 2 & 1 & 3.77 & 6.80 & 7.50 & 6.80 & 7.033 \\
\hline 2 & 2 & 11.32 & 7.49 & 7.69 & 8.64 & 7.940 \\
\hline 2 & 3 & 18.87 & 5.60 & 7.11 & 6.69 & 6.467 \\
\hline 2 & 4 & 26.41 & 4.26 & 4.47 & 4.05 & 4.260 \\
\hline 3 & 1 & 3.77 & 0.532 & 0.435 & 0.270 & 0.412 \\
\hline 3 & 2 & 11.32 & 0.459 & 0.399 & 0.613 & 0.490 \\
\hline 3 & 3 & 18.87 & 0.565 & 0.623 & 0.597 & 0.595 \\
\hline 3 & 4 & 26.41 & 0.293 & 0.365 & 0.345 & 0.334 \\
\hline 4 & 1 & 3.77 & 0.0582 & 0.0452 & 0.0578 & 0.054 \\
\hline 4 & 2 & 11.32 & 0.0476 & 0.0635 & 0.0447 & 0.052 \\
\hline 4 & 3 & 18.87 & 0.0575 & 0.0750 & 0.0632 & 0.065 \\
\hline 4 & 4 & 26.41 & 0.0710 & 0.0699 & 0.0511 & 0.064 \\
\hline & \multicolumn{2}{|c|}{ Averages ---------> } & 4.208 & 4.255 & 4.324 & 4.262 \\
\hline & \multicolumn{4}{|r|}{ Dev. from mean } & \multirow{4}{*}{$\begin{array}{l}\text { Std. Dev. } \\
\text { Cov as \% }\end{array}$} & \\
\hline & Mean & 4.26 & & & & \\
\hline & Min Point & 0.05 & & $-98.8 \%$ & & 5.25 \\
\hline & Max Point & 18.03 & & $323.1 \%$ & & 81.2 \\
\hline
\end{tabular}

Tracer tank pressure Injection flowmeter Stack Temp Pt. 2,4 air vel. Sampling flowmeter Ambient pressure Ambient humidity Ambient Temp B\&K vapor correction Back-Gd gas

No. Bk-Gd samples

\begin{tabular}{|c|c|c|}
\hline Start & Finish & \\
\hline 300 & 300 & \\
\hline 3.75 & 3.75 & \\
\hline 82 & 82 & \\
\hline 1790 & 1900 & \\
\hline 5 & 4 & \\
\hline 844 & 844 & \\
\hline 31 & 30 & \\
\hline 83 & 84 & \\
\hline $\mathrm{NO}$ & $\mathrm{NO}$ & \\
\hline $61,72,69,57$ & $70,78,55,71$ & \\
\hline 4 & 4 & \\
\hline
\end{tabular}

Notes:

Point 4 on all ports is about $1 / 4$ inch short of planned point due to probe interference with the permanent scaffold.

\begin{tabular}{|l|}
\hline \\
\hline \\
\hline \\
\hline \begin{tabular}{ll|}
\hline \\
Entries made by:
\end{tabular} \\
\hline \begin{tabular}{l} 
Signature/date \\
Quintin Quigley $7 / 21 / 10$ \\
\hline
\end{tabular}
\end{tabular}

Instruments Used: Cal Due

B\&K 1302 Gas Analyzer SN 1804888 TSI VelociCalc SN 305039

$5 / 27 / 2011$

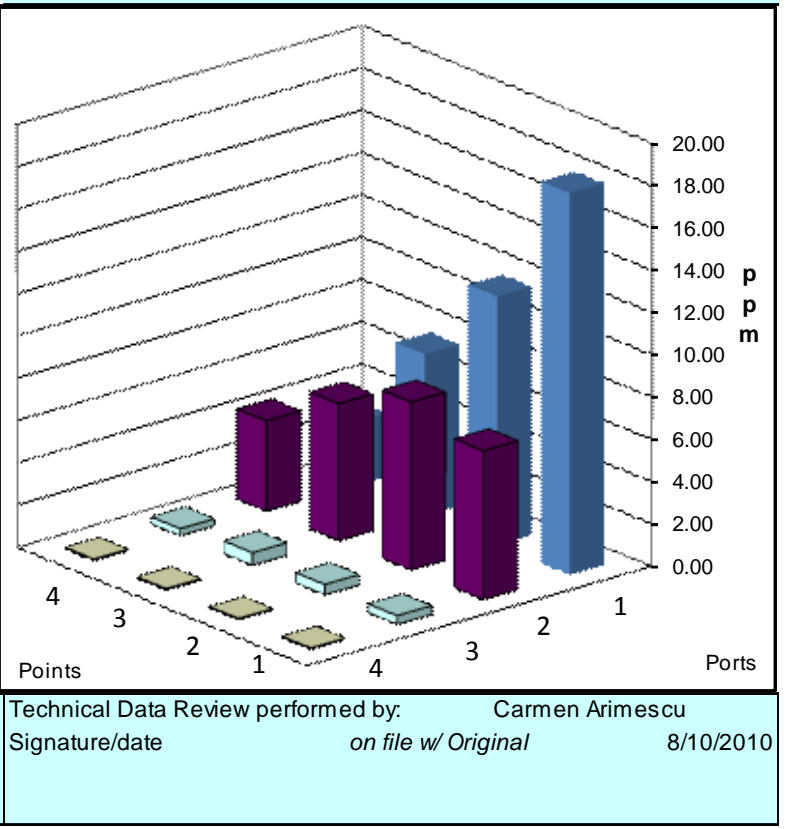




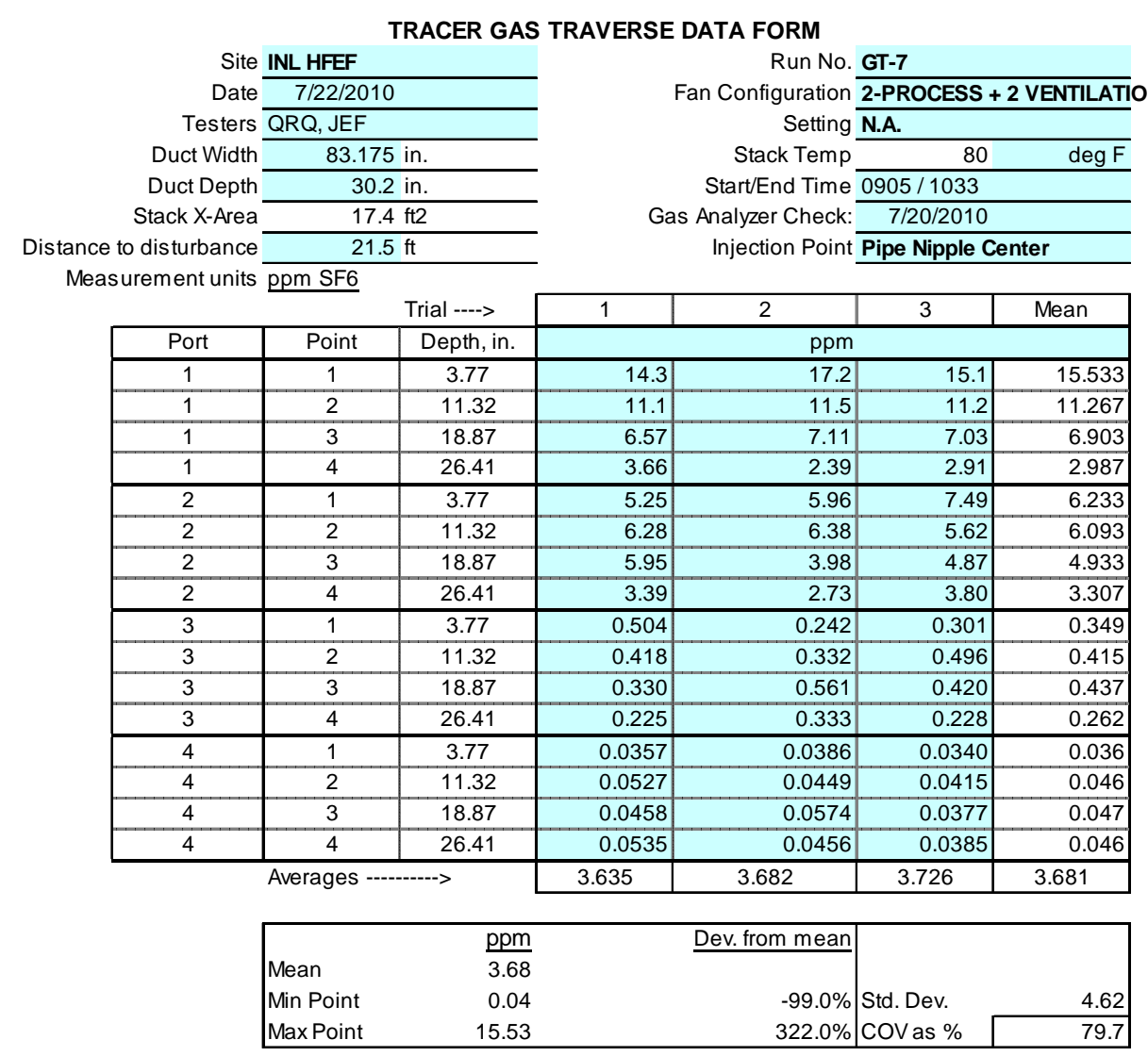

Tracer tank pressure Injection flowmeter Stack Temp Pt. 2,4 air vel. Sampling flowmeter Ambient pressure Ambient humidity Ambient Temp B\&K vapor correction Back-Gd gas

No. Bk-Gd samples

\begin{tabular}{|c|c|c|}
\hline Start & Finish & \\
\hline 300 & 300 & \\
\hline 3.75 & 3.75 & \\
\hline 80 & 80 & \\
\hline 1870 & 1890 & \\
\hline 5 & 5 & \\
\hline 843 & 844 & \\
\hline 30 & 30 & \\
\hline 76 & 70 & \\
\hline $\mathrm{N}$ & $\mathrm{N}$ & \\
\hline $52,50,39,50$ & $56,46,42,45$ & \\
\hline 4 & 4 & \\
\hline
\end{tabular}

Notes:

Done with port measurements at approximately 09:48.

Make measurements from sampling probe lines on 2nd floor. From the "bomb:"

$0.477,0.433,0.426 \mathrm{ppm}$

Final background measurements at 10:28.



\begin{tabular}{|c|c|c|}
\hline Entries made by. & Julia Flaherty & \\
\hline Signature/date & Signature on original & $7 / 22 / 2010$ \\
\hline
\end{tabular}

Instruments Used:

B\&K 1302 Gas Analyzer SN 1804888

TSI VelociCalc SN 305039

Omega FMA-2606A flowmeter SN 27708

Fisher Weather Station SN 90936818

Cal Due

N/A

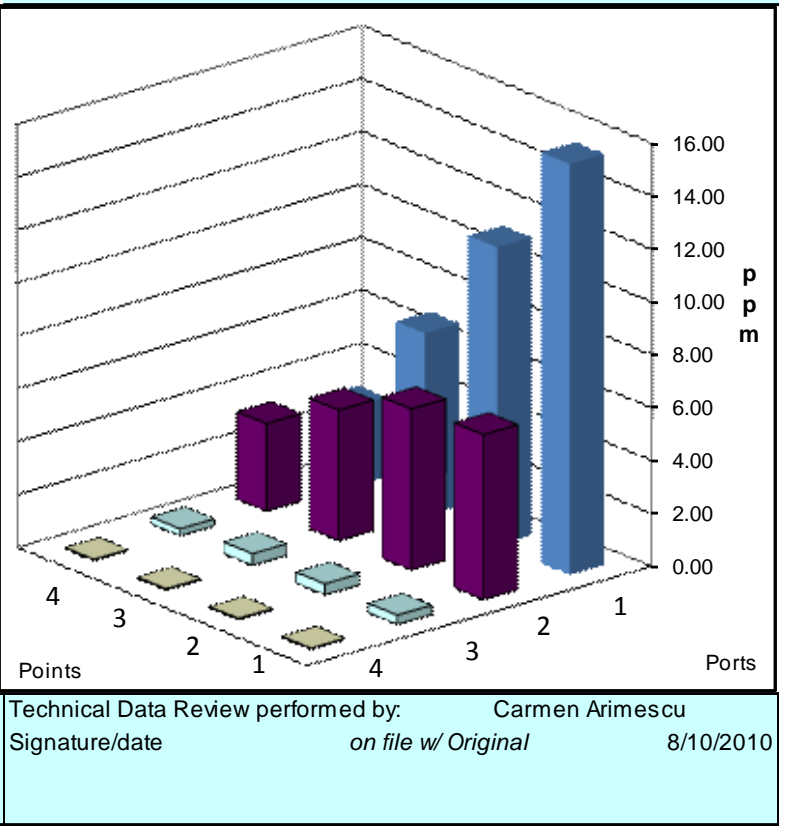




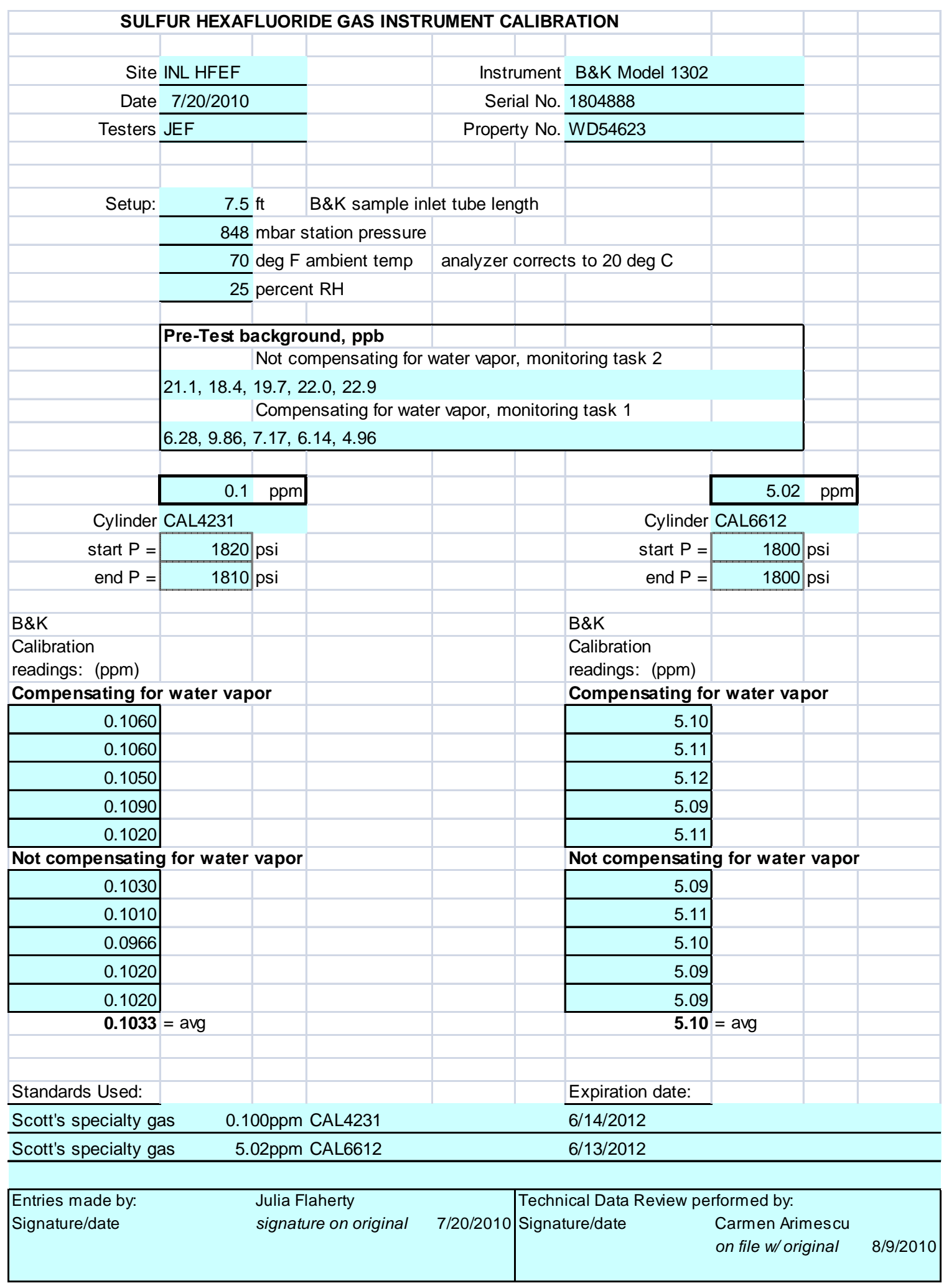




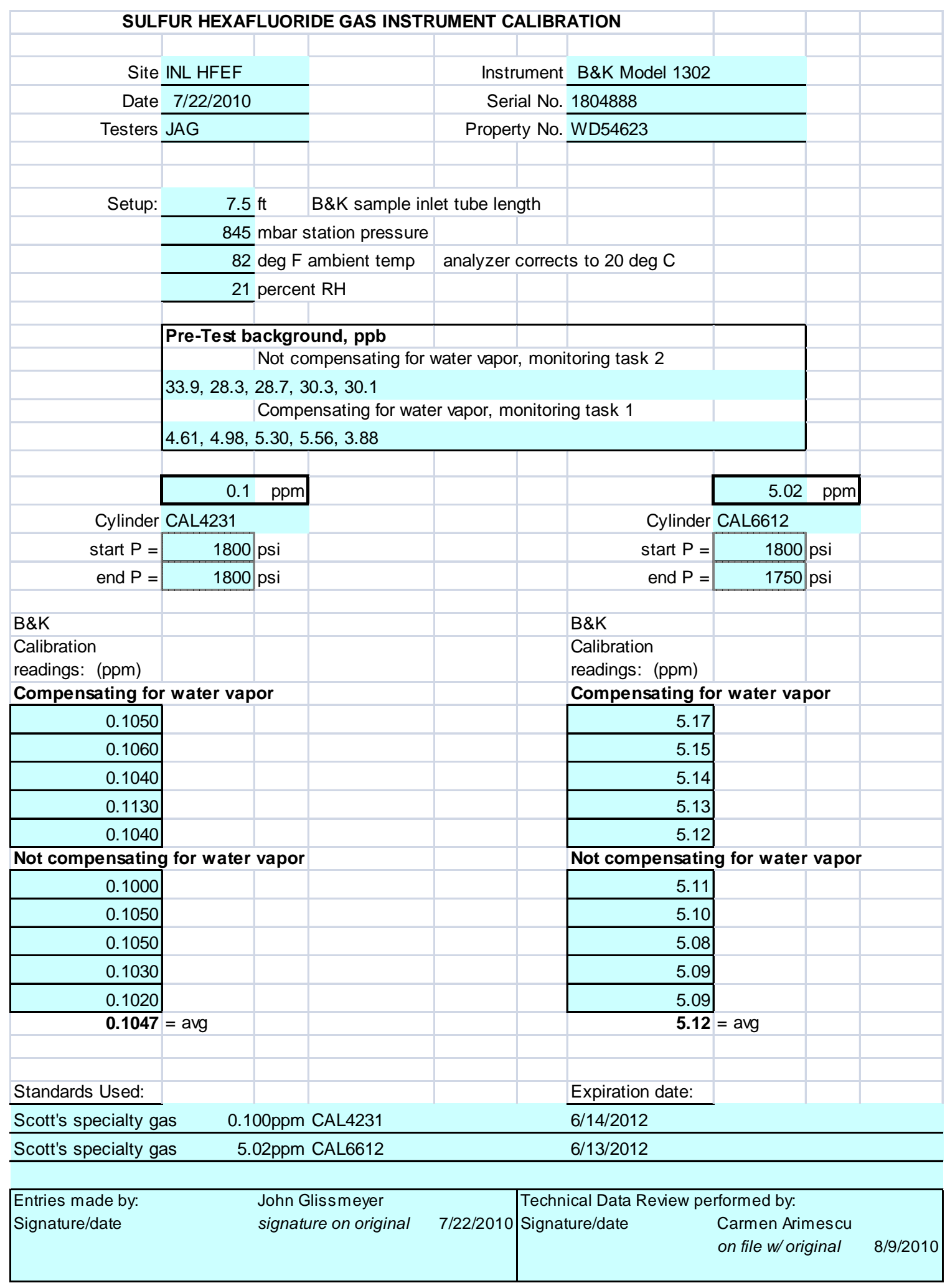




\section{Appendix D}

\section{Tracer Particle Uniformity Data Sheets}




\section{Appendix D: Tracer Particle Uniformity Data Sheets}

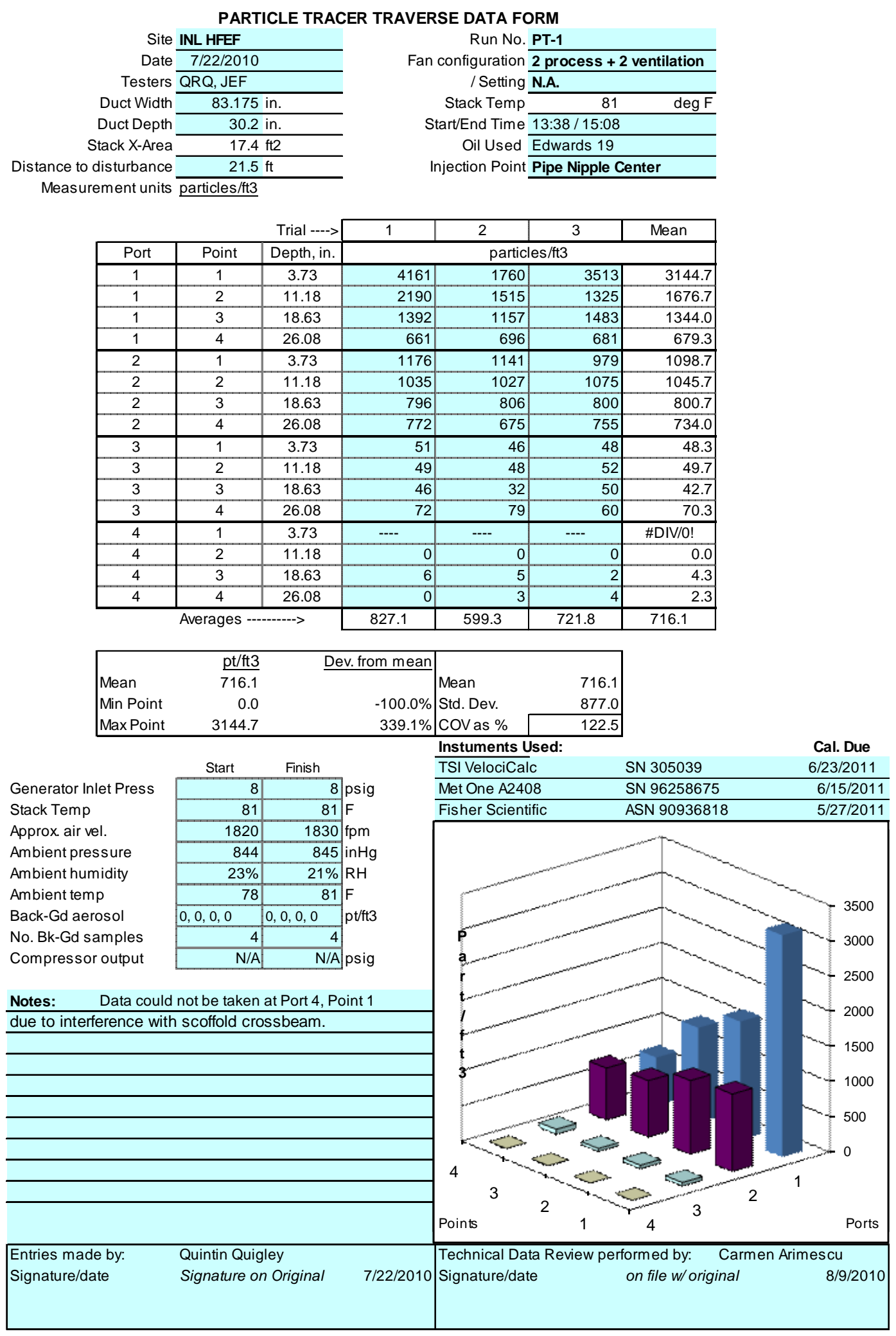

D. 1 


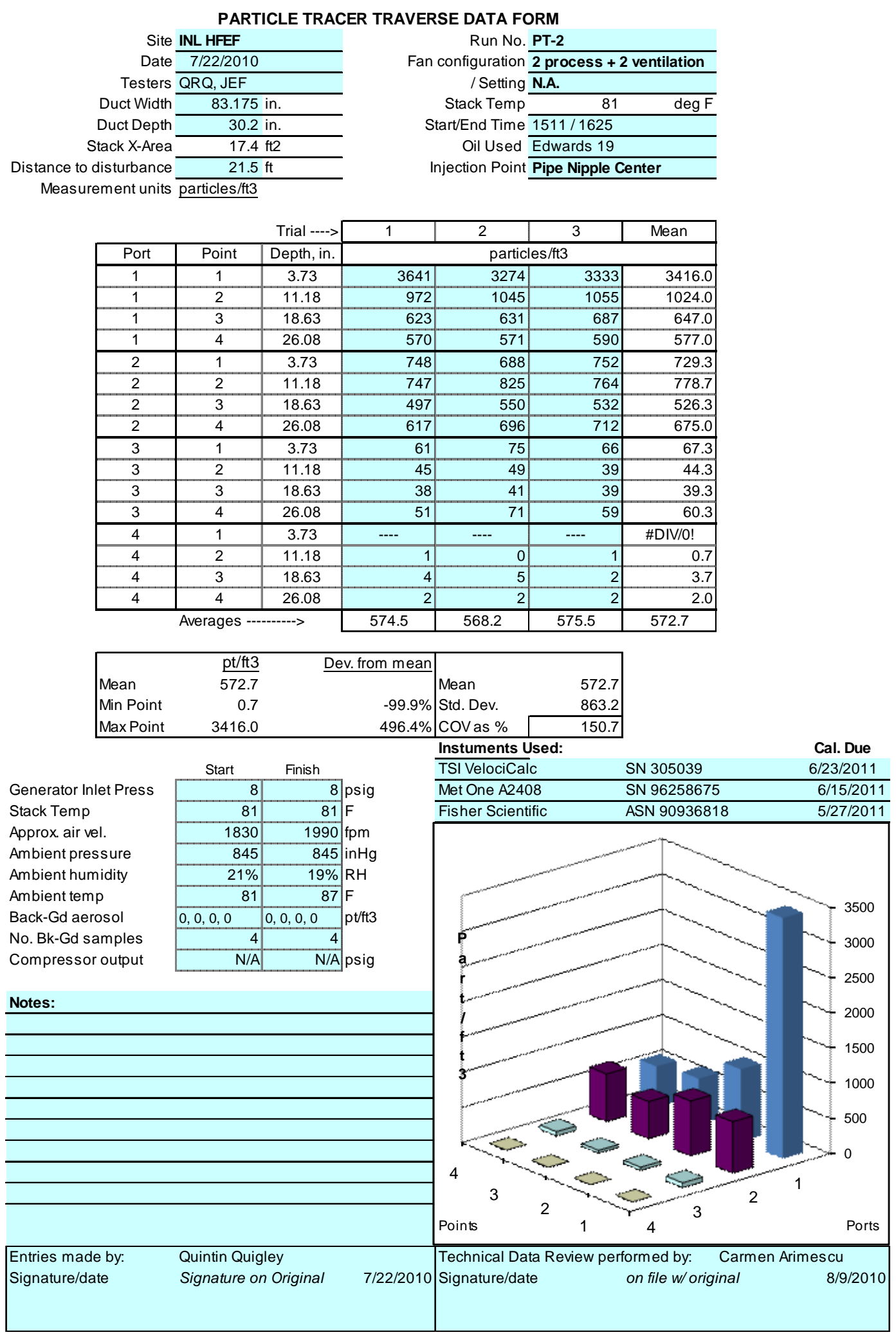




\section{Distribution}

No. of

Copies

\section{OFFSITE}

6 Tim Solle

Idaho National Laboratory

Materials \& Fuels Complex

Scoville, ID 83415

(208) 533-7544

[send FedEx/UPS]

\section{ONSITE}

8 Pacific Northwest National Laboratory

J.A. Glissmeyer (5) K9-30

J.E. Flaherty (1) K9-30

Information Release (2) P8-55

Distr. 1 